\title{
Lista das espécies de aranhas (Arachnida, Araneae) do estado do Rio Grande do Sul, Brasil
}

\author{
Erica Helena Buckup ${ }^{1}$, Maria Aparecida L. Marques ${ }^{1}$, Everton Nei Lopes Rodrigues ${ }^{1,2}$ \& Ricardo Ott ${ }^{1}$ \\ 1. Museu de Ciências Naturais, Fundação Zoobotânica do Rio Grande do Sul, Rua Dr. Salvador França, 1427, 90690-000 Porto Alegre, RS, \\ Brasil. (erica-buckup@fzb.rs.gov.br; maria-marques@fzb.rs.gov.br; rott@fzb.rs.gov.br) \\ 2. Programa de Pós-Graduação em Biologia Animal, Departamento de Zoologia, Instituto de Biociências, Universidade Federal do Rio \\ Grande do Sul, Av. Bento Gonçalves, 9500, Bloco IV, Prédio 43435, 91501-970 Porto Alegre, RS, Brasil. (enlrodrigues@yahoo.com.br)
}

\begin{abstract}
List of spiders species (Arachnida, Araneae) of the state of Rio Grande do Sul, Brazil. A spiders species list including 808 species of 51 families occurring in the state of Rio Grande do Sul, Brazil, is presented. Type locality, municipalities of occurrence and taxonomic bibliography concerning these species are indicated.
\end{abstract}

KEYWORDS. Inventory revision, type localities, municipalities records, Neotropical.

RESUMO. É apresentada uma lista de 808 espécies de aranhas, incluídas em 51 famílias ocorrentes no Rio Grande do Sul, Brasil. São indicados localidade-tipo, municípios de ocorrência e a bibliografia taxonômica de cada espécie.

PALAVRAS-CHAVES. Inventário, localidades-tipo, registros municipais, Neotropical.

A ordem Araneae reúne atualmente 110 famílias distribuídas em 3821 gêneros e 42055 espécies, mostrando nas últimas décadas um aumento progressivo no conhecimento das espécies e sua distribuição mundial (Platnick, 2011).

Na Europa do século XIX, era prática usual promover expedições com a finalidade de colecionar animais para os museus de história natural. Pesquisadores contavam com o auxílio de colaboradores ou de naturalistas viajantes para obtenção de espécimes. No Brasil inúmeras aranhas foram coligidas em localidades do Rio de Janeiro e Santa Catarina pelos naturalistas Emílio Goeldi e Fritz Plaumann, respectivamente.

Para o Rio Grande do Sul, um número significativo de espécimes foi reunido por Hermann von Ihering, médico e naturalista, nascido na Alemanha. Residiu em Taquara do Mundo Novo de 1880-1883, região que incluía o atual município de Taquara além de municípios limítrofes, em Rio Grande (1884/1885) e posteriormente em São Lourenço do Sul, locais onde colecionou centenas de aranhas. As coletas desses períodos foram enviadas ao aracnólogo alemão Eugen von Keyserling, o qual publicou os resultados em uma expressiva obra, "Die Spinnen Amerikas" (KEYSERLING, 1880b; 1884a; 1886; 1891; 1892; 1893). Um dos volumes, "Die Spinnen Amerikas. Brasilianische Spinnen" (1891), é dedicado às aranhas brasileiras, com ênfase aos estados do Rio de Janeiro e Rio Grande do Sul. A maioria dessas aranhas está depositada em museus europeus da Inglaterra e da Polônia.

Posteriormente, Mello-Leitão (1931) assinalou para o Rio Grande do Sul a ocorrência de três novas espécies de Cacimbinhas, atual município de Pinheiro Machado.

O primeiro catálogo de aranhas do estado do Rio Grande do Sul foi apresentado por MELLO-Leitão (1943), o qual relacionou 431 espécies, pertencentes a 173 gêneros e 31 famílias. Registrou as 219 espécies descritas por Keyserling em "Die Spinnen Amerikas" e relacionou mais 212 espécies, entre as quais 67 novas para a ciência. A maior parte dessas aranhas foi coletada pelo Padre Balduino Rambo, tendo sido depositadas no Museu Nacional do Rio de Janeiro. Ainda para o Rio Grande do Sul, BüCHERL (1952) realizou um estudo sobre aranhas e teceu comentários sistemáticos, ecológicos, biológicos e ação da peçonha.

A partir de 1970, intensificaram-se as pesquisas aracnológicas no Museu de Ciências Naturais (MCN), estabelecendo-se uma coleção científica para depositar aranhas coletadas em diversos locais do Estado. Nos últimos 40 anos, as pesquisas ambientais realizadas e o esforço empregado na organização e conservação do acervo propiciaram publicações nacionais e internacionais que resultaram em um maior conhecimento da taxonomia de aranhas e informações sobre a diversidade desse grupo em diferentes municípios do Estado.

No presente artigo é apresentada a lista das espécies de aranhas do Rio Grande do Sul com base em uma revisão bibliográfica e no acervo do $\mathrm{MCN}$, visando contribuir para o conhecimento da fauna de aranhas do Estado.

\section{MÉTODOS}

A listagem é apresentada em ordem alfabética priorizando a família, gêneros e espécies. Cada táxon é listado pelo binômio atual seguido pelo nome do autor e ano da descrição da espécie. São acrescentados dados bibliográficos originais como página da descrição, número das estampas e das figuras e, a seguir, citada a localidadetipo. A lista sinonímica é reduzida, constando apenas espécie(s) sinônima(s) com a localidade-tipo no Rio Grande do Sul, quando houver. Espécies originalmente descritas para o RS, não citadas em trabalhos revisivos, 
são apresentadas apenas pela localidade-tipo. Por último, constam artigos revisivos ou não, onde se encontram ilustrações atualizadas importantes para determinação da espécie. Referências sinonímicas completas também podem ser encontradas no catálogo de Platnick (2011). Ocorrências para o Estado foram citadas com base nos trabalhos taxonômicos originais e/ou revisivos, no material-testemunho examinado e material determinado por diversos especialistas, depositado na coleção de aranhas do Museu de Ciências Naturais (MCN), Fundação Zoobotânica do Rio Grande do Sul, Porto Alegre. Siglas dos estados usadas no texto: AM, Amazonas; AP, Amapá; BA, Bahia; ES, Espírito Santo; MG, Minas Gerais; MT, Mato Grosso; PA, Pará; PE, Pernambuco; PR, Paraná; RJ, Rio de Janeiro; RR, Roraima; RS, Rio Grande do Sul; SC, Santa Catarina.

\section{RESULTADOSE DISCUSSÃO}

Na lista são apresentadas 808 espécies de aranhas, incluídas em 51 famílias, as últimas correspondendo a 76\% das registradas por PlatNick (2011) para o Brasil (67). Algumas famílias apresentaram um grande incremento no número de espécies: Araneidae (210 espécies), seguida de Theridiidae (125), Anyphaenidae (60), Salticidae (74), Thomisidae (45) e Linyphiidae (44). Outras famílias como, Amaurobiidae, Dictynidae, Dipluridae, Hahniidae, Idiopidae, Liocranidae, Ochyroceratidae e Prodidomidae, são representadas por inúmeros espécimes coletados ao longo dos anos no Rio Grande do Sul, porém não registram nenhuma espécie nominal na presente lista. Houve um acréscimo de espécies nominais apreciável, sendo assinalado quase o dobro em relação ao número citado por MeLlo-Leitão (1943).

Áreas com maior cobertura florestal foram as mais pesquisadas, destacando-se a região nordeste do Estado, algumas áreas da Planície Costeira, a Depressão Central e áreas no entorno de Porto Alegre, todas priorizadas pela facilidade de acesso. A fauna de aranhas de regiões como a Campanha, Alto Uruguai e a Serra do Sudeste ainda são pouco conhecidas pelas escassas pesquisas nessas áreas.

Loxosceles gaucho Gertsch, 1967, com localidadetipo para São Paulo, foi indicada para o Rio Grande do Sul por GERTSCH (1967), com base na ilustração de MELLOLEITÃo (1934), no entanto, não foi incluída na lista por considerarmos esta informação duvidosa, pois até o momento, não há espécimes de L. gaucho tombados no acervo MCN

Trochanteria ranuncula Karsch, 1878 foi descrita originalmente para "St. Cruz", com base em espécime coletado por Reinhold Friedrich Hensel. PAPAVERO (1973) comentou que, no período de 1863-1866, Hensel fez coletas no Rio Grande do Sul, em Porto Alegre e nas colônias alemãs ao norte desta cidade. Platnick (1986) apresentou um histórico das localidades denominadas por St. Cruz nas America Central e América do Sul. Hensel (1872:62), em suas coletas no Estado, mencionou que esteve na colônia de Santa Cruz ao norte da cidade de Rio Pardo. Presume-se que a localidade-tipo de $T$. ranuncula é Santa Cruz do Sul. A espécie é rara e não está representada na coleção $\mathrm{MCN}$, mas foi relacionada na lista.

\section{Lista das espécies de aranhas do Rio Grande do Sul}

\section{ACTINOPODIDAE}

1. Actinopus ceciliae Mello-Leitão, 1931: 11, fig. 1. Localidadetipo: Pinheiro Machado, RS, Brasil. Registros: Pinheiro Machado, Taquara

2. Actinopus crassipes (Keyserling, 1891): 3, est. 1, fig. 1 Localidade-tipo: Taquara, RS, Brasil.

Registro: Taquara.

\section{AGELENIDAE}

3. Malthonica pagana (C. L. КосH, 1840): 31, figs 612, 613 Localidade-tipo: Grécia. Ramírez et al. (2004): 180. Registros: Canela, Porto Alegre, Santa Rosa,Viamão.

4. Tegenaria domestica (ClerCK, 1758): 76, est. 2, fig. 9.2. Localidade-tipo: Suécia.

Registros: Bagé, Canela, Porto Alegre, Rio Grande.

AMPHINECTIDAE

5. Metaltella iheringi (Keyserling, 1891): 154, est. 4, fig. 107. Localidade-tipo: Rio Grande, RS, Brasil. Registros: Barra do Ribeiro, Charqueadas, Rio Grande, Tapes.

6. Metaltella simoni (KeyserLing, 1878): 585, est. 14, figs 11, 12. Localidade-tipo: Uruguai. LeECH (1972): 107, figs 194, 195. Registros: Barra do Ribeiro, Charqueadas, Palmares do Sul, Pelotas, Porto Alegre, Rio Grande, São Francisco de Paula, Tapes, Triunfo, Viamão.

\section{ANAPIDAE}

7. Anapisona bordeaux Platnick \& Shadab, 1979: 13, figs 22 , 23. Localidade-tipo: St. John, Virgin Islands, EUA. Отт \& Brescovit (2003): 341, figs 7-14.

Registro: São Francisco de Paula.

\section{ANYPHAENIDAE}

8. Acanthoceto acupictus (Nicolet, 1849): 420. Localidade-tipo: San Carlos, Chile. Gayenna marginata Keyserling, 1891: 139, est. 4, fig. 95, localidade-tipo, Rio Grande, RS, Brasil. RamíreZ (1997): 186, figs $2,3,7,9,10,15-17,44-51$.

Registros: Cachoeira do Sul, Cachoeirinha, Canela, Capivari do Sul, Eldorado do Sul, Pedro Osório, Porto Alegre, Rio Grande, Santa Vitória do Palmar.

9. Acanthoceto riogrande RAmíRez, 1997: 189, figs 19, 58-63. Localidade-tipo: São José do Norte, RS, Brasil. Registros: Rio Grande, São Jerônimo, São José do Norte.

10. Anyphaenoides clavipes (Mello-LeITÃo, 1922): 34. Localidadetipo: Mendes, RJ, Brasil. Brescovit (1992a): 745, figs 7-12. Registros: Cachoeira do Sul, Guaíba, Montenegro, Porto Alegre, Santa Maria, São Leopoldo, São Pedro do Sul, Triunfo, Viamão.

11. Arachosia bergi (Simon, 1880): 345. Localidade-tipo: "Buenos Aires, Paraguai". RAMíREZ (2003): 139, figs 67b, 68d-f, 69a, 70, 75. Registros: Capivari do Sul, Eldorado do Sul, Pelotas, Porto Alegre, Rio Grande, Triunfo, Vacaria.

12. Arachosia honesta Keyserling, 1891: 127, est. 4, fig. 87 Localidade-tipo: Rio Grande, RS, Brasil. Oxysoma ramboi Mello-Leitão, 1943a: 238, localidade-tipo, RS, Brasil. RamíreZ (2003): 137, fig. 74.

Registros: Cachoeira do Sul, Canela, Capivari do Sul, Eldorado do Sul, Guaíba, Montenegro, Pinhal, Rio Grande, Salto do Jacuí, Santa Cruz do Sul.

13. Arachosia praesignis (Keyserling, 1891): 135, est. 4, fig. 92. Localidade-tipo: ES, Brasil. RAmírez (2003): 131, figs 61a, 67, $69 \mathrm{~b}, 71,72$.

Registros: Barra do Ribeiro, Butiá, Cachoeira do Sul, Cambará do Sul, Campo Bom, Candelária, Canela, Derrubadas, Erval Grande, Estrela Velha, Gravataí, Guaíba, Montenegro, Osório, Palmares do Sul, Pelotas, Porto Alegre, Rio Grande, Santa Maria, Santana do Livramento, Santa Vitória do Palmar, São Jerônimo, São Leopoldo, São Lourenço do Sul, São Sepé, Tapes, Tenente Portela, Triunfo, Viamão.

14. Arachosia striata (Keyserling, 1891): 133, est. 4, fig. 91 Localidade-tipo: Nova Friburgo, RJ, Brasil. Ramírez (2003): 136, fig. 73 Registro: Barracão.

15. Aysha albovittata Mello-Leitão, 1944: 356. Localidade-tipo Buenos Aires, Argentina. Brescovit (1992b): 33, figs 25-30. Registro: Xangri-lá. 
16. Aysha bonaldoi Brescovit, 1992b: 55, figs 79-81. Localidadetipo: Canela, RS, Brasil.

Registro: Canela.

17. Aysha borgmeyeri (Mello-Leitão, 1926): 9, figs 7, 8. Localidade-tipo: Petrópolis, RJ, Brasil. BRESCOvit (1992b): 58, figs 88-91.

Registros: Canela, Carazinho, Esmeralda, Machadinho, Nova Petrópolis, Novo Hamburgo, Pelotas, Rio Grande, Rio Pardo, Rolante, São Francisco de Paula, São Leopoldo.

18. Aysha chicama Brescovit, 1992b: 56, figs 82-84. Localidadetipo: Morro Reuter, RS, Brasil.

Registros: Nova Petrópolis, São Francisco de Paula, Triunfo.

19. Aysha clarovittata (Keyserling, 1891): 100, est. 3, fig. 60. Localidade-tipo: Nova Friburgo, RJ, Brasil. BRESCOvit (1992b): 31 , figs $18-22$. Registro: Iraí.

20. Aysha curumin Brescovit, 1992b: 73, figs 129. Localidadetipo: Praia do Curumim, Capão da Canoa, RS, Brasil Registro: Capão da Canoa.

21. Aysha diversicolor (Keyserling, 1891): 124, est. 4, fig. 85. Localidade-tipo: Nova Friburgo, RJ, Brasil. BREsCovit (1997a): 99. Registros: Arroio do Meio, Bom Jesus, Canela, Canoas, Caxias do Sul, Esmeralda, Farroupilha, Guaíba, Rio Grande, Santa Vitória do Palmar, São Francisco de Paula, São Leopoldo, Tapes, Triunfo, Vacaria, Viamão.

22. Aysha ericae Brescovit, 1992b: 60, figs 92-95, 148-157. Localidade-tipo: General Câmara, RS, Brasil.

Registros: Campo Bom, Canela, Carlos Barbosa, Estrela Velha, General Câmara, Guaíba, Machadinho, Montenegro, Porto Alegre, Salto do Jacuí, São Francisco de Paula, Triunfo, Viamão.

23. Aysha garruchos Brescovit, 1992b: 42, figs 50-53. Localidadetipo: Garruchos, RS, Brasil. Registro: Garruchos.

24. Aysha guaiba Brescovit, 1992b: 50, figs 64, 65. Localidadetipo: Guaíba, RS, Brasil. Registro: Guaíba.

25. Aysha guarapuava Brescovit, 1992b: 44, figs 59-63. Localidade-tipo: Guarapuava, PR, Brasil.

Registros: Bom Jesus, Canela, Caxias do Sul, Garruchos, Iraí, São Borja, Vacaria.

26. Aysha helvola (Keyserling, 1891): 98, est. 3, fig. 58. Localidade-tipo: Rio Grande, RS, Brasil.

Registros: Canela, Caxias do Sul, Dois Irmãos, Gravataí, Rio Grande, São Francisco de Paula, Viamão.

27. Aysha lisei Brescovit, 1992b: 38, figs 38-41. Localidadetipo: Canela, RS, Brasil.

Registros: Cambará do Sul, Canela, Farroupilha, Nova Petrópolis.

28. Aysha montenegro Brescovit, 1992b: 40, figs 44-49, 144147. Localidade-tipo: Montenegro, RS, Brasil.

Registros: Campo Bom, Canoas, Guaíba, Machadinho, Montenegro, Novo Hamburgo, Porto Alegre, São Leopoldo, Terra de Areia, Triunfo, Viamão.

29. Aysha piassaguera Brescovit, 1992b: 71, figs 117-122. Localidade-tipo: Salesópolis, SP, Brasil. Registro: Canela.

30. Aysha proseni Mello-Leitão, 1944: 357, figs 47-49. Localidade-tipo: Buenos Aires, Argentina. Brescovit (1992b): 35 , figs $31-37$.

Registro: Rio Grande.

31. Aysha prospera Keyserling, 1891: 129, est. 4, fig. 88 Localidade-tipo: Rio Grande, RS, Brasil. Teudis puma MelloLEITÃo, 1943a: 240, fig. 67, localidade-tipo: RS, Brasil. BRESCOVIT (1992b): 47, figs 1-13, 130-143.

Registros: Bagé, Cambará do Sul, Encantado, General Câmara, Gravataí, Montenegro, Osório, Pelotas, Porto Alegre, Rio Grande, Rio Pardo, Santa Maria, São Francisco de Paula, São Leopoldo, São Sepé, Terra de Areia, Triunfo, Vacaria, Viamão.

32. Aysha robusta (Keyserling, 1891): 103, est. 3, fig. 63. Localidade-tipo: Nova Friburgo, RJ, Brasil. Registros: Porto Alegre, São Leopoldo, Triunfo.

33. Aysha rubromaculata (Keyserling, 1891): 99, est. 3, fig. 59. Localidade-tipo: Rio Grande, RS, Brasil. Osoriella punctata Mello-Leitão, 1943a: 236, fig. 63, localidade-tipo: RS, Brasil. Registros: Alegrete, Arroio dos Ratos, Campo Bom, Canela, Canoas, Carlos Barbosa, Charqueadas, Esteio, Farroupilha, General Câmara, Gravataí, Guaíba, Montenegro, Palmares do
Sul, Pelotas, Porto Alegre, Rio Grande, Santa Cruz do Sul, Santa Maria, São Borja, São Francisco de Paula, São Jerônimo, São Valentim, Tapes, Triunfo, Vacaria, Viamão.

34. Aysha taeniata (Keyserling, 1891): 105, fig. 65. Localidadetipo: Nova Fribugo, RJ, Brasil. Brescovit (1992b): 66, figs 101-106.

Registros: Iraí, Nonoai.

35. Aysha taim Brescovit, 1992b: 74, fig. 128. Localidade-tipo: Santa Vitória do Palmar, RS, Brasil.

Registro: Santa Vitória do Palmar.

36. Aysha tapejara Brescovit, 1992b: 36, figs 23, 24. Localidadetipo: Vacaria, RS, Brasil

Registros: Cambará do Sul, Vacaria.

37. Aysha tertulia BRESCOvIT, 1992b: 53, figs 74-78. Localidadetipo: São Francisco de Paula, RS, Brasil.

Registros: Barra do Ribeiro, Bom Jesus, Caçapava do Sul, Cambará do Sul, Canela, Caxias do Sul, Derrubadas, Estrela Velha, Guaíba, Iraí, Maquiné, Nonoai, Novo Hamburgo, Rio Grande, Santa Vitória do Palmar, São Francisco de Paula, Sobradinho, Taquara, Triunfo, Vacaria.

38. Aysha triunfo Brescovit, 1992b: 67, figs 123-127. Localidadetipo: Triunfo, RS, Brasil.

Registros: Arroio do Meio, Barra do Ribeiro, Campo Bom, Canela, Canoas, Derrubadas, Eldorado do Sul, Estrela Velha, Garruchos, Gravataí, Guaíba, Iraí, Montenegro, Nonoai, Novo Hamburgo, Osório, Porto Alegre, Salto do Jacuí, Santa Maria, São Borja, São Francisco de Paula, São Leopoldo, Sertão Santana, Sobradinho, Tapes, Taquara, Tenente Portela, Três Coroas, Triunfo, Viamão.

39. Aysha vacaria Brescovit, 1992b: 52, fig. 73. Localidadetipo: Vacaria, RS, Brasil.

Registros: Estrela Velha, Vacaria.

40. Aysha zenzesi (Mello-Leitão, 1945): 264, fig. 51. Localidadetipo: Puerto Victoria, Misiones, Argentina. Brescovit (1992b): 61, figs 96-100.

Registros: Cambará do Sul, Campo Bom, Canela, Cruz Alta, Derrubadas, Estrela Velha, Novo Hamburgo, Ronda Alta, São Francisco de Paula, São Leopoldo, Torres.

41. Buckupiella imperatriz BrESCOVIT, 1997a: 77, figs 175-179. Localidade-tipo: Santo Amaro da Imperatriz, SC, Brasil. Registros: Canela, Derrubadas.

42. Iguarima censoria (Keyserling, 1891): 84, est. 2 fig. 48 Localidade-tipo: Nova Friburgo, RJ, Brasil. Brescovit (1997a): 49 , figs $84-90$ Registros: Derrubadas, Iraí.

43. Italaman santamaria Brescovit, 1997a: 79, figs 190-203. Localidade-tipo: Santa Maria, RS, Brasil.

Registros: Cachoeira do Sul, Guaíba, Porto Alegre, Santa Maria, São Leopoldo, Tapes, Viamão.

44. Jessica erythrostoma (Mello-LeITão, 1939a): 292. Localidadetipo: Pereira Barreto, SP, Brasil. BRescovit (1999): 257, figs 20-22, 26-31. Registro: Torres.

45. Jessica fidelis (Mello-Leitão, 1922): 23. Localidade-tipo: Belo Horizonte, MG, Brasil. Brescovit (1999): 250, figs 8-12, 23-25.

Registros: Estrela Velha, Garruchos, Salto do Jacuí.

46. Jessica glabra (Keyserling, 1891): 111, fig. 71. Localidadetipo: Nova Friburgo, RJ, Brasil. Brescovit (1999): 260, figs 32-35.

Registros: Derrubadas, Novo Hamburgo, Salto do Jacuí, Triunfo.

47. Jessica osoriana (Mello-Leitão, 1922): 36. Localidade-tipo: Petrópolis, RJ, Brasil. Anyphaena rufibarbis Mello-LeItão, 1943a: 224, fig. 61, localidade-tipo: RS, Brasil. BRESCOvit (1997a): 45; 1999: 50, figs 1-7.

Registros: Cachoeira do Sul, Derrubadas, Garruchos, Gravataí, Guaíba, Montenegro, Novo Hamburgo, Porto Alegre, Rio Pardo, Santa Maria, São Borja, São Francisco de Paula, São Jerônimo, São Sepé, Tapes, Triunfo, Viamão.

48. Jessica puava BRESCOvIT, 1999: 260, figs 59-61. Localidadetipo: Estrela Velha, RS, Brasil. Registros: Estrela Velha, Triunfo.

49. Macrophyes jundiai Brescovit, 1993: 114, figs 1-4. Localidade-tipo: Jundiaí, SP, Brasil.

Registros: Barra do Ribeiro, Guaíba, Porto Alegre, Triunfo, Viamão. 
50. Osoriella domingos Brescovit, 1998: 113, figs 3-6, 17-20. Localidade-tipo: Poços de Caldas, MG, Brasil.

Registros: Novo Hamburgo, Osório, Pelotas, Sobradinho, Viamão.

51. Osoriella tahela Brescovit, 1998: 115, figs 7-10, 21-24. Localidade-tipo: Santa Helena, PR, Brasil.

Registros: Candelária, Garruchos, Machadinho, São Borja.

52. Oxysoma itambezinho Ramírez, 2003: 225, figs 118e-i. Localidade-tipo: Cambará do Sul, RS, Brasil.

Registro: Cambará do Sul.

53. Patrera cita (Keyserling, 1891): 94, est. 3, fig. 55. Localidadetipo: Corcovado, RJ, Brasil. Brescovit (1997a): 33. Registro: Torres.

54. Patrera longipes (Keyserling, 1891): 91, est. 3, fig. 53 Localidade-tipo: Nova Friburgo, RJ, Brasil. BResCovit (1997a): 33. Registros: Arroio do Meio, Barra do Ribeiro, Canela, Carazinho, Derrubadas, Dois Irmãos, Estrela Velha, Maquiné, Marcelino Ramos, Montenegro, Novo Hamburgo, Palmares do Sul, Porto Alegre, Rio Grande, São Francisco de Paula, São Leopoldo, Sobradinho, Tapes, Triunfo, Viamão.

55. Patrera procera (Keyserling, 1891): 86, est. 3, fig. 49. Localidade-tipo: Nova Friburgo, RJ, Brasil. BRESCovit (1997a): 33. Registros: Cambará do Sul, Campo Bom, Canela, Caxias do Sul, Derrubadas, Estrela Velha, Farroupilha, General Câmara, Iraí, Marcelino Ramos, Montenegro, Nova Petrópolis, Novo Hamburgo, Passo Fundo, São Borja, São Francisco de Paula, São Leopoldo, Triunfo.

56. Sanogasta maculatipes (KeyserLING, 1878): 603. est. 14, fig. 23. Localidade-tipo: Uruguai. Ramírez (2003): 144, figs 61b, 76a, 77e, 78a, b, d, e, 79a, 80a-c, 81d, e.

Registros: Arroio dos Ratos, Bagé, Barra do Ribeiro, Cachoeira do Sul, Cachoeirinha, Cambará do Sul, Campo Bom, Canela, Canoas, Capivari do Sul, Cidreira, Eldorado do Sul, Guaíba, Muçum, Nova Tramandaí, Novo Hamburgo, Osório, Palmares do Sul, Pedro Osório, Pelotas, Porto Alegre, Restinga Seca, Rio Grande, Santa Maria, Santa Vitória do Palmar, São Francisco de Paula, São Leopoldo, Tenente Portela, Tramandaí, Vacaria, Viamão.

57. Sanogasta minuta (Keyserling, 1891): 136, est. 4, fig. 93 Localidade-tipo: Rio Grande, RS, Brasil. Ramírez (2003): 167, figs $84 a-b, 86 a-d$.

Registros: Cambará do Sul, Guaíba, Rio Grande, Vacaria.

58. Sanogasta $x$-signata (KeYserLing, 1891): 138, est. 4, fig. 94. Localidade-tipo: Rio Grande, RS, Brasil. Ramírez (2003): 166, figs $61 \mathrm{e}, 84 \mathrm{e}, \mathrm{f}, 85 \mathrm{f}-\mathrm{h}$.

Registros: Barra do Ribeiro, Cachoeira do Sul, Palmares do Sul, Pelotas, Porto Alegre, Quaraí, Rio Grande, Santa Vitória do Palmar, Viamão.

59. Tasata fuscotaeniata (Keyserling, 1891): 140, est. 4, fig. 96. Localidade-tipo: Rio Grande, RS, Brasil.

Registro: Rio Grande.

60. Tasata reticulata (Mello-Leitão, 1943a): 235, fig. 61 Localidade-tipo: RS, Brasil. Registro: Só a localidade-tipo.

61. Tasata taim Ramírez, 2003: 236, fig. 130. Localidade-tipo: Santa Vitória do Palmar, RS, Brasil.

Registros: Guaíba, Porto Alegre, Rio Grande, Santa Vitória do Palmar, Vacaria, Viamão.

62. Tasata variolosa Mello-LeItão, 1943a: 239, fig. 66. Localidadetipo: RS, Brasil. Ramírez (2003): 233, figs 125a, 128a-g. Registros: Arroio dos Ratos, Cachoeira do Sul, Canela, Guaíba, Porto Alegre.

63. Teudis angusticeps (Keyserling, 1891): 109, est. 3, fig. 69. Localidade-tipo: Corcovado, RJ, Brasil. Brescovit (1997a): 41, figs 73-78.

Registros: Barra do Ribeiro, Cachoeira do Sul, General Câmara, Montenegro, Novo Hamburgo, Passo Fundo, Porto Alegre, São Francisco de Paula, Triunfo.

64. Teudis bicornutus (TullgRen, 1905): 46, est. 7, fig. 21. Localidade-tipo: Bolívia. BRESCOVIT (1997a): 39.

Registros: Agudo, Canoas, Derrubadas, Dona Francisca, Eldorado do Sul, Gravataí, Guaíba, Montenegro, Nonoai, Novo Hamburgo, Porto Alegre, Santa Maria, Santa Rosa, São Borja, São Sepé, Triunfo, Vacaria, Xangri-lá.

65. Wulfila albus (Mello-Leitão, 1945): 264, fig. 50. Localidadetipo: Puerto Victoria, Misiones, Argentina. Brescovit (1997a): 23 , figs $15-21$.
Registros: Cachoeira do Sul, Canela, Derrubadas, Estrela Velha, Farroupilha, General Câmara, Iraí, Montenegro, Novo Hamburgo, Passo Fundo, Porto Alegre, Santa Maria, São Francisco de Paula, São Leopoldo, São Valentim, Triunfo, Vacaria, Viamão.

66. Wulfilopsis tripunctata (Mello-Leitão, 1947a): 132, fig. 6 . Localidade-tipo: Curitiba, PR, Brasil. Brescovit (1997b): 7 , figs $8-12,25,26,30-32$.

Registros: Canela, Gravataí, Machadinho.

67. Xiruana gracilipes (Keyserling, 1891): 130, est. 4, fig. 89. Localidade-tipo: RS, Brasil. Aysha fulviceps KeYserling, 1891 131, est. 4, fig. 90, localidade-tipo, RS, Brasil. Brescovit (1997a): 104, figs 274-282

Registros: Bagé, Canoas, Caxias do Sul, Guaíba, Machadinho, Montenegro, Pelotas, Sertão Santana, Triunfo, Viamão.

\section{ARANEIDAE}

68. Acacesia graciosa Lise \& Braul, 1995: 179, figs 1-17. Localidade-tipo: Morretes, PR, Brasil.

Registros: Cachoeira do Sul, Estrela Velha, Maquiné, Torres, Triunfo.

69. Acacesia hamata (Hentz, 1847): 474, est. 31, fig. 10 Localidade-tipo: Alabama, EUA. Glueck (1994): 69, figs 4-8. Registros: Butiá, Canoas, Encantado, Estrela Velha, General Câmara, Gravataí, Maquiné, Montenegro, Muçum, Passo Fundo, Porto Alegre, Roca Sales, Santa Maria, São Borja, São Leopoldo, Taquara, Triunfo, Viamão.

70. Acacesia tenella (L. Косн, 1871): 76, est. 6, figs 5, 6 Localidade-tipo: "Neuholland". Glueck (1994): 73, figs 2-3, 9-16. Framenau et al. (2009): 23, figs 1, 2

Registros: Derrubadas, Garruchos, Gravataí, Maquiné, Montenegro, Nonoai, Novo Hamburgo, Porto Alegre, Porto Mauá, Salto do Jacuí, São Borja, Tenente Portela, Triunfo, Viamão.

71. Acacesia villalobosi Glueck, 1994: 79, figs 28-33. Localidadetipo: Serra dos Órgãos, RJ, Brasil.

Registros: Bom Jesus, Cambará do Sul, Canela, Caxias do Sul, Derrubadas, Estrela Velha, Guabiju, Novo Hamburgo, Porto Alegre, São Francisco de Paula, Sobradinho.

72. Aculepeira travassosi (SoARes \& Camargo, 1948): 377 , figs 33, 34. Localidade-tipo: Chavantina, MT, Brasil. Levi (1991a): 298, figs 543-547

Registro: Derrubadas.

73. Aculepeira vittata (Pikelin \& Schiapelli, 1948): 17, figs 26, 27. Localidade-tipo: Santa Maria, Misiones, Argentina. Levi (1991a): 300, figs 548-552.

Registros: Garruchos, Vacaria.

74. Alpaida albocincta (Mello-Leitão, 1945): 236. Localidadetipo: Puerto Victoria, Misiones, Argentina. Levi (1988): 466, figs $525-529$.

Registros: Canoas, Derrubadas, Encantado, Estrela Velha, Mata, Montenegro, Muçum, Novo Hamburgo, Salto do Jacuí, Santa Maria, Três Coroas, Triunfo.

75. Alpaida alticeps (Keyserling, 1879): 311, est. 4, fig. 13. Localidade-tipo: Nova Friburgo, RJ, Brasil. Levi (1988): 415, figs 182-187.

Registros: Canela, General Câmara, Lages, Montenegro, Osório, Sapiranga, Torres, Viamão.

76. Alpaida alto LEVI, 1988: 434, figs 320-323. Localidade-tipo Alto Paraná, Paraguai.

Registro: Derrubadas

77. Alpaida bicornuta (TaCzanowski, 1878): 168, est. 2, fig. 18. Localidade-tipo: Pumamarca e Amable Maria, Junín, Peru. LeVI (1988): 387, figs 11-18.

Registros: Canela, Derrubadas, Estrela Velha, Montenegro, Novo Hamburgo, Salto do Jacuí, Santa Maria, São Borja, Tenente Portela.

78. Alpaida bischoffi Levi, 1988: 424, figs 234-238. Localidadetipo: Farroupilha, RS, Brasil.

Registro: Farroupilha.

79. Alpaida canela Levi, 1988: 421, figs 216-118. Localidadetipo: Canela, RS, Brasil Registros: Cambará do Sul, Canela.

80. Alpaida canoa Levi, 1988: 439, figs 348-353. Localidadetipo: Praia do Curumim, Capão da Canoa, RS, Brasil. 
Registros: Canela, Capão da Canoa, Glorinha, Santo Antônio da Patrulha, Torres, Viamão.

81. Alpaida caxias Levi, 1988: 439, figs 346, 347. Localidadetipo: Duque de Caxias, RJ, Brasil.

Registro: Candelária.

82. Alpaida citrina (Keyserling, 1892): 88, est. 4, fig. 66. Localidade-tipo: Nova Friburgo, RJ, Brasil. Levi (1988): 418, figs 204-206. Rodrigues \& Mendonça (2011): 61, figs 1-4. Registros: Arroio do Meio, Caxias do Sul, Maquiné.

83. Alpaida ericae Levi, 1988: 460, figs 486-490. Localidadetipo: Montenegro, RS, Brasil.

Registros: Arroio dos Ratos, Cambará do Sul, Canela, Montenegro, Santa Maria, São Francisco de Paula.

84. Alpaida gallardoi Levi, 1988: 432, figs 300-305. Localidadetipo: Buenos Aires, Argentina.

Registros: Derrubadas, Garruchos, Montenegro, Nonoai, Porto Alegre, Rio Pardo, São Francisco de Paula, São Leopoldo.

85. Alpaida grayi (BLACKwall, 1863): 34. Localidade-tipo: RJ, Brasil. Levi (1988): 394, figs 44-49.

Registros: Bom Jesus, Cambará do Sul, Canela, Capão do Leão, Caxias do Sul, Derrubadas, Erechim, Esmeralda, Estrela Velha, Farroupilha, Maquiné, Nonoai, Passo Fundo, Porto Alegre, Salto do Jacuí, São Francisco de Paula, São Leopoldo, São Valentim.

86. Alpaida hartliebi Levi, 1988: 430, figs 294-297. Localidadetipo: Porto Alegre, RS, Brasil.

Registro: Porto Alegre.

87. Alpaida hoffmanni Levi, 1988: 400, figs 92-96. Localidadetipo: Chapada dos Guimarães, MT, Brasil. Registro: Santa Rosa.

88. Alpaida iguazu Levi, 1988: 436, figs 330-335. Localidadetipo: Misiones, Argentina.

Registros: Arroio do Tigre, São Francisco de Paula.

89. Alpaida itapua Levi, 1988: 433, figs 310-312. Localidadetipo: Itapúa, Paraguai.

Registro: Derrubadas.

90. Alpaida itauba Levi, 1988: 445, figs 386-391. Localidadetipo: Itaúba, Arroio do Tigre, RS, Brasil. Registros: Arroio do Tigre, Triunfo.

91. Alpaida lanei Levi, 1988: 412, figs 170, 171. Localidadetipo: São Paulo, SP, Brasil.

Registros: Derrubadas, Passo Fundo.

92. Alpaida latro (FABricius, 1793): 412. Localidade-tipo: América. Levi (1988): 414, figs 175-181.

Registros: Bossoroca, Pelotas, Porto Alegre.

93. Alpaida leucogramma (White, 1841): 474. Localidade-tipo: RJ, Brasil. LeVI (1988): 391, figs 32-38.

Registros: Arroio do Tigre, Bagé, Canela, Eldorado do Sul, General Câmara, Gravataí, Maquiné, Montenegro, Porto Alegre, São Leopoldo, Triunfo, Viamão.

94. Alpaida lomba Levi, 1988: 421, figs 219-222. Localidadetipo: Novo Hamburgo, RS, Brasil.

Registros: Canela, Novo Hamburgo.

95. Alpaida nigrofrenata (Simon, 1895a): 816. Localidade-tipo: Serra do Caraça, Catas Altas, MG, Brasil. Levi (1988): 421, figs 223-225.

Registros: Cambará do Sul, Estrela Velha, Garruchos, Iraí, São Francisco de Paula, Triunfo.

96. Alpaida nonoai Levi, 1988: 478, figs 617-622. Localidadetipo: Nonoai, RS, Brasil.

Registros: Arroio do Meio, Canela, Caxias do Sul, Estrela Velha, Gravataí, Igrejinha, Montenegro, Nonoai, Novo Hamburgo, Rio Pardo, Santa Maria, São Fancisco de Paula, Três Coroas, Triunfo.

97. Alpaida octolobata Levi, 1988: 460, figs 483-485. Localidadetipo: Montenegro, RS, Brasil. Rodrigues \& Mendonça (2011): 61, figs 5-8.

Registros: Arroio Grande, Cambará do Sul, Cristal, Estrela Velha, Montenegro, São Francisco de Paula, Tapes, Triunfo.

98. Alpaida pedro Levi, 1988: 425, figs 246-252. Localidadetipo: São Pedro do Sul, RS, Brasil.

Registros: Bagé, Cambará do Sul, Canela, Carazinho, Caxias do Sul, Estrela Velha, Farroupilha, Nonoai, Passo Fundo, Porto Alegre, Salto do Jacuí, São Francisco de Paula, São Pedro do Sul, Vacaria, Viamão.

99. Alpaida quadrilorata (Simon, 1897a): 5. Localidade-tipo: Asunción, Paraguai. Levi (1988): 467, figs 530-536. Registros: Bagé, Cambará do Sul, Canoas, Cruz Alta, Garruchos,
Gravataí, Montenegro, Pelotas, Porto Alegre, Quaraí, São Borja, Taquari, Triunfo, Viamão.

100. Alpaida rosa Levi, 1988: 461, figs 495-500. Localidadetipo: Santa Rosa, RS, Brasil.

Registros: Espumoso, Salto do Jacuí, Santa Maria, Santa Rosa.

101. Alpaida rostratula (Keyserling, 1892): 82, est. 4, fig. 62. Localidade-tipo: Taquara, RS, Brasil. Levi (1988): 394, figs 50-56.

Registros: Cambará do Sul, Canela, Rio Pardo, São Francisco de Paula, Taquara.

102. Alpaida rubellula (Keyserling, 1892): 81, est. 4, fig. 61. Localidade-tipo: RS, Brasil. Levi (1988): 395, figs 57-62.

Registros: Catuípe, Estrela Velha, Garruchos, Montenegro, Nonoai, Passo Fundo, Quaraí, Santa Rosa, São Borja.

103. Alpaida scriba (Mello-Leitão, 1940a): 203. Localidadetipo: Colatina, ES, Brasil. Levi (1988): 416, figs 188-190. BucKup \& MEYer (1993): 353, figs 1-3.

Registros: Cambará do Sul, Derrubadas, Gravataí, São Francisco de Paula.

104. Alpaida sobradinho Levi, 1988: 433, figs 306-309. Localidade-tipo: Sobradinho, RS, Brasil.

Registros: Palmares do Sul, São Francisco de Paula, Sobradinho.

105. Alpaida trispinosa (Keyserling, 1892): 78, est. 4, fig. 59 Localidade-tipo: Nova Friburgo, RJ, Brasil. Levi (1988): 396, figs 63-68.

Registros: Estrela Velha, Santa Maria, Santa Rosa.

106. Alpaida truncata (Keyserling, 1865): 807, est. 19, figs 21, 22 Localidade-tipo: Uruguai. Levi (1988): 472, figs 570-578. Registros: Derrubadas, Triunfo, Viamão.

107. Alpaida vanzolinii LeVI, 1988: 411, figs 160-165. Localidadetipo: Caraguatatuba, SP, Brasil.

Registro: Derrubadas.

108. Alpaida veniliae (Keyserling, 1865): 817, est. 19, figs 23, 24. Localidade-tipo: "Nova Granada, Colômbia e Panamá". Epeira unguiformis Keyserling, 1893, localidade-tipo, RS, Brasil. LeVI (1988): 402, figs 103-109.

Registros: Arroio do Tigre, Barra do Ribeiro, Cachoeira do Sul, Cachoeirinha, Camaquã, Campo Bom, Candelária, Canela, Canoas, Capão do Leão, Capivari do Sul, Caxias do Sul, Derrubadas, Eldorado do Sul, General Câmara, Gravataí, Guabiju, Guaíba, Iraí, Jaquirana, Lajeado, Machadinho, Maquiné, Marcelino Ramos, Montenegro, Muçum, Nova Santa Rita, Novo Hamburgo, Osório, Palmares do Sul, Passo Fundo, Pelotas, Portão, Porto Alegre, Restinga Seca, Rio Grande, Rio Pardo, Salto do Jacuí, Santa Maria, Santa Vitória do Palmar, São Borja, São Francisco de Paula, São Jerônimo, São Leopoldo, São Pedro do Sul, Tapes, Taquara, Terra de Areia, Torres, Triunfo, Viamão, Xangri-lá.

109. Alpaida versicolor (Keyserling, 1877a): 86, est. 3, fig. 2. Localidade-tipo: Uruguai. Levi (1988): 411, figs 154-159.

Registros: Canoas, Capão da Canoa, Cidreira, Gramado, Júlio de Castilhos, Montenegro, Porto Alegre, São Sepé, Torres, Xangri-lá.

110. Alpaida yucuma Levi, 1988: 460, figs 491-494. Localidadetipo: Derrubadas, RS, Brasil. Registros: Derrubadas, Montenegro.

111. Araneus bandelieri (Simon, 1891a): 10, est. 1. Localidadetipo: Tovar, Venezuela. Levi (1991a): 214, figs 113-115. Registro: Canela.

112. Araneus blumenau Levi, 1991a: 200, figs 42-48. Localidadetipo: Blumenau, SC, Brasil. Registros: São Vicente do Sul.

113. Araneus corporosus (KEYSERLING, 1892): 189, est. 9, fig. 140. Localidade-tipo: Taquara, RS, Brasil. Levi (1991a): 206, figs 71-77.

Registros: Bom Jesus, Cambará do Sul, Canoas, Caxias do Sul, Esmeralda, Gravataí, Guabiju, Montenegro, Santa Maria, São Francisco de Paula, São Leopoldo, Taquara.

114. Araneus guttatus (KeYserling, 1865): 823, est. 18, figs 17, 18. Localidade-tipo: "Nova Granada, Colômbia e Panamá". Levi (1991a): 253, figs 303-315.

Registros: Candelária, Derrubadas, Garruchos, Itaqui, Santa Maria, Santa Rosa.

115. Araneus horizonte LevI, 1991a: 211, figs 99-104. Localidadetipo: Belo Horizonte, MG, Brasil. BRAUL et al. (2000): 124, figs 1-3. Registro: São Francisco de Paula. 
116. Araneus iguacu Levi, 1991a: 256, figs 321-325. Localidadetipo: Foz do Iguaçu, PR, Brasil.

Registro: Derrubadas.

117. Araneus lathyrinus (Holmberg, 1875): 283, est. 6, fig. 1. Localidade-tipo: Buenos Aires, Argentina. Epeira caerulea BertKAu, 1880: 87, est. 2, fig. 31, localidade-tipo: Rio Grande, RS, Brasil. LeVI (1991a): 210, figs 85-91.

Registros: Bagé, Barra do Ribeiro, Bom Jesus, Cambará do Sul, Canela, Canoas, Capão do Leão, Derrubadas, Dona Francisca, Eldorado do Sul, Esmeralda, General Câmara, Glorinha, Gravataí, Guaíba, Montenegro, Palmares do Sul, Pelotas, Porto Alegre, Restinga Seca, Rio Grande, Rio Pardo, Santa Maria, Santa Vitória do Palmar, Sapiranga, São Borja, São Francisco de Paula, São Leopoldo, São Sepé, Tapes, Torres, Triunfo, Viamão.

118. Araneus omnicolor (KEYSERLING, 1893): 210, est. 10, fig. 155. Localidade-tipo: ES, Brasil. Levi, 1991a: 202, figs 49-57.

Registros: Barra do Ribeiro, Bom Jesus, Caçapava do Sul, Cambará do Sul, Canela, Canoas, Capão do Leão, Caxias do Sul, Dois Irmãos, Eldorado do Sul, Esmeralda, Machadinho, Maquiné, Montenegro, Nova Petrópolis, Palmares do Sul, Rio Grande, Rio Pardo, São Francisco de Paula, São Leopoldo, Tapes, Terra de Areia, Triunfo, Vacaria, Viamão.

119. Araneus orgaos Levi, 1991a: 211, figs 92-94. Localidadetipo: Serra dos Órgãos, RJ, Brasil. Registro: São Francisco de Paula.

120. Araneus sicki Levi, 1991a: 250, figs 286-289. Localidadetipo: Serra dos Órgãos, RJ, Brasil.

Registros: Cambará do Sul, São Francisco de Paula.

121. Araneus stabilis (Keyserling, 1893): 213, est. 10, fig. 158. Localidade-tipo: ES, Brasil. Levi (1991a): 226, figs 174-178. Registros: Canela, Dois Irmãos, Erechim, Estrela Velha, Gravataí, Machadinho, Maquiné, Pelotas, Porto Alegre, Sapiranga, São Francisco de Paula, Triunfo.

122. Araneus unanimus (Keyserling, 1879): 306, est. 4, fig. 9. Localidade-tipo: Nova Friburgo, RJ, Brasil. Levi (1991a): 203 , figs 58-63.

Registros: Arroio dos Ratos, Bagé, Barra do Ribeiro, Butiá, Caçapava do Sul, Cachoeira do Sul, Cambará do Sul, Canela, Canoas, Caxias do Sul, Erechim, Garruchos, General Câmara, Glorinha, Gravataí, Guaíba, Montenegro, Nova Petrópolis, Novo Hamburgo, Osório, Pelotas, Porto Alegre, Rio Grande, Salvador do Sul, São Francisco de Paula, São Jerônimo, São Leopoldo, Tapes, Taquari, Terra de Areia, Torres, Tramandaí, Triunfo, Vacaria, Viamão.

123. Araneus uniformis (KeYserling, 1879): 307, est. 4, figs 10 . Localidade-tipo: Nova Friburgo, RJ, Brasil. Epeira lucida Keyserling, 1884b: 650, est. 21, fig. 2, localidade-tipo: Santa Isabel do Sul, Arroio Grande, RS, Brasil. Levi (1991a): 246, figs 272-275.

Registros: Arroio Grande, Cambará do Sul, Canela, Canoas, Derrubadas, Eldorado do Sul, Guaíba, Igrejinha, Montenegro, Nonoai, Pelotas, Porto Alegre, Quaraí, Rio Grande, Santa Rosa, Santa Vitória do Palmar, São Francisco de Paula, São Sepé, São Valentim, Tapes, Torres, Triunfo, Viamão.

124. Araneus venatrix (C. L. Косн, 1839a): 56, fig. 373. Localidade-tipo: Brasil. Levi (1991a): 252, figs 295-302. Registros: Canela, Capão do Leão, Caxias do Sul, Derrubadas, Eldorado do Sul, Estrela Velha, Gravataí, Guaíba, Machadinho, Maquiné, Marcelino Ramos, Osório, Palmares do Sul, Pelotas, Porto Alegre, São Francisco de Paula, Sapiranga, Torres, Triunfo, Viamão.

125. Araneus vincibilis (Keyserling, 1893): 209, est. 9, fig. 154. Localidade-tipo: RS, Brasil. Levi (1991a): 206, figs 64-70. Registros: Barra do Ribeiro, Bom Jesus, Canela, Derrubadas, Eldorado do Sul, Garruchos, General Câmara, Maquiné, Montenegro, Nonoai, Osório, Pelotas, Porto Alegre, São Francisco de Paula, São Pedro do Sul, Sobradinho, Torres, Triunfo.

126. Araneus workmani (Keyserling, 1884b): 649, est. 21, fig. 1. Localidade-tipo: Santa Isabel do Sul, Arroio Grande, RS, Brasil. Levi (1991a): 207, figs 78-84.

Registros: Arroio Grande, Canela, Estrela Velha, Maquiné, Nova Petrópolis, Palmares do Sul, Pelotas, Porto Alegre, São Francisco de Paula, Vacaria.

127. Argiope argentata (FABricius, 1775): 433. Localidade-tipo: West Indies. Levi (2004): 58, figs 16, 17, 36-45.

Registros: Alvorada, Arroio do Tigre, Bom Jesus, Caçapava do
Sul, Cachoeira do Sul, Cachoeirinha, Camaquã, Cambará do Sul, Candelária, Canela, Canoas, Capão da Canoa, Caxias do Sul, Charqueadas, Cruz Alta, Derrubadas, Eldorado do Sul, Erechim, Estrela Velha, Farroupilha, General Câmara, Gravataí, Guaíba, Maximiliano de Almeida, Montenegro, Nova Petrópolis, Passo Fundo, Pelotas, Porto Alegre, Quaraí, Rio Grande, Santa Maria, Santa Vitória do Palmar, São Borja, São Francisco de Paula, São José do Norte, São Leopoldo, Sobradinho, Tenente Portela, Torres, Triunfo, Veranópolis, Viamão, Xangri-lá.

128. Argiope ericae Levi, 2004: 62, figs 64-73. Localidade-tipo: Garruchos, RS, Brasil.

Registros: Cachoeira do Sul, Garruchos, São Leopoldo.

129. Argiope trifasciata (FonsKÅL, 1775): 86. Localidade-tipo: Cairo, Egito. Levi (2004): 54, figs 18-26.

Registros: Cachoeirinha, Capão Novo, Porto Alegre, Restinga Seca, Santa Maria, Viamão.

130. Bertrana rufostriata Simon, 1893: 325. Localidade-tipo: Pebas, Loreto, Peru. Levi (1989): 87, figs 19-24.

Registros: Butiá, Cambará do Sul, Canela, Canoas, Caxias do Sul, Derrubadas, Farroupilha, General Câmara, Gravataí, Guaíba, Igrejinha, Maquiné, Montenegro, Porto Alegre, Ronda Alta, Santa Maria, São Borja, São Francisco de Paula, São Jerônimo, São Leopoldo, Tenente Portela, Terra de Areia, Torres, Triunfo, Viamão.

131. Bertrana striolata Keyserling, 1884b: 654, est. 21, fig. 6 Localidade-tipo: Pebas, Loreto, Peru. Levi (1989): 84, figs 11-18. Registro: Derrubadas.

132. Cyclosa bifurcata (Walckenaer, 1841): 45. Localidade-tipo: Guyana. Epeira walckenaerii KeYSERLING, 1892: 98, est. 5, fig. 73, localidade-tipo: Taquara, RS, Brasil. Levi (1999): 365, figs 368-377.

Registros: Caçapava do Sul, Cachoeira do Sul, Campo Bom, Capão do Leão, Derrubadas, Estrela Velha, Gravataí, Guaíba, Montenegro, Salto do Jacuí, Santa Maria, São Leopoldo, Taquara, Tenente Portela, Triunfo, Viamão.

133. Cyclosa camargoi Levi, 1999: 343, figs 212-217. Localidadetipo: Campos do Jordão, SP, Brasil. Registros: Esteio, Santo Antônio da Patrulha.

134. Cyclosa diversa (O. P.-CAMbridge, 1894): 136, est. 16, fig. 11. Localidade-tipo: Teapa, Tabasco, Mexico. Levi (1999): 369, figs 391-412.

Registros: Arroio do Tigre, Arroio Grande, Cachoeira do Sul, Derrubadas, Encantado, Novo Hamburgo, Porto Alegre, Santa Maria, São Francisco de Paula, São Leopoldo, Triunfo, Viamão.

135. Cyclosa espumoso Levi, 1999: 355, figs 298-303. Localidadetipo: Salto do Jacuí, Espumoso, RS, Brasil.

Registros: Espumoso, Machadinho, Pelotas, Tenente Portela.

136. Cyclosa fililineata Hingston, 1932: 116, 371. Localidadetipo: Essequibo River, Guyana. Levi (1999): 330, figs 96-107. Registros: Arroio do Meio, Campo Bom, Derrubadas, Estrela Velha, General Câmara, Iraí, Machadinho, Montenegro, Nonoai, Osório, Santa Maria, Tenente Portela, Torres, Triunfo, Viamão.

137. Cyclosa inca Levi, 1999: 326, figs 86-95. Localidade-tipo: Puerto Inca, Huánaco, Peru.

Registros: Derrubadas, Montenegro, Santo Antônio da Patrulha.

138. Cyclosa machadinho LevI, 1999: 351, figs 265-274. Localidadetipo: Machadinho, RS, Brasil.

Registros: Arvorezinha, Bagé, Butiá, Cachoeira do Sul, Cambará do Sul, Campo Bom, Canela, Canoas, Caxias do Sul, Derrubadas, Dom Feliciano, Eldorado do Sul, Erechim, Erval Grande, Estrela Velha, Guabiju, Guaíba, Machadinho, Maquiné, Marcelino Ramos, Minas do Leão, Montenegro, Novo Hamburgo, Passo Fundo, Porto Alegre, Quaraí, Ronda Alta, Salto do Jacuí, Santa Maria, São Francisco de Paula, São Leopoldo, São Pedro do Sul, São Valentim.

139. Cyclosa morretes Levi, 1999: 350, figs 256-264. Localidadetipo: Morretes, PR, Brasil.

Registros: Canela, Carazinho, Derrubadas, Eldorado do Sul, Guaíba, Montenegro, Passo Fundo, Pelotas, Porto Alegre, Rio Pardo, Terra de Areia, Viamão.

140. Cyclosa pantanal LeVI, 1999: 348, figs 248-255. Localidadetipo: MT, Brasil.

Registro: Santana do Livramento.

141. Cyclosa rubronigra CAPORIACCo, 1947: 24. Localidade-tipo: Guyana. Levi (1999): 325, figs 77-85.

Registro: Viamão. 
142. Cyclosa tapetifaciens Hingston, 1932: 370. Localidade-tipo: Essequibo River, Guyana. Levi (1999): 338, figs 181-194. Registros: Derrubadas, Maquiné, Montenegro, São Francisco de Paula, São Leopoldo.

143. Cyclosa turvo Levi, 1999: 342, figs 204-207. Localidadetipo: Derrubadas, RS, Brasil. Registros: Derrubadas, Estrela Velha.

144. Cyclosa vicente Levi, 1999: 369, figs 387-390. Localidadetipo: São Vicente do Sul, RS, Brasil.

Registros: Guaíba, São Vicente do Sul, Viamão.

145. Eustala albiventer (KeYserLing, 1884b): 651, est. 21, fig. 3. Localidade-tipo: Santa Isabel do Sul, Arroio Grande, RS, Brasil. Eustala sanguinosa (KeYserling, 1893): 225, est. 11, fig. 167, localidade-tipo: Taquara, RS, Brasil. PoETA et al. (2010a): 155, figs $20-24$.

Registros: Arroio Grande, Barra do Ribeiro, Cambará do Sul, Canela, Capão do Leão, Capivari do Sul, Eldorado do Sul, Gravataí, Maquiné, Montenegro, Muçum, Osório, Palmares do Sul, Porto Alegre, Rio Grande, Santa Maria, Santa Vitória do Palmar, São Francisco de Paula, São Leopoldo, São Lourenço do Sul, Tapes, Taquara, Tavares, Triunfo, Vacaria, Viamão.

146. Eustala belissima Poeta, Marques \& Buckup, 2010b: 267, figs 4-9. Localidade-tipo: Cambará do Sul, RS, Brasil.

Registros: Bom Jesus, Cambará do Sul, Caxias do Sul, Estrela Velha, Vacaria.

147. Eustala crista Poeta, Marques \& Buckup, 2010b: 268, figs 10-15. Localidade-tipo: Iraí, RS, Brasil.

Registros: Campo Bom, Canela, Cristal, Derrubadas, Encantado, Estrela Velha, Iraí, Maquiné, Montenegro, Porto Alegre, São Francisco de Paula, São Valentim, Viamão.

148. Eustala itapocuensis Strand, 1916: 107. Localidade-tipo: Joinville, SC, Brasil. Poeta et al. (2010b): 270, figs 16-21. Registros: Barra do Ribeiro, Capão do Leão, Eldorado do Sul, Maquiné, Triunfo.

149. Eustala levii Poeta, Marques \& Buckup, 2010a: 151, figs 813. Localidade-tipo: São Francisco de Paula, RS, Brasil. Registros: Arroio Grande, Canela, Capão do Leão, Caxias do Sul, Eldorado do Sul, Gravataí, Montenegro, Porto Alegre, Rio Grande, São Francisco de Paula, Tapes, Triunfo, Viamão.

150. Eustala minuscula (KeYserLing, 1892): 140, est. 7, fig. 103. Localidade-tipo: RS, Brasil. Levi (2007b).

Registros: Bom Jesus, Cachoeirinha, Cambará do Sul, Campo Bom, Candelária, Canoas, Capão da Canoa, Charqueadas, Estrela Velha, Gravataí, Guaíba, Montenegro, Porto Alegre, Rio Grande, Rio Pardo, São Francisco de Paula, Sertão Santana, Triunfo, Vacaria.

151. Eustala palmares Poeta, Marques \& Buckup, 2010a: 152, figs 14-19. Localidade-tipo: Palmares do Sul, RS, Brasil. Registros: Arroio Grande, Barra do Ribeiro, Canela, Capão do Leão, Capivari do Sul, Eldorado do Sul, Estrela Velha, Glorinha, Gravataí, Guaíba, Maquiné, Montenegro, Palmares do Sul, Pelotas, Porto Alegre, Rio Grande, Santa Vitória do Palmar, Santo Antônio da Patrulha, São Leopoldo, Tapes, Triunfo, Viamão.

152. Eustala perfida Mello-Leitão, 1947b: 243, fig. 11. Localidade-tipo: Volta Grande, PR, Brasil. PoETA et al. (2010b): 271 , figs 22-26.

Registros: Bom Jesus, Cambará do Sul, Canela, Caxias do Sul, Eldorado do Sul, Iraí, Montenegro, Passo Fundo, São Valentim, Triunfo, Viamão.

153. Eustala photographica Mello-Leitão, 1944: 329, figs 13, 14. Localidade-tipo: Buenos Aires, Argentina. Poeta et al. (2010a): 158, figs 30-34.

Registros: Arroio Grande, Bagé, Cristal, Roca Sales.

154. Eustala saga (Keyserling, 1893): 253, est. 13, fig. 188. Localidade-tipo: Uruguai, Brasil. LEVI (2007b).

Registros: Bom Jesus, Cachoeirinha, Cambará do Sul, Candelária, Canela, Canoas, Capão da Canoa, Caxias do Sul, Derrubadas, Estrela Velha, Gravataí, Guaíba, Igrejinha, Machadinho, Mariana Pimentel, Maquiné, Montenegro, Porto Alegre, Restinga Seca, Roca Sales, Salto do Jacuí, Santa Maria, São Francisco de Paula, São Leopoldo, São Pedro do Sul, Tapes, Triunfo, Viamão.

155. Eustala sagana (Keyserling, 1893): 254, est. 13, fig. 189. Localidade-tipo: RJ, Brasil. Levi (2007b).

Registros: Candelária, Derrubadas, Estrela Velha, Farroupilha, Júlio de Castilhos, Morro Reuter, Pelotas, Pinhal Grande, São Francisco de Paula, Tenente Portela.
156. Eustala secta Mello-Leitão, 1945: 238, fig. 11. Localidadetipo: Misiones, Argentina. PoETA et al. (2010b): 272, figs 27-31. Registro: Derrubadas.

157. Eustala taquara (Keyserling, 1892): 143, est. 7, fig. 105. Localidade-tipo: Taquara, RS, Brasil. Poeta et al. (2010a): 157, figs 25-29.

Registros: Arroio dos Ratos, Arroio Grande, Barra do Ribeiro, Cambará do Sul, Candelária, Canela, Capão do Leão, Cristal, Derrubadas, Eldorado do Sul, Encantado, Estrela Velha, Gravataí, Guaíba, Júlio de Castilhos, Maquiné, Novo Hamburgo, Parobé, Pelotas, Porto Alegre, Rio Grande, Roca Sales, Salto do Jacuí, São Francisco de Paula, São Leopoldo, Taquara, Triunfo.

158. Eustala ulecebrosa (Keyserling, 1892): 104, est. 5, fig. 77 Localidade-tipo: Taquara, RS, Brasil. Levi (2007b). Registro: Taquara.

159. Gasteracantha cancriformis (Linné, 1767): 1037. Localidade-tipo: América. Levi (1996a): 140, figs 292-312. Registros: Bagé, Barra do Ribeiro, Barracão, Bossoroca, Butiá, Cachoeira do Sul, Campo Bom, Candelária, Canela, Canoas, Capão da Canoa, Capão do Leão, Caxias do Sul, Cidreira, Dom Feliciano, Dona Francisca, Eldorado do Sul, Estância Velha, Esteio, Estrela Velha, Garibaldi, General Câmara, Glorinha, Gravataí, Guaíba, Lajeado, Maquiné, Montenegro, Novo Hamburgo, Osório, Palmares do Sul, Pelotas, Portão, Porto Alegre, Rio Grande, Rio Pardo, Salto do Jacuí, Santa Maria, São Borja, São Jerônimo, São Leopoldo, São Pedro do Sul, Sapiranga, Tapes, Taquara, Tavares, Torres, Triunfo, Vacaria, Viamão.

160. Gea heptagon (HENTz, 1850): 20. Localidade-tipo: Carolina do Norte e Alabama, EUA. Levi (2004): 49, figs 1-8.

Registros: Cachoeirinha, Guaíba, Montenegro, Palmares do Sul, Porto Alegre, Rio Grande, Xangri-lá.

161. Hypognatha cambara Levi, 1996a: 114, figs 112-118, Localidade-tipo: Cambará do Sul, RS, Brasil.

Registros: Bom Jesus, Cambará do Sul, São Francisco de Paula.

162. Hypognatha scutata (PerTy, 1833): 194, est. 38, fig. 7. Localidade-tipo: "Provincia Bahiensis". Levi (1996a): 105, figs 56-63.

Registros: Bom Jesus, Cambará do Sul, Derrubadas.

163. Hypognatha triunfo Levi, 1996a: 120, figs 168-170. Localidade-tipo: Triunfo, RS, Brasil.

Registro: Triunfo.

164. Hypognatha viamao Levi, 1996a: 112, figs 106-111. Localidade-tipo: Capivari, Viamão, RS, Brasil.

Registros: Barra do Ribeiro, Bom Jesus, Cachoeira do Sul, Campo Bom, Eldorado do Sul, Guaíba, Montenegro, Muçum, Novo Hamburgo, Pelotas, Porto Alegre, São Jerônimo, Sertão Santana, Tapes, Torres, Triunfo, Viamão.

165. Kaira altiventer O. P.-CAMbridge, 1889: 56, est. 3, fig. 13 Localidade-tipo: Veraguas, Panamá. Haliger corniferus MelloLeitão, 1943a: 180, fig. 18, localidade-tipo: RS, Brasil. Levi (1993a): 213, figs 3-22.

Registros: Derrubadas, Montenegro, Porto Alegre, Triunfo, Viamão.

166. Kaira cobimcha Levi, 1993a: 223, figs 86-92. Localidadetipo: Xavantina-Cachimbo, MT, Brasil. Registro: Santa Maria.

167. Kaira conica Pikelin \& Schiapelli, 1948: 11, figs 11-13. Localidade-tipo: Santa María, Misiones, Argentina. Levi (1993a): 221, figs 70-74. Registro: General Câmara.

168. Kaira echinus (Simon, 1897b): 479. Localidade-tipo: rio Salobro, BA, Brasil. Levi (1993a): 222, figs 75-81.

Registros: Cambará do Sul, Derrubadas, Salto do Jacuí, Triunfo, Viamão.

169. Kaira gibberosa O. P.-Cambridge, 1890: 57, est. 3, fig. 12. Localidade-tipo: Veraguas, Panamá. Kaira obtusa KeYserling, 1892: 66, est. 3, fig. 49, localidade-tipo: Taquara, RS, Brasil. Levi (1993a): 216, figs 29-47.

Registros: Pelotas, Porto Alegre, Taquara, Vacaria, Viamão.

170. Kaira sexta (Chamberlin, 1916): 255, est. 19, fig. 7. Localidade-tipo: Panamá. Levi (1991a): 259, figs 339-342. Registro: Eldorado do Sul.

171. Kapogea alayoi (Archer, 1958): 9, figs 14-16. Localidadetipo: Holguin, Cuba. Levi (1997): 246, figs 133-139. Registros: Garruchos, Santa Maria. 
172. Kapogea cyrtophoroides (F. O. P.-CAMbridge, 1904): 518, est. 51, fig. 4. Localidade-tipo: Teapa, México. Levi (1997): 244, figs 123-131.

Registros: Derrubadas, Estrela Velha, Viamão.

173. Larinia bivittata Keyserling, 1884b: 526, est. 13, fig. 25. Localidade-tipo: Maldonado, Uruguai. Epeira lintearia KeyserLing, 1893: 236, est. 11, fig. 176, localidade-tipo: RS, Brasil. Harrod et al. (1991): 256, figs 20-25.

Registros: Bom Jesus, Cambará do Sul, Capivari do Sul, Palmares do Sul, Pelotas, Rio Grande, Santa Cruz do Sul, Santa Vitória do Palmar, São Francisco de Paula, São José do Norte, São Leopoldo, Vacaria.

174. Larinia montecarlo (Levi, 1988): 414, figs 172-174. Localidade-tipo: Montecarlo, Misiones, Argentina. HARRoD et al. (1991): 260, figs 43-48.

Registros: Arroio do Meio, Cambará do Sul, Campo Bom, Derrubadas, Estrela Velha, Nonoai, São Valentim, Triunfo.

175. Larinia t-notata (Tullgren, 1905): 28 , est. 3, fig. 8 Localidade-tipo: Quinta, Jujuy, Argentina. Harrod et al. (1991): 259, figs 36-42.

Registros: Cachoeirinha, Cambará do Sul, Campo Bom, Guaíba, Passo Fundo, Santa Maria, Sertão Santana.

176. Larinia tucuman HARRod, LeVI \& LeIBENSPERgER, 1991: 253 , figs 10-15. Localidade-tipo: Tucumán, Argentina.

Registros: Cachoeirinha, Capivari do Sul, Itaqui, Restinga Seca, Tapes.

177. Mangora bocaina Levi, 2007a: 57, figs 177-185. Localidadetipo: RJ, Brasil.

Registros: Canela, Capão Novo, Guaíba, Roca Sales, Santo Antônio da Patrulha, São Francisco de Paula, Tenente Portela, Torres, Viamão.

178. Mangora botelho LEVI, 2007a: 66, figs 221, 222. Localidadetipo: São Miguel Arcanjo, SP, Brasil. Registro: Gravataí.

179. Mangora caballero Levi, 2007a: 67, figs 231-237. Localidade-tipo: Misiones, Argentina. Registro: Tenente Portela.

180. Mangora fundo Levi, 2007a: 56, figs 170-176. Localidadetipo: Passo Fundo, RS, Brasil.

Registros: Arroio do Tigre, Arroio dos Ratos, Bagé, Barra do Ribeiro, Candelária, Canela, Canoas, Eldorado do Sul, Estrela Velha, General Câmara, Guaíba, Machadinho, Marcelino Ramos, Montenegro, Passo Fundo, Pinhal Grande, Porto Alegre, Santa Rosa, São Sepé, Tapes, Tenente Portela, Viamão.

181. Mangora lactea Mello-Leitão, 1944: 331, fig. 16 Localidade-tipo: Buenos Aires, Argentina. Levi, 2007a: 140, figs 638-642.

Registro: Bom Jesus

182. Mangora maximiano Levi, 2007a: 95, figs 393-396. Localidade-tipo: Guaíba, RS, Brasil. Registro: Guaíba.

183. Mangora melanocephala (TACZANowski, 1874): 70. Localidade-tipo: Cayenne, Guiana Francesa. Levi (2007a): 61, figs 199-211.

Registros: Arroio do Tigre, Cachoeirinha, Derrubadas, Estrela Velha, Gravataí, Iraí, Lajeado, Machadinho, Marcelino Ramos, Montenegro, Muçum, Roca Sales, Tenente Portela, Triunfo, Viamão.

184. Mangora missa Levi, 2007a: 53, figs 154-163. Localidadetipo: Santa Maria, Misiones, Argentina.

Registros: Derrubadas, Estrela Velha, Glorinha, Porto Alegre, Rio Pardo, Salto do Jacuí, Triunfo, Viamão.

185. Mangora nonoai LEvI, 2007a: 138, figs 629-632. Localidadetipo: Nonoai, RS, Brasil. Registro: Nonoai.

186. Mangora paula Levi, 2007a: 91, figs 372-376. Localidadetipo: São Francisco de Paula, RS, Brasil. Registro: São Francisco de Paula.

187. Mangora piratini Rodrigues \& MendonÇA, 2011: 66, figs 1416. Localidade-tipo: Arroio Grande, RS, Brasil. Registro: Arroio Grande.

188. Mangora ramirezi LEVI, 2007a: 79, figs 296-301. Localidadetipo: Misiones, Argentina. Registros: Derrubadas, Tenente Portela.

189. Mangora sobradinho Levi, 2007a: 108, figs 465-471. Localidade-tipo: Sobradinho, RS, Brasil.
Registros: Candelária, Canela, Espumoso, Machadinho, São Francisco de Paula, Sobradinho, Viamão.

190. Mangora strenua (Keyserling, 1893): 257, est. 13, fig. 192. Localidade-tipo: Taquara, RS, Brasil. Levi (2007a): 136 figs 622-628.

Registros: Arroio do Tigre, Arroio Grande, Bom Jesus, Cambará do Sul, Campo Bom, Canela, Caxias do Sul, Farroupilha, Machadinho, Maquiné, Nova Petrópolis, Novo Hamburgo, Porto Alegre, São Francisco de Paula, Taquara, Terra de Areia, Torres, Triunfo, Vacaria, Viamão.

191. Mangora velha Levi, 2007a: 54, figs 164-169. Localidadetipo: Estrela Velha, RS, Brasil. Registro: Estrela Velha

192. Mangora v-signata Mello-Leitão, 1943a: 184, fig. 21. Localidade-tipo: Porto Alegre, RS, Brasil. Theridion fidum Mello-Leitão, 1943a: 169, figs 13, 14, localidade-tipo: RS, Brasil. Levi (2007a): 88, figs 356-362.

Registros: Derrubadas, Estrela Velha, Muçum, Porto Alegre, Tenente Portela, Três Coroas.

193. Manogea porracea (C. L. Косн, 1839a): 49, fig. 368. Localidade-tipo: Brasil. Levi (1997): 234, figs 79-93. Registros: Derrubadas, Tenente Portela.

194. Mastophora brescoviti Levi, 2003: 363, figs 322-328. Localidade-tipo: Porto Alegre, RS, Brasil. Registro: Porto Alegre.

195. Mastophora carpogastra Mello-Leitão, 1925: 460 Localidade-tipo: Rio de Janeiro, RJ, Brasil. Levi (2003): 340, figs $128-134$. Registros: Porto Alegre, São Leopoldo.

196. Mastophora extraordinaria Holmberg, 1876: 20. Localidadetipo: Buenos Aires, Argentina. Levi (2003): 357, figs 281-287. Registros: Canela, Garibaldi.

197. Mastophora melloleitaoi CANALs, 1931: 20, figs 1-4. Localidadetipo: Buenos Aires, Argentina. Levi (2003): 356, figs 274-280. Registros: Bagé, Santa Maria.

198. Mastophora pesqueiro LevI, 2003: 352, figs 237-243. Localidade-tipo: Montenegro, RS, Brasil. Registro: Montenegro.

199. Mastophora satan Canals, 1931: 25, figs 1-5. Localidadetipo: La Rioja, Argentina. Levi (2003): 370, figs 387-398 Registros: Bagé, Canela, Porto Alegre, Santa Maria, Santo Antônio da Patrulha, São Leopoldo, Sapucaia do Sul.

200. Mecynogea bigibba Simon, 1903b: 25. Localidade-tipo: Goiânia, GO, Brasil. Levi (1997): 222, figs 1-25.

Registros: Cachoeira do Sul, Canoas, Derrubadas, Montenegro, Nonoai, São Leopoldo, São Pedro do Sul, Sobradinho, Tenente Portela, Triunfo, Viamão.

201. Mecynogea lemniscata (WALCKENAER, 1841): 263. Localidadetipo: Georgia, EUA. Levi (1997): 228, figs 40-54.

Registro: Garruchos.

202. Mecynogea sucre Levi, 1997: 228, figs 34-39. Localidadetipo: Sucre, Venezuela. Registro: Sobradinho.

203. Metazygia floresta Levi, 1995b: 132, figs 314-317. Localidade-tipo: RJ, Brasil.

Registros: Marcelino Ramos, Parobé

204. Metazygia genialis (KeYSERLING, 1892): 156, est. 8, fig. 114 Localidade-tipo: RS, Brasil. LeVI (1995b): 118, figs 239-246. Registros: Capivari do Sul, Cidreira, Eldorado do Sul, Guaíba, Osório, Palmares do Sul, Pelotas, Porto Alegre, Rio Grande, Santa Vitória do Palmar, Santo Antônio da Patrulha, Tapes, Viamão.

205. Metazygia gregalis (O. P.-CAMBRIDGE, 1889): 22, est. 5, fig. 3 . Localidade-tipo: Veraguas, Panamá. Levi (1995b): 121, figs 253-262.

Registros: Arroio do Tigre, Barra do Ribeiro, Bom Jesus, Butiá, Campo Bom, Canela, Canoas, Capivari do Sul, Derrubadas, Eldorado do Sul, Estrela Velha, Gravataí, Guaíba, Lajeado, Maquiné, Marcelino Ramos, Montenegro, Mostardas, Osório, Palmares do Sul, Pelotas, Porto Alegre, Rio Grande, Roca Sales, Salto do Jacuí, Santa Maria, Santa Vitória do Palmar, São Francisco de Paula, São Leopoldo, Taquara, Tramandaí, Triunfo, Viamão.

206. Metazygia lagiana Levi, 1995b: 134, figs 328-332. Localidadetipo: Misiones, Argentina.

Registro: Derrubadas. 
207. Metazygia limonal Levi, 1995b: 128, figs 292-294. Localidade-tipo: Madre de Díos, Peru.

Registro: Santa Rosa.

208. Metazygia rogenhoferi (KEYSERLING, 1878): 578, est. 14, fig. 6. Localidade-tipo: Brasil. Levi (1995b): 98, figs 94-99. Registros: Campo Bom, Canela, Capão da Canoa, Capivari do Sul, Charqueadas, Eldorado do Sul, General Câmara, Gravataí, Guaíba, Montenegro, Osório, Palmares do Sul, Porto Alegre, Rio Grande, Santa Vitória do Palmar, Santo Antônio da Patrulha, São Leopoldo, Tapes, Torres, Triunfo, Viamão.

209. Metazygia saturnino Levi, 1995b: 111, figs 197-202. Localidade-tipo: Santa Maria, RS, Brasil.

Registros: Eldorado do Sul, Palmares do Sul, Rio Grande, Santa Maria.

210. Metazygia valentim Levi, 1995b: 144, figs 405-408. Localidade-tipo: São Valentim, RS, Brasil.

Registro: São Valentim.

211. Metazygia viriosa (Keyserling, 1892): 165, est. 8, fig. 122. Localidade-tipo: RS, Brasil. Levi (1995b): 126, figs 285-288. Registros: Canela, São Francisco de Paula.

212. Metazygia voluptifica (Keyserling, 1892): 152, est. 7, fig. 112. Localidade-tipo: Rio Grande, RS, Brasil. Epeira mundula Keyserling, 1892: 179, est. 9, fig. 132, localidade-tipo: RS, Brasil. Levi (1995b): 125, figs 277-284.

Registros: Bom Jesus, Eldorado do Sul, Encantado, Guaíba, Montenegro, Porto Alegre, Rio Grande, Roca Sales, Santa Vitória do Palmar, Triunfo, Viamão.

213. Metepeira compsa (Chamberlin, 1916): 252, est. 19, fig. 6 . Localidade-tipo: Cusco, Peru. PIel (2001): 48, figs 129-140. Registros: Cachoeira do Sul, Candelária, Dom Feliciano, Glorinha, Itaqui, Montenegro, Santa Vitória do Palmar, São Francisco de Paula, São Leopoldo, Viamão.

214. Metepeira glomerabilis (KEYSERLING, 1892): 154, est. 8, fig. 113. Localidade-tipo: Taquara, RS, Brasil. Piel (2001): 28 , figs $46-52$.

Registros: Candelária, Canoas, Dom Feliciano, Encantado, General Câmara, Gravataí, Guabiju, Guaíba, Montenegro, Pelotas, Porto Alegre, Salto do Jacuí, Santa Maria, São Francisco de Paula, Taquara, Torres, Triunfo, Viamão.

215. Metepeira gressa (Keyserling, 1892): 166, est. 8, fig. 123. Localidade-tipo: Taquara, RS, Brasil. Epeira seditiosa KeyserLing, 1893: 212, est. 10, fig. 157, localidade-tipo: RS, Brasil. Piel (2001): 54, figs 149-156.

Registros: Bagé, Bom Jesus, Capivari do Sul, Cidreira, Porto Alegre, São Francisco de Paula, Taquara, Tavares, Tramandaí, Viamão, Xangri-lá.

216. Metepeira vigilax (Keyserling, 1893): 211, est. 10, fig. 156. Localidade-tipo: Taquara, RS, Brasil. PIel (2001): 30, figs 53-59.

Registros: Cachoeirinha, Gravataí, Porto Alegre, Quaraí, Rio Pardo, Santa Maria, São Leopoldo, Taquara, Viamão.

217. Micrathena annulata ReImoser, 1917: 149, est. 9, fig. 31. Localidade-tipo: SC, Brasil. Levi, 1985: 532, figs 440-447. Registro: Maquiné

218. Micrathena brevispina (KeYSERLING, 1864): 70, est. 2, fig. 3. Localidade-tipo: Bogotá, Colômbia. LeVI (1985): 522, figs 386-393. Registros: Derrubadas, Terra de Areia.

219. Micrathena crassispina (C. L. Косн, 1836): 55, fig. 209. Localidade-tipo: América. Levi (1985): 494, figs 235-241. Registros: Cambará do Sul, Canela, Garruchos, Gramado, Guaíba, Maquiné, Montenegro, Passo Fundo, Pelotas, Porto Alegre, Santa Maria, São Borja, São Francisco de Paula, Sobradinho, Tapes, Tavares, Triunfo, Viamão.

220. Micrathena digitata (C. L. Косн, 1839b): 128, fig. 523. Localidade-tipo: Brasil. Levi, 1985: 475, figs 122-128. Registros: Cambará do Sul, Caxias do Sul, Pelotas, São Francisco de Paula, Torres.

221. Micrathena excavata (C. L. Косн, 1836): 80, fig. 227. Localidade-tipo: Brasil. Levi, 1985: 516, figs 347-353. Registro: Derrubadas.

222. Micrathena flaveola (Perty) in C. L. Косн (1839): 126, fig. 522. Localidade-tipo: Brasil. LeVI (1985): 544, figs 508-520. Registro: Derrubadas.

223. Micrathena furcata (HAHN, 1822): 2, est. 11, fig. A. Localidade-tipo: Cayenne, Guiana Francesa. Levi (1985): 568, figs $625-632$.
Registros: Arroio Grande, Barra do Ribeiro, Cambará do Sul, Canela, Estrela Velha, Gravataí, Lagoa Vermelha, Montenegro, Pelotas, Porto Alegre, Rio Grande, Santa Maria, Santa Vitória do Palmar, Santo Antônio da Patrulha, São Borja, São Francisco de Paula, Torres, Três Coroas, Triunfo, Vacaria, Viamão.

224. Micrathena furva (Keyserling, 1892): 7, est. 1, fig. 4. Localidade-tipo: Taquara, RS, Brasil. Levi (1985): 476, figs 129-135.

Registros: Bagé, Cambará do Sul, Canela, Caxias do Sul, Derrubadas, Estrela Velha, Gramado, Guabiju, Iraí, Machadinho, Marcelino Ramos, Montenegro, Pelotas, Porto Alegre, Quaraí, Santa Maria, São Borja, São Francisco de Paula, São Pedro do Sul, Taquara, Triunfo, Viamão.

225. Micrathena guanabara Levi, 1985: 505, figs 283-289. Localidade-tipo: RJ, Brasil.

Registros: Canela, São Francisco de Paula, Terra de Areia, Torres.

226. Micrathena horrida (TACZANowski, 1873): 281, est. 6, fig. 31. Localidade-tipo: Cayenne, Guiana Francesa. Levi (1985): 596, figs $774-783$.

Registro: Sapiranga.

227. Micrathena jundiai Levi, 1985: 532, figs 432-439. Localidade-tipo: SP, Brasil. Registros: Derrubadas, Iraí, Torres.

228. Micrathena lata Chickering, 1960: 5, figs 8-12. Localidadetipo: Teresópolis, RJ, Brasil. Levi (1985): 565, figs 608-615. Registros: Montenegro, Novo Hamburgo, Osório, Pelotas, São Borja, São Francisco de Paula, São Leopoldo, Torres, Triunfo.

229. Micrathena macfarlanei CHICKering, 1961: 430, figs 99-102. Localidade-tipo: Barro Colorado, Panamá. Levi (1985): 498, figs $252-260$.

Registro: Torres.

230. Micrathena nigrichelis STRAnd, 1908a: 4. Localidade-tipo: Joinville, SC, Brasil. Micrathena henseli ReImoser, 1917: 121, est. 7, fig. 19, localidade-tipo, Porto Alegre, RS, Brasil. LeVI (1985): 455, figs 53-60.

Registros: Arroio do Tigre, Canela, Barra do Ribeiro, Bom Jesus, Caçapava do Sul, Cambará do Sul, Candelária, Canela, Canoas, Caxias do Sul, Derrubadas, Dom Feliciano, Esmeralda, Estrela Velha, General Câmara, Gravataí, Guaíba, Lajeado, Machadinho, Maquiné, Montenegro, Morro Reuter, Nova Petrópolis, Palmares do Sul, Pelotas, Pinhal Grande, Porto Alegre, Quaraí, Salto do Jacuí, Santo Antônio da Patrulha, São Borja, São Francisco de Paula, São Jerônimo, São Leopoldo, Tapes, Terra de Areia, Triunfo, Vacaria, Viamão.

231. Micrathena plana (C. L. Косн, 1836): 81, fig. 228. Localidade-tipo: Brasil. Levi (1985): 509, figs 311-325. Registros: Bom Jesus, Cambará do Sul, Canela, Derrubadas, Garruchos, São Francisco de Paula.

232. Micrathena reali Levi, 1985: 458, figs 66-73. Localidadetipo: Itaimbézinho, Cambará do Sul, RS, Brasil. Registro: Cambará do Sul.

233. Micrathena spitzi Mello-LeITÃo, 1932: 79, fig. 2. Localidadetipo: Santo André, SP, Brasil. Levi (1985): 550, figs 543-550. Registros: Arroio Grande, Caçapava do Sul, Cachoeira do Sul, Capão do Leão, Caxias do Sul, Derrubadas, Estrela Velha, Machadinho, Marcelino Ramos, Palmares do Sul, Pelotas, Tapes, Viamão.

234. Micrathena swainsoni (Perty, 1833): 194, est. 38, fig, 10 Localidade-tipo: Piauí, Brasil. Levi (1985): 571, figs 638-645. Registro: São Francisco de Assis.

235. Micrathena triangularis (C. L. КосH, 1836): 78, fig. 226. Localidade-tipo: Brasil. Levi (1985): 512, figs 326-336. Registros: Bom Jesus, Caxias do Sul.

236. Neoscona moreli (VINSON, 1863): 166, 309, est. 4, fig. 4 Localidade-tipo: Ilha Réunion. Levi, 1993c: 232, figs 18-21. Registros: Canoas, Capão da Canoa, Pelotas, Porto Alegre, Santa Maria, Torres, Viamão, Xangri-lá.

237. Neoscona nautica (L. KocH, 1875): 17, est. 2, fig. 2. Localidade-tipo: Sudão. Levi, 1993c: 228, figs 10-13. Registros: Pelotas, Santa Rosa.

238. Ocrepeira fiebrigi (DAHL, 1906): 735. Localidade-tipo: Paraguai. LeVI (1993b): 102, figs 192-199.

Registro: Garruchos. 
239. Ocrepeira galianoae Levi, 1993b: 100, figs 186-191. Localidade-tipo: General Belgrano, Misiones, Argentina. Registros: Arroio dos Ratos, Bom Jesus, Cambará do Sul, Canela, Carazinho, Caxias do Sul, Cidreira, Derrubadas, Esmeralda, Estrela Velha, Iraí, Machadinho, Marcelino Ramos, Nonoai, Nova Petrópolis, Pelotas, Rio Pardo, Salto do Jacuí, Santa Maria, São Borja, São Francisco de Paula, Sobradinho, Vacaria.

240. Ocrepeira gnomo (Mello-Leitão, 1943a): 195, fig. 25. Localidade-tipo: RS, Brasil. Levi (1993b): 108, figs 224-231. Registros: Barra do Ribeiro, Campo Bom, Carazinho, Derrubadas, Estrela Velha, Glorinha, Guabiju, Montenegro, São Francisco de Paula, Terra de Areia, Triunfo.

241. Ocrepeira hirsuta (Mello-Leitão, 1942): 400, figs 16-18. Localidade-tipo: Chaco, Argentina. Levi (1993b): 89, figs 119-125. Registros: Arroio do Tigre, Cambará do Sul, Catuípe, Eldorado do Sul, Farroupilha, Guaíba, Itaqui, Marcelino Ramos, Nonoai, Salto do Jacuí, Santa Maria, São Borja, São Leopoldo, São Pedro do Sul, Triunfo, Viamão.

242. Ocrepeira lisei Levi, 1993b: 109, figs 232-235. Localidadetipo: Canela, RS, Brasil.

Registros: Bagé, Cambará do Sul, Canela, Porto Alegre.

243. Ocrepeira malleri Levi, 1993b: 100, figs 180-185. Localidadetipo: Pinhal, SC, Brasil. Registros: Cristal, Guaíba

244. Ocrepeira pinhal Levi, 1993b: 105, figs 212-215. Localidadetipo: Pinhal, SC, Brasil Registro: Garruchos.

245. Ocrepeira venustula (KeyserLING, 1879): 308, est. 4, fig. 11. Localidade-tipo: Nova Friburgo, RJ, Brasil. Levi (1993b): 94, figs 29-33, 143-154.

Registros: Bom Jesus, Canela, Cidreira, Garruchos, Gravataí, Machadinho, Marcelino Ramos, Nonoai, Passo Fundo, Salto do Jacuí, São Leopoldo, São Pedro do Sul, Viamão.

246. Parawixia audax (Blackwall, 1863): 29. Localidade-tipo: Rio de Janeiro, RJ, Brasil. Levi (1992): 36, figs 136-142. Registros: Arroio dos Ratos, Arroio do Tigre, Barra do Ribeiro, Barracão, Bom Jesus, Butiá, Caçapava do Sul, Cambará do Sul, Campo Bom, Candelária, Canela, Canoas, Capão da Canoa, Capão do Leão, Capivari do Sul, Catuípe, Caxias do Sul, Charqueadas, Derrubadas, Dois Irmãos, Dom Feliciano, Eldorado do Sul, Encantado, Erechim, Esmeralda, Esteio, Estrela Velha, Farroupilha, Garibaldi, Garruchos, General Câmara, Gravataí, Guabiju, Guaíba, Iraí, Maquiné, Marcelino Ramos, Montenegro, Morro Reuter, Mostardas, Nonoai, Novo Hamburgo, Osório, Palmares do Sul, Passo Fundo, Pelotas, Pinhal Grande, Portão, Porto Alegre, Rio Grande, Rio Pardo, Roca Sales, Salto do Jacuí, Santa Cruz do Sul, Santa Maria, Santa Vitória do Palmar, São Borja, São Francisco de Paula, São Jerônimo, São Leopoldo, São Vicente do Sul, Sapiranga, Tapes, Tenente Portela, Terra de Areia, Torres, Triunfo, Vacaria, Viamão.

247. Parawixia inopinata CAmargo, 1950: 233, est. 2, figs 7-9, est. 3, figs 2, 3, est. 4, fig. 4. Localidade-tipo: Boracéia, Salesópolis, SP, Brasil. Levi (1992): 22, figs 69-73. Registro: Canela.

248. Parawixia monticola (Keyserling, 1892): 94, est. 4, fig. 70. Localidade-tipo, RJ, Brasil. Levi (1992): 25, figs 81-97. Registros: Porto Alegre, Terra de Areia.

249. Parawixia undulata (Keyserling, 1892): 67, est. 3, fig. 52. Localidade-tipo: RS, Brasil. Levi (1992): 40, figs 143-149. Registros: Cambará do Sul, Canela, Caxias do Sul, Esmeralda, Gramado, Guaíba, Jaguarão, Pelotas, Porto Alegre, Rio Grande, Santa Vitória do Palmar, São Francisco de Paula, Sertão Santana, Vacaria.

250. Parawixia velutina (TACZAnowski, 1878): 159, est. 1, fig. 10 Localidade-tipo: Amable Maria, Junín, Peru. Levi (1992): 24, figs 74-80.

Registros: Bagé, Barra do Ribeiro, Farroupilha, Garruchos, Novo Hamburgo, Passo Fundo, Porto Alegre, São Francisco de Paula, Tenente Portela, Triunfo, Viamão.

251. Pozonia bacillifera (Simon, 1895a): 819, fig. 870. Localidadetipo: Paraguai. Levi (1993b): 60, figs 11-14. Magalhães \& SAntos (2011): 112, figs $1-5$

Registros: Pelotas, Porto Alegre, Triunfo.

252. Scoloderus cordatus (TACZANOWSKI, 1879): 129, est. 2, fig. 41. Localidade-tipo: Amable María, Junín, Peru. Traw (1996): 56 , figs $1-8$.
Registros: Arroio dos Ratos, Butiá, Canela, Caxias do Sul, Derrubadas, Encantado, Estrela Velha, Garruchos, General Câmara, Guaíba, Igrejinha, Iraí, Montenegro, Passo Fundo, Porto Alegre, Santa Maria, São Francisco de Paula, Taquara, Tenente Portela, Triunfo, Viamão.

253. Scoloderus gibber O. P.-Cambridge, 1898: 282, est. 36, fig. 4. Localidade-tipo: Bugaba, Panamá. Traw (1996): 61, figs $9-17$

Registros: São Leopoldo, Tenente Portela.

254. Scoloderus tuberculifer (O. P.-Cambridge, 1889): 48, est. 4, fig. 9. Localidade-tipo: Bugaba, Panamá. Traw (1996): 67, figs 27-34.

Registros: Barra do Ribeiro, Canela, Canoas, Derrubadas, Eldorado do Sul, Encantado, Estrela Velha, General Câmara, Gravataí, Montenegro, Muçum, Pelotas, Porto Alegre, Tapes, Triunfo, Viamão.

255. Taczanowskia mirabilis Simon, 1897b: 481. Localidadetipo: Cametá, PA, Brasil. Levi (1996b): 188, figs 1-8. Registro: Viamão.

256. Taczanowskia sextuberculata KeyserLing, 1892: 60, est. 3 , fig. 47. Localidade-tipo: Taquara, RS, Brasil. Levi (1996b): 188 , figs $9-12,21,22$.

Registro: Taquara.

257. Taczanowskia striata Keyserling, 1879: 298, est. 4, fig. 3 Localidade-tipo: Amable Maria, Junín, Peru. Levi (1996b) 189, figs 13-19.

Registros: Arroio do Tigre, Barra do Ribeiro, Derrubadas, Glorinha.

258. Tatepeira itu Levi, 1995a: 207, figs 225-230. Localidadetipo: Itu, SP, Brasil.

Registros: Glorinha, Montenegro, Tapes.

259. Tatepeira tatarendensis (Tullgren, 1905): 34, est. 5, fig 12. Localidade-tipo: Tatarenda, Tarija, Bolívia. Levi (1995a) 204, figs 217-224. Registro: Viamão.

260. Testudinaria bonaldoi Levi, 2005: 192, figs 27-32. Localidade-tipo: Viamão, RS, Brasil. Registros: Guaíba, Viamão.

261. Testudinaria gravatai Levi, 2005: 192, figs 39-41 Localidade-tipo: Gravataí, RS, Brasil. TeIXeIRA \& Lise, 2010: 128, figs $1-5$. Registros: Gravataí, Viamão.

262. Testudinaria lemniscata (Simon, 1893): 328, est. 7, fig. 7 Localidade-tipo: Serra do Caraça, Catas Altas, MG, Brasil. Levı (2005): 192, figs 33-38. Rodrigues \& Mendonça (2011): 64 figs 9-13. Registros: Derrubadas, Maquiné, Tenente Portela.

263. Testudinaria quadripunctata TACZANOwsKI, 1879: 135, est. 2, fig. 44. Localidade-tipo: Amable Maria, Peru. Levi (2005): 190 , figs $13-20$ Registro: Maquiné.

264. Testudinaria unipunctata (Simon, 1893): 327, est. 7, fig. 6 . Localidade-tipo: Serra do Caraça, Catas Altas, MG, Brasil. Levı (2005): 190, figs 21-26.

Registro: Vacaria.

265. Verrucosa meridionalis (KeYSERLING, 1892): 74, est. 3, fig. 57 Localidade-tipo: RS, Brasil.

Registros: Arroio Grande, Bom Jesus, Cambará do Sul, Canela, Carlos Barbosa, Caxias do Sul, Condor, Derrubadas, Dom Feliciano, Esmeralda, Estrela Velha, General Câmara, Gramado, Guabiju, Nonoai, Passo Fundo, Pelotas, Porto Alegre, Salto do Jacuí, Santa Maria, São Borja, São Francisco de Paula, Triunfo, Vacaria, Viamão.

266. Verrucosa undecimvariolata (O. P.-CAMbridge, 1889): 53 , est. 3, figs 8, 9. Localidade-tipo: Bugaba, Panamá. Registros: Arroio dos Ratos, Barra do Ribeiro, Butiá, Caçapava do Sul, Canela, Canoas, Caxias do Sul, Condor, Derrubadas, Eldorado do Sul, Estrela Velha, General Câmara, Glorinha, Gravataí, Guaíba, Machadinho, Montenegro, Novo Hamburgo, Pelotas, Porto Alegre, Santa Maria, São Jerônimo, São Leopoldo, São Vicente do Sul, Triunfo, Vacaria.

267. Wagneriana atuna Levi, 1991b: 392, figs 93-97. Localidadetipo: Cali, Valle, Colômbia. Registros: Eldorado do Sul, Porto Alegre, Sapucaia do Sul

268. Wagneriana eupalaestra (Mello-LeITÃo, 1943a): 177, fig. 17. Localidade-tipo: RS, Brasil. LeVI (1991b): 396, figs 110-115. 
Registros: Cambará do Sul, Derrubadas, Porto Alegre, São Francisco de Paula, Viamão.

269. Wagneriana grandicornis Mello-LeITão, 1935b: 96, fig. 6. Localidade-tipo: Pesqueira, PE, Brasil. Levi, 1991b: 386, figs 60-66. Registros: Montenegro, Triunfo.

270. Wagneriana heteracantha (Mello-Leitão, 1943a): 174, fig. 15. Localidade-tipo: RS, Brasil. Marxia labidura MelloLeITÃo, 1943a: 184, fig. 22, localidade-tipo: RS, Brasil. Levi (1991b): 394, figs 105-109.

Registros: Canela, Caxias do Sul, Derrubadas, Porto Alegre, São Francisco de Paula, Taquara.

271. Wagneriana iguape LeVI, 1991b: 402, figs 140-144. Localidadetipo: Iguape, SP, Brasil.

Registros: Cambará do Sul, Canela, Derrubadas, Machadinho, São Francisco de Paula, Triunfo.

272. Wagneriana juquia LEVI, 1991b: 393, figs 98-101. Localidadetipo: Juquiá, SP, Brasil. Registros: Cambará do Sul, Derrubadas.

273. Wagneriana neblina LevI, 1991b: 384, figs 54-59. Localidadetipo: Amazonas, Venezuela.

Registro: Derrubadas.

274. Wagneriana neglecta (Mello-Leitão, 1939b): 65, figs 38-40. Localidade-tipo: Paraguai. Levi (1991b): 397, figs 116-122. Registros: Garruchos, São Gabriel.

275. Wagneriana taim LeVI, 1991b: 388, figs 72-76. Localidadetipo: Novo Hamburgo, RS, Brasil.

Registros: Canela, Derrubadas, Iraí, Novo Hamburgo, Rio Grande, Salto do Jacuí, Santa Vitória do Palmar, São Francisco de Paula.

276. Wagneriana transitoria (C. L. Косн, 1839b): 119, est. 208, fig. 518. Localidade-tipo: Brasil. LeVI (1991b): 381, figs 40-44. Registros: Derrubadas, Estrela Velha, Garruchos, Tenente Portela.

277. Wagneriana uzaga LEVI, 1991b: 398, figs 123-128. Localidadetipo: Misiones, Argentina.

Registro: São Francisco de Paula.

\section{CAPONIIDAE}

278. Caponina alegre Platnick, 1994: 8, figs 24, 26-28. Localidadetipo: Porto Alegre, RS, Brasil.

Registros: Porto Alegre, São Francisco de Paula, Viamão.

279. Caponina notabilis (Mello-LeItão, 1939c): 629. Localidadetipo: Córdoba, Argentina. Platnick (1994): 9, figs 25, 29-31. Registros: Derrubadas, Machadinho, Quaraí.

280. Nops meridionalis Keyserling, 1891: 24, est. 1, fig. 6. Localidade-tipo. Taquara, RS, Brasil.

Registros: Barra do Ribeiro, Minas do Leão, Palmares do Sul, Porto Alegre, São Francisco de Paula, Taquara.

281. Nyetnops guarani Platnick \& Lise, 2007: 8, figs 1-30. Localidade-tipo: Três Barras do Paraná, PR, Brasil. Registros: Derrubadas, Vicente Dutra.

\section{CLUBIONIDAE}

282. Elaver brevipes (Keyserling, 1891): 39, est. 1, fig. 16. Localidade-tipo: Nova Friburgo, RJ, Brasil. Brescovit \& Bonaldo (1992): 686, figs 1-4.

Registros: Campo Bom, Canela, Carazinho, Eldorado do Sul, Estrela Velha, Garruchos, General Câmara, Glorinha, Montenegro, Novo Hamburgo, Palmares do Sul, Porto Alegre, São Borja, São Francisco de Paula, Tapes, Terra de Areia, Triunfo, Viamão.

\section{CORINNIDAE}

283. Castianeira chrysura Mello-Leitão, 1943a: 216, fig. 43. Localidade-tipo: RS, Brasil. Registro: Só a localidade-tipo.

284. Castianeira gaucha Mello-Leitão, 1943a: 217, fig. 44. Localidade-tipo: RS, Brasil.

Registro: Só a localidade-tipo.

285. Castianeira patellaris Mello-Leitão, 1943a: 218, fig. 45. Localidade-tipo: RS, Brasil.

Registro: Roca Sales.

286. Corinna bicincta Simon, 1896: 420. Localidade-tipo: PE, Brasil. CAMARgo (1953): 315, figs 1-5, 45-47. Registro: São Borja.

287. Corinna colombo Bonaldo, 2000: 52, figs 149-152. Localidade-tipo: Colombo, PR, Brasil.
Registros: Barracão, Canela, Carazinho, Derrubadas, Estrela Velha, Frederico Westphalen, Machadinho, Porto Alegre, São Borja.

288. Corinna mourai Bonaldo, 2000: 42, figs 123-126. Localidade-tipo: Curitiba, PR, Brasil.

Registros: Arroio do Tigre, Cambará do Sul, Eldorado do Sul, Machadinho, Pelotas, Porto Alegre, São Francisco de Paula, Triunfo.

289. Corinna nitens (Keyserling, 1891): 57, est. 2, fig. 30. Localidade-tipo: Blumenau, SC, Brasil. Bonaldo (2000): 41, figs. 13, 27, 33, 57, 67, 77-82, 119-122.

Registros: Arroio do Sal, Arroio do Tigre, Canela, Canoas, Caxias do Sul, Derrubadas, Dois Irmãos, Estrela Velha, Garruchos, Gravataí, Maquiné, Não-Me-Toque, Novo Hamburgo, Porto Alegre, Santa Maria, São Borja, São Francisco de Paula, São Leopoldo, Sapucaia do Sul, Soledade, Torres, Triunfo, Viamão.

290. Creugas gulosus Thorell, 1878: 175. Localidade-tipo: Ambón, Indonesia. Bonaldo (2000): 99, figs 5, 6, 18, 28, 44, 106, 107, 261-270.

Registros: Canela, General Câmara, Lajeado, Porto Alegre, Viamão.

291. Creugas lisei Bonaldo, 2000: 106, figs 280-283. Localidadetipo: São Francisco de Paula, RS, Brasil.

Registros: Barracão, Bento Gonçalves, Bom Jesus, Canela, Carazinho, Caxias do Sul, Derrubadas, Esmeralda, Garibaldi, Iraí, Machadinho, Montenegro, Porto Alegre, Santa Cruz do Sul, São Borja, São Francisco de Paula, São Jerônimo, Triunfo.

292. Falconina gracilis (KeYSERLing, 1891): 56, est. 2, fig. 29. Localidade-tipo: RS, Brasil. Bonaldo (2000): 79, figs 36-38, 41, 42, 63, 101, 215-228.

Registros: Porto Alegre, Santa Maria.

293. Ianduba varia (Keyserling, 1891): 69, est. 2, fig. 38 Localidade-tipo: Blumenau, SC, Brasil. Bonaldo (1997): 178, figs $1,2,7-10,13,14,29-32$.

Registro: São Leopoldo.

294. Meriola cetiformis (Strand, 1908b): 241. Localidade-tipo: Junín, Peru. Platnick \& Ewing (1995): 15, figs 29-33.

Registros: Capivari do Sul, Derrubadas, Palmares do Sul, Pelotas, Porto Alegre, Quaraí, Rio Grande, Santana do Livramento, Santa Vitória do Palmar, Santo Antônio da Patrulha, Viamão, Xangri-lá.

295. Meriola fasciata (Mello-Leitão, 1941): 178, est. 10, fig. 48. Localidade-tipo: Córdoba, Argentina. Platnick \& EwIng (1995): 26, figs 59-63.

Registro: Quaraí.

296. Meriola foraminosa (Keyserling, 1891): 60, est. 2, fig. 32. Localidade-tipo: Rio Grande, RS, Brasil. Platnick \& EwING (1995): 29, figs. 72-76.

Registros: Capão do Leão, Pelotas, Rio Grande.

297. Meriola hyltonae (Mello-Leitão, 1940c): 53, figs 52, 53. Localidade-tipo: Comodoro Rivadavia, Chubut, Argentina. Platnick \& Ewing (1995): 32, figs 82-86.

Registros: Canela, Quaraí, São Francisco de Paula.

298. Meriola mauryi Platnick \& Ewing, 1995: 39, figs 97-101. Localidade-tipo: Buenos Aires, Argentina.

Registros: Minas do Leão, São Francisco de Paula.

299. Paradiestus giganteus (KARSCH, 1880): 375, est. 12, fig. 3. Localidade-tipo: Brasil. Bonaldo (2000): 63, figs 40, 61, 69, 95, 178-182.

Registros: Bom Jesus, Cambará do Sul, Canela, Gramado, São Francisco de Paula.

300. Paradiestus vitiosus (Keyserling, 1891): 51, est. 2, fig. 24. Localidade-tipo: Rio Grande, RS, Brasil. Bonaldo (2000): 62. Registros: Barra do Ribeiro, Eldorado do Sul, Glorinha, Rio Grande, Salto do Jacuí, São Francisco de Paula, Triunfo, Viamão.

301. Trachelas robustus Keyserling, 1891: 64, est. 2, fig. 35. Localidade-tipo: Nova Friburgo, RJ, Brasil. Registro: Derrubadas.

302. Trachelas rugosus Keyserling, 1891: 62, est. 2, fig. 34. Localidade-tipo: ES, Brasil.

Registro: Derrubadas.

303. Trachelopachys ammobates Platnick \& Rocha, 1995: 3, figs 1-5. Localidade-tipo: RJ, Brasil. Registro: Palmares do Sul.

304. Trachelopachys cingulipes (SIMON, 1886): 569. Localidadetipo: Buenos Aires, Argentina. Platnick (1975): 11, figs 22-25. Registros: Arroio dos Ratos, Bom Jesus, Butiá, Cambará do Sul, 
Eldorado do Sul, General Câmara, Guaíba, Montenegro, São Jerônimo, Tapes, Triunfo.

305. Trachelopachys gracilis (KeYSERLING, 1891): 61, fig. 33. Localidade-tipo: Blumenau, SC, Brasil. Platnick (1975): 18, figs 38-41.

Registros: Cambará do Sul, Canela, Glorinha, Montenegro, Osório, Rio Grande, Santa Maria, Santo Antônio da Patrulha, São Francisco de Paula, Torres, Triunfo, Viamão.

306. Trachelopachys keyserlingi (ROEWER, 1951): 446, nomen novum para Trachelas flavipes KeYserLING, 1891: 59, est. 2, fig. 31. Localidade-tipo: Rio Grande, RS, Brasil. Platnick (1975): 17, figs 34-37.

Registros: Barra do Ribeiro, Bom Jesus, Cambará do Sul, Canela, Capão do Leão, Caxias do Sul, Derrubadas, Estrela Velha, Gravataí, Montenegro, Pelotas, Porto Alegre, São Borja, Rio Grande, Santa Maria, Santa Vitória do Palmar, Tapes, Vacaria, Viamão.

307. Tupirinna albofasciata (Mello-Leitão, 1943a): 238, fig. 65. Localidade-tipo: RS, Brasil. Ramírez (2003): 230. Registro: Só a localidade-tipo.

\section{CTENIDAE}

308. Ancylometes concolor (PERTY, 1833): 197, est. 39, fig. 4 Localidade tipo: Brasil. HöFer \& BRESCOVIT (2000): 332, figs 16, 28-30.

Registros: Pirapó, Santo Ângelo, São Borja.

309. Ancylometes rufus (WALCKENAER, 1837): 367. Localidadetipo: Guiana Francesa. Höfer \& Brescovit (2000): 337, est. 1, figs. 7-11, 31-35. Registro: Garruchos.

310. Asthenoctenus borellii Simon, 1897a: 7. Localidade-tipo: San Pablo, Tucumán, Argentina. Brescovit \& Simó (1998): 2, figs 1-6.

Registros: Bagé, Guaíba, Nova Prata, Novo Hamburgo, Pelotas, Pinhal, Porto Alegre, Rio Grande, Santa Maria, Santa Vitória do Palmar, São Borja, São Jerônimo.

311. Ctenus griseus Keyserling, 1891: 152, est. 4, fig. 105. Localidadetipo: Taquara, RS, Brasil. Registro: Taquara.

312. Ctenus longipes Keyserling, 1891: 150, est. 4, fig. 103 Localidade-tipo: Rio Grande, RS, Brasil.

Registros: Bento Gonçalves, Canela, Gramado, Gravataí, Guaíba, Itaúba, Machadinho, Nova Prata, Novo Hamburgo, Pelotas, Porto Alegre, Rio Grande, Santa Cruz do Sul, São Francisco de Paula, São Leopoldo, Taquara, Torres, Viamão.

313. Ctenus medius Keyserling, 1891: 153, est. 4, fig. 106 Localidade-tipo: Rio Grande, RS, Brasil. Brescovit \& Simó (2007): 3, figs 7-13.

Registros: Barracão, Canela, Canoas, Gravataí, Iraí, Maquiné, Montenegro, Osório, Porto Alegre, Rio Grande, São Francisco de Paula, Sapiranga, Taquara, Torres, Triunfo, Viamão.

314. Ctenus ornatus (Keyserling, 1877b): 687, est. 2, fig. 62. Localidade-tipo: Brasil. Brescovit \& Simó (2007): 5, figs 14-20. Registros: Bento Gonçalves, Derrubadas, Maquiné, Tenente Portela.

315. Ctenus tarsalis F. O. P.-CAMbridge, 1902: 404, est. 7, fig. 9. Localidade-tipo: Brasil.

Registros: Cambará do Sul, Canela, Carazinho, Caxias do Sul, Dois Irmãos, Maquiné, Porto Alegre, São Francisco de Paula.

316. Enoploctenus cyclothorax (BERTKAU, 1880): 56, est. 1, fig. 18. Localidade-tipo: Brasil. BüCHERL (1950): 30, figs 10-22. Registros: Canela, Caxias do Sul, Derrubadas, Sapiranga, Viamão.

317. Isoctenus coxalis (F. O. P.-CAMBRIDGE, 1902): 412. Localidade-tipo: Nova Friburgo, RJ, Brasil. Polotow et al. (2005): 38, figs 1-5.

Registros: Bom Jesus, Guaíba, Porto Alegre, São Jerônimo, Viamão.

318. Isoctenus malabaris Polotow \& Brescovit in Polotow et al. (2007): 216, figs 1-5. Localidade-tipo: São Francisco de Paula, RS, Brasil.

Registros: Barracão, Canela, Derrubadas, Maquiné, São Francisco de Paula, São Jerônimo.

319. Isoctenus minusculus (KeyserLing, 1891): 149, est. 4, fig. 102. Localidade-tipo: Rio Grande, RS, Brasil. Polotow \& BRESCOVIT (2009): 601, figs 14a-d, 19b.
Registros: Bossoroca, Canela, Caxias do Sul, Esmeralda, Farroupilha, Guaíba, Montenegro, Porto Alegre, Rio Grande, São Francisco de Paula, Sobradinho, Triunfo, Viamão.

320. Isoctenus ordinario Polotow \& Brescovit, 2009: 598, figs 9a-d, 19h, i. Localidade-tipo: Mangueirinha, PR, Brasil. Registros: Derrubadas, Esmeralda.

321. Parabatinga brevipes (Keyserling, 1891): 148, est. 4, fig. 101. Localidade-tipo: RS, Brasil. Ctenus taeniatus KeyserLing, 1891: 151, est. 4, fig. 104, localidade-tipo, Rio Grande, RS, Brasil. Eickstedt (1978): 213, figs 1-4. Polotow \& BRescoviT (2009): 603, figs $16,17,20 \mathrm{c}$

Registros: Canoas, Porto Alegre, Rio Grande.

322. Phoneutria nigriventer (KeYSERLING, 1891): 144, est. 4, fig. 94 Localidade-tipo: Rio Grande, RS, Brasil. EICKSTEDT (1978): 106, figs 1, 3, 5-10. Simó \& BRESCOvit (2001): 72, figs 3-4, 7, 10-13, 15,24 . Martins \& Bertani, 2007: 5, figs $1-5,9,13,17,24,28,32$, 36, 40, 44, 48, 52, 56, 60, 68.

Registros: Arroio do Tigre, Barra do Ribeiro, Barracão, Bento Gonçalves, Cambará do Sul, Campo Bom, Canoas, Caxias do Sul, Cidreira, Derrubadas, Dois Irmãos, Erechim, Esteio, Estrela Velha, Garibaldi, Gramado, Gravataí, Guaíba, Iraí, Lajeado, Machadinho, Maquiné, Montenegro, Morro Reuter, Nova Petrópolis, Novo Hamburgo, Osório, Palmeira das Missões, Pelotas, Porto Alegre, Rio Grande, Salto do Jacuí, Santa Cruz do Sul, Santa Maria, São Borja, São José do Ouro, São Leopoldo, São Sebastião do Caí, Sapucaia do Sul, Soledade, Tenente Portela, Triunfo, Tuparendi, Viamão.

\section{DEINOPIDAE}

323. Deinopis guasca Mello-Leitão, 1943a: 158, fig. 4 Localidade-tipo: RS, Brasil.

Registro: Só a localidade-tipo.

324. Deinopis rodophthalma Mello-Leitão, 1939d: 173 Localidade-tipo: São Francisco de Paula, RS, Brasil. Registro: São Francisco de Paula.

\section{FILISTATIDAE}

325. Kukulcania hibernalis (Hentz, 1842): 227, est. 8, fig. 6. Localidade-tipo: EUA. Ramírez \& Grismado (1997): 348, figs 4, 7, 107-111.

Registros: Canela, Dois Irmãos, Lajeado, Pelotas, Porto Alegre, Quaraí, Salto do Jacuí, Santa Maria, Taquara.

326. Misionella mendensis (Mello-Leitão, 1920): 171 Localidade-tipo: Rio de Janeiro, RJ, Brasil. RAMírez \& GRISMADO (1997): 344, figs 91-103. Registros: Porto Alegre, Taquara.

327. Pikelinia arenicola Lise, Ferreira \& Silva, 2010: 62, figs 132. Localidade-tipo: Viamão, RS, Brasil. Registro: Viamão.

\section{GNAPHOSIDAE}

328. Apodrassodes chula Brescovit \& Lise, 1993: 104, figs 6, 7. Localidade-tipo: Rio Grande, RS, Brasil

Registro: Rio Grande.

329. Apodrassodes guatemalensis (F. O. P.-CAMBRIDGE, 1899): 58, est. 5, fig. 1. Localidade-tipo: Guatemala. Platnick \& SHADAB (1983): 5, figs 6-9.

Registros: Arroio do Tigre, Bom Jesus, Dom Feliciano, Guaíba, Machadinho, Montenegro, Porto Alegre, Quaraí, São Jerônimo, São Leopoldo, Triunfo, Viamão.

330. Apodrassodes mono MülLER, 1987: 145, figs 1-4. Localidadetipo: Nova Teutônia, SC, Brasil

Registro: Viamão.

331. Apodrassodes taim Brescovit \& Lise, 1993: 102, figs 1-5. Localidade-tipo: Rio Grande, RS, Brasil Registro: Rio Grande.

332. Apopyllus silvestrii (Simon, 1905): 3. Localidade-tipo: Argentina. Platnick \& Shadab (1984a): 3, figs 1-4. Registros: Carlos Barbosa, Minas do Leão.

333. Camillina chilensis (Simon, 1902b): 12. Localidade-tipo: Valparaíso, Chile. Platnick \& Shadab (1982): 26, figs 83-86. Registros: Campo Bom, Rio Grande, Rio Pardo, Triunfo.

334. Camillina claro Platnick \& Shadab, 1982: 23, figs 69, 70. Localidade-tipo: Rio Claro, SP, Brasil. Registro: Triunfo. 
335. Camillina mahnerti Platnick \& Murphy, 1987: 21, figs 57-60. Localidade-tipo: San Lorenzo, Paraguai.

Registro: Triunfo.

336. Camillina major (Keyserling, 1891): 32, est 1, fig. 11. Localidade-tipo: Rio Grande, RS, Brasil. Platnick \& Shadab (1982): 24, figs 71, 72 .

Registros: Porto Alegre, Rio Grande.

337. Camillina pilar Platnick \& Murphy, 1987: 22, figs 61-64. Localidade-tipo: Neembucú, Paraguai.

Registro: Porto Alegre.

338. Camillina pulchra (Keyserling, 1891): 31, est. 1, fig. 10. Localidade-tipo: Rio Grande, RS, Brasil. Platnick \& Shadab (1982): 22, figs 61-64.

Registros: Guaíba, Porto Alegre, Rio Grande, Santana do Livramento, Xangri-lá.

339. Eilica obscuta (Keyserling, 1891): 28, est. 1, fig. 8. Localidade-tipo: Rio Grande, RS, Brasil. Platnick \& Shadab (1981): 184, figs 3, 4

Registro: Rio Grande.

340. Eilica pomposa Medam, 2001: 424, figs 5-7. Localidadetipo: Buenos Aires, Argentina. Registro: Porto Alegre.

341. Eilica trilineata (Mello-Leitão, 1941): 173, fig. 63. Localidade-tipo: Salta, Argentina. Platnick (1985): 1075. Registro: Esmeralda.

342. Trachyzelotes lyonneti (Audouin, 1826): 216, fig. 42. Localidade-tipo: Egito ou Siria. Drassus brasilianus KeyserLING 1891: 34, fig. 13, localidade-tipo: Rio Grande, RS, Brasil. Platnick \& Shadab (1984b): 6, figs 7-10.

Registros: Porto Alegre, Rio Grande.

343. Urozelotes rusticus (L. KoсH, 1872): 309. Localidade-tipo: Itália. Drassus agelastus Keyserling 1891: 35, fig. 14. Localidade-tipo: Taquara, RS, Brasil. Platnick \& ShadAB (1984b): 6, figs 7-10.

Registros: Canela, Capão da Canoa, Porto Alegre, Taquara.

344. Zimiromus medius (Keyserling, 1891): 33, est. 1, fig. 12. Localidade-tipo: RS, Brasil. Platnick \& Shadab (1976): 12, figs 29-32.

Registros: Guaíba, Porto Alegre.

345. Zimiromus montenegro BuCKUP \& BRescovit, 1993: 182 , figs 5-8. Localidade-tipo: Montenegro, RS, Brasil.

Registros: Barra do Ribeiro, Campo Bom, Eldorado do Sul, Estrela Velha, Glorinha, Gravataí, Guaíba, Iraí, Montenegro, Porto Alegre, Salto do Jacuí, Santa Maria, São Leopoldo, Triunfo.

\section{HERSILIIDAE}

346. Iviraiva pachyura (Mello-LeItão, 1935a): 363. figs 1, 2. Localidade-tipo: MG, Brasil. RheIMs \& BRESCOvit (2004): 229, figs 23-24, 28, 38, 100-106.

Registro: Porto Alegre.

347. Ypypuera crucifera (Vellard, 1924): 139, fig. 51. Localidade-tipo: Niterói, RJ, Brasil. RHEIMS \& BRESCOvIT (2004): 221, figs 7, 19-22, 81-87.

Registros: Eldorado do Sul, Gravataí, São Leopoldo,Triunfo, Viamão.

\section{LINYPHIIDAE}

348. Anodoration claviferum Millidge, 1991: 125, figs 504-509. Localidade-tipo: Santa Teresa, ES, Brasil. Miller (2007): 35, figs 23b, 25a-f, 26-28.

Registros: Agudo, Canela, Cambará do Sul, Derrubadas, Eldorado do Sul, Encantado, Estrela Velha, Guabiju, Machadinho, Montenegro, Pelotas, São Francisco de Paula, Três Coroas, Viamão.

349. Asemostera latithorax (KeyserLing, 1886): 274, est. 21, fig. 324. Localidade-tipo: Blumenau, SC, Brasil. Miller (2007): 168 , figs $122,124 \mathrm{f}, 126 \mathrm{e}, \mathrm{f}, \mathrm{i}, 128 \mathrm{~d}$. Registros: Canela, São Francisco de Paula

350. Asemostera tacuapi Rodrigues, 2007b: 883, figs 1-9. Localidade-tipo: Triunfo, RS, Brasil.

Registros: Canela, Maquiné, Montenegro, São Francisco de Paula, Triunfo.

351. Dubiaranea argenteovittata Mello-Leitão, 1943a: 167, fig. 10. Localidade-tipo: RS, Brasil. Registro: São Francisco de Paula.
352. Dubiaranea levii Millidge, 1991: 49, figs 157-160. Localidade-tipo: Lavras, MG, Brasil.

Registro: Canela.

353. Eurymorion mourai RodRigues \& OTT, 2010b: 656, figs 20, 21, 31, 50. Localidade-tipo: São Francisco de Paula, RS, Brasil. Registro: São Francisco de Paula.

354. Eurymorion triunfo Rodrigues \& OTT 2010b: 650, figs 110, 32-50. Localidade-tipo: Triunfo, RS, Brasil.

Registros: Arroio do Ratos, Cachoeirinha, Campo Bom, Canela, Canoas, Gravataí, Novo Hamburgo, Palmares do Sul, Porto Alegre, Santa Maria, Tapes, Triunfo.

355. Gigapassus octarine Miller, 2007: 111, figs 71f, 72, 8184. Localidade-tipo: Jujuy, Argentina.

Registros: Minas do Leão, São Francisco de Paula.

356. Labicymbium otti Rodrigues, 2008: 323, figs 1-8. Localidade-tipo: São Francisco de Paula, RS, Brasil. Registro: São Francisco de Paula.

357. Labicymbium rusticulum (KEYSERLING, 1891): 240, est. 10, fig. 183. Localidade-tipo: RS, Brasil. Labicymbium cygnus Oтт \& Lise, 1997b: 54, figs 1-7, localidade-tipo: Viamão, RS, Brasil. Rodrigues, 2008: 325, figs 16-20.

Registros: Barracão, Barra do Ribeiro, Cachoeira do Sul, Campo Bom, Novo Hamburgo, São Francisco de Paula, Tapes, Vacaria, Viamão.

358. Laminacauda montevidensis (KeYSERLING, 1878): 582, est. 14, figs 9, 10. Localidade-tipo: Uruguai. Millidge (1991): 85, figs 315-319. Registro: Capivari do Sul, Eldorado do Sul, Pelotas.

359. Linyphia rubriceps (Keyserling, 1891): 236, est. 9, fig. 178. Localidade-tipo: RS, Brasil Registro: Só a localidade-tipo.

360. Lygarina silvicola Millidge, 1991: 108, figs 433-437. Localidade-tipo: Itu, SP, Brasil. Miller (2007): 97, figs 68a-c, i, 69, 70, 71a, b, 72 . Registros: Cachoeira do Sul, Estrela Velha, Viamão.

361. Moyosi prativaga (Keyserling, 1886): 269, est. 21, fig. 318. Localidade-tipo: Blumenau, SC, Brasil. Miller (2007): 217, figs $151 \mathrm{~h}, 169,170 \mathrm{a}, \mathrm{b}, \mathrm{f}$. Registros: Derrubadas, São Francisco de Paula.

362. Moyosi rugosa (Millidge, 1991): 177, figs 765, 766. Localidade-tipo: Buenos Aires, Argentina. Miller (2007): 220, figs $169,170 \mathrm{~h}, 176 \mathrm{a}$. Registro: Derrubadas.

363. Neomaso arundicola Millidge, 1991: 87, figs 326-328. Localidade-tipo: Teresópolis, RJ, Brasil. Registro: Minas do Leão.

364. Neomaso damocles Miller, 2007: 110, figs 71e, 72, 78c,e, h, i. Localidade-tipo: Cruce Caballero, Misiones, Argentina Registros: Minas do Leão, São Francisco de Paula.

365. Notiohyphantes excelsus (KEYSERLING, 1886): 114, est. 15, fig. 197. Localidade-tipo: Nancho, Peru. Notiohyphantes elegans (Keyserling, 1891): 233, est. 9, fig. 174, localidadetipo: Rio Grande, RS, Brasil.

Registros: Cachoeira do Sul, Cachoeirinha, Capão do Leão, Capivari do Sul, Derrubadas, Eldorado do Sul, Machadinho, Montenegro, Pelotas, Rio Grande, Santa Maria, Taquara, Triunfo.

366. Ostearius melanopygius (O. P.-CAMbridge, 1879): 696, est. 53, fig. 13. Localidade-tipo, Nova Zelândia. Erigone matei Keyserling, 1886: 159 , est. 16, fig. 224, localidade-tipo: Rio Grande, RS, Brasil. Registro: Rio Grande.

367. Pseudotyphistes biriva Rodrigues, 2007a: 177, figs 1-8. Localidade-tipo: São Francisco de Paula, RS, Brasil. Registro: São Francisco de Paula.

368. Pseudotyphistes cambara (Отт \& Lise, 1997a): 200, figs 14-20, 25. Localidade-tipo: Cambará do Sul, RS, Brasil. MilLeR (2007): 78, figs 51d, 55 . Registro: Cambará do Sul

369. Pseudotyphistes cristatus (OTt \& Lise, 1997a):196, figs 16, 24. Localidade-tipo: Santa Cruz do Sul, RS, Brasil. Miller (2007): 73, figs 43g, 51a, b, 52a, b, d, 53-55.

Registros: Canela, Caxias do Sul, Santa Cruz do Sul, São Francisco de Paula, Viamão. 
370. Pseudotyphistes vulpiscaudatus (Отt \& Lise, 1997a): 198, figs 7-13. Localidade-tipo: Cambará do Sul, RS, Brasil.

Registros: Cambará do Sul, São Francisco de Paula.

371. Psilocymbium lineatum (Millidge, 1991): 132, figs 533, 534. Localidade-tipo: Teresópolis, RJ, Brasil. Rodrigues \& OTT (2010a): 447, figs 10-18.

Registros: Arroio Grande, Capão do Leão, Cristal.

372. Scolecura cambara RodRigues, 2005b: 411, figs 1-10. Localidade-tipo: Cambará do Sul, RS, Brasil.

Registros: Barra do Ribeiro, Cambará do Sul, Canela, Derrubadas, Minas do Leão, Porto Alegre, Santa Maria, São Francisco de Paula, São Jerônimo, Triunfo, Vacaria, Viamão.

373. Scolecura parilis Millidge, 1991: 120, figs 493-495. Localidade-tipo: São Paulo, SP, Brasil. Miller (2007): 28, figs 9h, 15d, e, 19 .

Registros: Cachoeira do Sul, Capão do Leão, Caxias do Sul, Piratini, Santana do Livramento.

374. Smermisia parvoris Miller, 2007: 94, figs 60h, 64a-c, 66a, b, 67e, f. Localidade-tipo: Calilegua, Jujuy, Argentina. Registros: Eldorado do Sul, Porto Alegre, Triunfo.

375. Smermisia vicosana (Bishop \& Crosby, 1938): 83, figs 62, 64. Localidade-tipo: Viçosa, MG, Brasil. Miller (2007): 89, figs 60g, 61, 63a-c, 65, 66e, f, 67a-d.

Registros: Guaíba, Minas do Leão, Santa Cruz do Sul, Santana do Livramento, Viamão.

376. Sphecozone diversicolor (KeyserLing, 1886): 271, est. 21, fig. 320. Localidade-tipo: Blumenau, SC, Brasil. Miller (2007): 196, figs $148,151 \mathrm{a}, 164$.

Registros: Bom Jesus, Cachoeira do Sul, Maquiné, Montenegro, Palmares do Sul, Porto Alegre, Rio Grande, Santo Antônio da Patrulha, São Borja, São Francisco de Paula, São Sepé, Tapes, Torres, Triunfo.

377. Sphecozone fastibilis (KEYSERLING, 1886): 217, est. 19, fig. 274. Localidade-tipo: Nova Friburgo, RJ, Brasil. Miller (2007): 208, figs $154 \mathrm{a}-\mathrm{e}, 164$.

Registros: Cachoeira do Sul, Santo Antônio da Patrulha, Triunfo, Viamão.

378. Sphecozone ignigena (KeYSERLING, 1891): 268, est. 21, fig. 316 Localidade-tipo: Rio Grande, RS, Brasil. Sphecozone tincta Millidge, 1991: 174, figs 731-733, localidade-tipo: Pelotas, RS, Brasil. Rodrigues (2005a): 103, figs 1-11. Miller (2007): 198 , figs $143,148 \mathrm{a}, \mathrm{b}, \mathrm{g}, 151 \mathrm{~b}, 164$.

Registros: Cachoeirinha, Capão do Leão, Capivari do Sul, Eldorado do Sul, Osório, Palmares do Sul, Pelotas, Porto Alegre, Rio Grande, Triunfo, Viamão.

379. Sphecozone modica Millidge, 1991: 177, figs 750-752, 754, 755. Localidade-tipo: La Rioja, Argentina. Registros: Cachoeirinha, Triunfo.

380. Sphecozone novaeteutoniae (BAERT, 1987): 265, figs 7-13. Localidade-tipo: Nova Teutônia, SC, Brasil.

Registros: Canela, Derrubadas, Estrela Velha, Santa Cruz do Sul.

381. Sphecozone personata (SImon, 1894): 672, figs 748-749. Localidade-tipo: sul do Brasil. Millidge (1991): 175, figs 739-742. Registros: Cambará do Sul, Estrela Velha, Maquiné, Montenegro, Santa Maria, São Francisco de Paula, Tapes, Triunfo.

382. Sphecozone rostrata Millidge, 1991: 175, figs 743-746. Localidade-tipo: Encruzilhada, BA, Brasil.

Registros: Barra do Ribeiro, Canela, Estrela Velha, Glorinha, Gravataí, Montenegro, Porto Alegre, Santa Maria, Salto do Jacuí, Santo Antônio da Patrulha, São Francisco de Paula, Tapes, Terra de Areia, Viamão.

383. Sphecozone rubescens O. P.-CAmbridge, 1870: 733, est. 44, fig. 2. Localidade-tipo: Santa Fé de Minas, MG, Brasil. Erigone vegeta Keyserling, 1891: 241, est. 10, fig. 184, localidadetipo: RS, Brasil. Miller (2007): 187, figs 134, 142e, 144a, b, e, f, h, 145, 155-157.

Registros: Cachoeirinha, Canela, Guaíba, Pelotas, Torres, Triunfo, Viamão.

384. Sphecozone venialis (Keyserling, 1886): 270, est. 21, fig. 319. Localidade-tipo: RJ, Brasil. Miller (2007): 203, figs 151d, $152 \mathrm{a}-\mathrm{c}, 164$.

Registro: Derrubadas.

385. Totua gracilipes Keyserling, 1891: 216, est. 8, fig. 158 Localidade-tipo: RS, Brasil. Millidge (1991): 55, figs 180, 181. Registro: Só a localidade-tipo.
386. Triplogyna ignitula (KeYSERLING, 1886): 267, est. 21, fig. 315. Localidade-tipo: Rio Grande, RS, Brasil. Miller (2007): 13, figs 3d-f, h, 5e, f, 6b, 7d-f, 8e, 9b, 10. Registros: Guaíba, Rio Grande, Triunfo, Viamão.

387. Tutaibo fucosus (KeYSERLing, 1891): 240, est. 9, fig. 182a, b. Localidade-tipo: RS, Brasil. Miller (2007): 185, figs 139a, b. Registro: Só a localidade-tipo.

388. Tutaibo rusticellus (Keyserling, 1891): 238, est. 9, fig. 180a-c. Localidade-tipo: RS, Brasil. Miller (2007): 182, figs 138a, b, e, $142 \mathrm{c}$.

Registros: Barracão, Cachoeira do Sul, Campo Bom, Machadinho, Novo Hamburgo, São Francisco de Paula, Vacaria, Viamão.

389. Tutaibo velox (Keyserling, 1886): 273, est. 21, fig. 322. Localidade-tipo: Blumenau, SC, Brasil. Erigone nitida Keyserling, 1891: 239, est. 9 fig. 181, localidade-tipo: RS, Brasil. Miller (2007): 184, figs 138c, d, f, 142d, 143. Registros: Bom Jesus, Cambará do Sul, Canela, Caxias do Sul, Guaíba, Machadinho, Pelotas, Porto Alegre, Viamão.

390. Vesicapalpus serranus Rodrigues \& OTT, 2006: 407, figs 19. Localidade-tipo: São Francisco de Paula, RS, Brasil. Registro: São Francisco de Paula.

391. Vesicapalpus simplex Millidge, 1991: 56, figs 182, 183 Localidade-tipo: Misiones, Argentina. Rodrigues \& OTT (2006): 410 , figs $10-16$.

Registros: Derrubadas, Santa Cruz do Sul, Triunfo.

\section{LYCOSIDAE}

392. Aglaoctenus lagotis (Holmberg, 1876): 26. Localidade-tipo: Argentina. Tetragonophtalma obscura KeyserLING, 1891: 256, est. 10, fig. 192, localidade-tipo: Taquara, RS, Brasil. Porrima glieschi Mello-Leitão, 1926: 2, localidade-tipo: RS, Brasil. Santos \& Brescovit, 2001: 83, figs 3d-f, 7a-e.

Registros: Canela, Carazinho, Caxias do Sul, Derrubadas, Flores da Cunha, Garruchos, Guaíba, Mariana Pimentel, Montenegro, Novo Hamburgo, Passo Fundo, Pelotas, Porto Alegre, Quaraí, Salto do Jacuí, São Borja, Taquara, Tenente Portela, Viamão.

393. Aglaoctenus oblongus (C. L. Косн, 1847): 114, fig. 1350. Localidade-tipo: Montevideo, Uruguai. Lycosa thoas MelloLeITÃo, 1938: 314, fig. 2, localidade-tipo: Alfredo Chaves (atual Veranópolis), RS, Brasil. SANTos et al. (2003): 90, figs 1-6.

Registros: Canela, Caxias do Sul, Santa Cruz do Sul, São Francisco de Paula, Veranópolis.

394. Alopecosa moesta (Holmberg, 1876): 26. Localidade-tipo: Argentina.

Registros: Bossoroca, Rio Pardo.

395. Arctosa sapiranga Silva \& Lise, 2009: 27, figs 1-26. Localidade-tipo: Sapiranga, RS, Brasil.

Registro: Sapiranga.

396. Diapontia uruguaiensis Keyserling, 1877: 675, est. 8, fig. 48. Localidade-tipo: Uruguai. KeyserLing, 1891: 257, est. 10, fig. 193.

Registros: Rio Grande, Santana do Livramento.

397. Dingosa venefica Keyserling, 1891: 261, est. 10, fig. 197. Localidade-tipo: Rio Grande, RS, Brasil.

Registro: Rio Grande.

398. Hogna nervosa Keyserling, 1891: 260, est. 10, fig. 196 Localidade-tipo: Rio Grande, RS, Brasil.

Registro: Rio Grande.

399. Lycosa auricoma (Keyserling, 1891): 262, est. 10, fig. 198 Localidade-tipo: Taquara, RS, Brasil.

Registros: Bagé, Bom Jesus, Cambará do Sul, Dom Feliciano, Nova Petrópolis, Palmares do Sul, Quaraí, Taquara, Torres, Vacaria, Viamão, Xangri-lá.

400. Lycosa auroguttata (KeYSERLING, 1891): 259, est. 10, fig. 195. Localidade-tipo: Rio Grande, RS, Brasil.

Registros: Bagé, Porto Alegre, Quaraí, Rio Grande, Xangri-lá.

401. Lycosa erythrognatha (LucAs, 1836): 522. Localidade-tipo: Brasil.

Registros: Alvorada, Arroio do Tigre, Bagé, Bom Jesus, Caçapava do Sul, Camaquã, Cambará do Sul, Campo Bom, Canela, Canoas, Carazinho, Caxias do Sul, Cruz Alta, Derrubadas, Encruzilhada do Sul, Erechim, Esteio, Estrela, Estrela Velha, Farroupilha, Garibaldi, Gravataí, Guaíba, Lajeado, Machadinho, Maquiné, Marcelino Ramos, Montenegro, Nova Petrópolis, Novo Hamburgo, Osório, Passo Fundo, Pelotas, Portão, Porto Alegre, Quaraí, Rio Grande, 
Rio Pardo, Salto do Jacuí, Salvador do Sul, Santa Cruz do Sul, Santa Maria, Santana do Livramento, Santo Ângelo, São Borja, São Francisco de Paula, São Leopoldo, Sapiranga, Sapucaia do Sul, Sarandi, Sobradinho, Taquara, Tenente Portela, Torres, Três Coroas, Triunfo, Vacaria, Viamão.

402. Lycosa langei Mello-Leitão, 1947b: 264, est. 41, fig. 18. Localidade-tipo: Curitiba, PR, Brasil.

Registros: Cambará do Sul, Canela, Nova Prata.

403. Lycosa pampeana Holmberg, 1876: 25. Localidade-tipo: Argentina.

Registros: Cruz Alta, Quaraí, Santana do Livramento, Viamão.

404. Lycosa paranensis Holmberg, 1876: 25. Localidade-tipo: Argentina.

Registros: Bom Jesus, Cambará do Sul, Caxias do Sul, Porto Alegre, Rolante, São Francisco de Paula, Vacaria.

405. Lycosa pictipes (Keyserling, 1891): 266, est. 10, fig. 201. Localidade-tipo: Rio Grande, RS, Brasil. Registro: Rio Grande.

406. Lycosa pintoi Mello-Leitão, 1931: 12, fig. 3. Localidadetipo: Pinheiro Machado, RS, Brasil.

Registro: Pinheiro Machado.

407. Lycosa poliostoma (C. L. Косн, 1847): 152, fig. 1379. Localidade-tipo: Montevideo, Uruguai. CAPOCASALE (2001): 80, figs $1-5$.

Registros: Alegrete, Arroio do Tigre, Bossoroca, Caçapava do Sul, Canela, Canoas, Dom Feliciano, Dom Pedrito, Encruzilhada do Sul, Gravataí, Guaíba, Montenegro, Osório, Pelotas, Porto Alegre, Quaraí, Rio Grande, Santa Maria, Soledade, Torres, Tupanciretã, Vacaria, Viamão.

408. Lycosa thorelli (Keyserling, 1877): 650, est. 7, fig. 28. Localidade-tipo: "Nova Granada, Colômbia e Panamá". Keyserling, 1891: 257, est. 10, fig. 194.

Registros: Arroio dos Ratos, Canela, Novo Hamburgo, Palmares do Sul, Porto Alegre, Rio Pardo, Taquara.

409. Orthocosa sternomaculata (Mello-Leitão, 1943a): 163, fig. 8. Localidade-tipo: RS, Brasil.

Registro: Só a localidade-tipo.

410. Pardosa rara (Keyserling, 1891): 264, est. 10, fig. 199. Localidade-tipo: Rio Grande, RS, Brasil. Registro: Rio Grande.

411. Pirata velox Keyserling, 1891: 265, est. 10, fig. 200. Localidade-tipo: Rio Grande, RS, Brasil.

Registro: Rio Grande.

412. Schizocosa chelifasciata (Mello-Leitão, 1943a): 161, fig. 7. Localidade-tipo: RS, Brasil. Registro: Só a localidade-tipo.

413. Schizocosa malitiosa (Tullgren, 1905): 57, est. 7, fig. 27. Localidade-tipo: Tatarenda, Bolívia.

Registro: Quaraí.

\section{MICROSTIGMATIDAE}

414. Xenonemesia araucaria Indicatti, Lucas, Ott \& Brescovit, 2008b: 531, figs 1-14, 30-34. Localidade-tipo: São Francisco de Paula, RS, Brasil.

Registro: São Francisco de Paula.

415. Xenonemesia otti Indicatti, Lucas \& Brescovit, 2007: 44, figs 5-8, 18-28. Localidade-tipo: Viamão, RS, Brasil. Registro: Viamão.

416. Xenonemesia platensis Gоloвоғғ, 1988: 358, figs 1-14. Localidade-tipo: Buenos Aires, Argentina. InDiCATTI et al. (2007): 44, figs 1-4, 9-17.

Registro: Caçapava do Sul.

\section{MIMETIDAE}

417. Ero catharinae Keyserling, 1886: 251, est. 20, fig. 302. Localidade-tipo: Blumenau, SC, Brasil. Mello-Leitão, 1929c: 550 , est. 3, fig. 15 .

Registro: Porto Alegre.

418. Ero lata Keyserling, 1891: 220, est. 8, fig. 162. MelloLeitão, 1929c: 554, est. 3, fig. 18. Localidade-tipo: Nova Friburgo, RJ, Brasil.

Registros: Campo Bom, Canela, Derrubadas, Novo Hamburgo, Porto Alegre.

419. Ero valida Keyserling, 1891: 220, est. 8, fig. 161. Localidadetipo: Santo Antônio, RJ, Brasil.

Registro: Passo Fundo.
420. Gelanor altithorax Keyserling, 1893: 370, est. 19, fig. 276. Localidade-tipo: Blumenau, SC, Brasil. Mello-Leitão, 1929c: 559, est. 5, fig. 28 .

Registros: Arroio do Meio, Campo Bom, Derrubadas, Guaíba, Iraí, Passo Fundo, Porto Alegre, São Leopoldo, Taquara, Torres.

421. Gelanor zonatus (C. L. Косн, 1845): 105, fig. 1032. Localidade-tipo: Egito. Mello-Leitão, 1929c: 560, est. 4, figs 22,25 , est. 6 , figs 34,35 .

Registros: Bagé, Cambará do Sul, Campo Bom, Canela, Caxias do Sul, Derrubadas, Esmeralda, Estrela Velha, General Câmara, Gravataí, Guabiju, Guaíba, Montenegro, Nonoai, Nova Petrópolis, Novo Hamburgo, Osório, Porto Alegre, São Borja, São Francisco de Paula, São Jerônimo, São Leopoldo, São Pedro do Sul, Tenente Portela, Torres, Triunfo, Vacaria, Viamão.

422. Mimetus debilispinis Mello-Leitão, 1943a: 156, fig. 1. Localidade-tipo: RS, Brasil.

Registro: Só a localidade-tipo.

423. Mimetus hieroglyphicus (Mello-LeItão, 1929c): 545, est. 1, fig. 7. Localidade-tipo: MT, Brasil.

Registros: Butiá, Charqueadas, Derrubadas, Eldorado do Sul, Estrela Velha, General Câmara, Glorinha, Gravataí, Guaíba, Iraí, Montenegro, Muçum, Nova Petrópolis, Palmares do Sul, Pelotas, Porto Alegre, Salto do Jacuí, Santa Maria, Santo Antônio da Patrulha, São Borja, Tapes, Triunfo, Viamão.

\section{MITURGIDAE}

424. Cheiracanthium inclusum (Hentz, 1847): 451, est. 23, fig. 18. Localidade-tipo: South Carolina, North Carolina, EUA. Bonaldo \& Brescovit (1992): 731-740, figs 1-4.

Registros: Arroio do Tigre, Arroio dos Ratos, Barra do Ribeiro, Butiá, Caçapava do Sul, Canela, Canoas, Capão da Canoa, Charqueadas, Encantado, Erechim, Garruchos, General Câmara, Gravataí, Guaíba, Machadinho, Montenegro, Mostardas, Muçum, Nova Petrópolis, Pelotas, Porto Alegre, Rio Grande, Rio Pardo, Roca Sales, Santo Ângelo, Santo Antônio da Patrulha, São Francisco de Paula, São Jerônimo, São Leopoldo, São Sepé, Sertão Santana, Sobradinho, Taquara, Tavares, Terra de Areia, Torres, Tramandaí, Triunfo, Viamão, Xangri-lá.

425. Eutichurus ravidus Simon, 1897b: 501. Localidade-tipo: RJ, Brasil. Philisca pallida Mello-Leitão, 1943a: 219, fig. 46, localidade-tipo, RS, Brasil. BonALDo (1994): 125, figs 12, 18, 65-69. Registros: Canela, Montenegro, Novo Hamburgo, São Leopoldo, Triunfo.

426. Radulphius cambara Bonaldo \& Buckup, 1995: 138, figs 18-22; 40-57. Localidade-tipo: Cambará do Sul, RS, Brasil. Registro: Cambará do Sul.

427. Teminius insularis (Lucas, 1857): 79, est. 4, fig. 4. Localidadetipo: Havana, La Habana, Cuba. Teminius brasilianus KeYserling, 1891: 40, est. 1, fig. 17, localidade-tipo, Rio Grande, RS, Brasil. Platnick \& Shadab (1989): 4, figs 1-4.

Registros: Arroio do Meio, Capão da Canoa, Estância Velha, Machadinho, Nova Petrópolis, Porto Alegre, Quaraí, Rio Grande, São Borja, Tenente Portela, Tramandaí, Viamão.

\section{MYSMENIDAE}

428. Trogloneta cantareira Brescovit \& Lopardo, 2008: 94, fig. 1. Localidade-tipo: Garulhos, SP, Brasil.

Registro: Cristal.

\section{NEMESIIDAE}

429. Acanthogonatus ericae Indicatti, Lucas, OTt \& Brescovit, 2008b: 534, figs 15-26, 35-39. Localidade-tipo: São Francisco de Paula, RS, Brasil.

Registro: São Francisco de Paula.

430. Pycnothele auronitens (KEYSERLIng, 1891): 18, est. 1, fig. 3. Localidade-tipo: Taquara, RS, Brasil.

Registro: Taquara.

431. Pycnothele perdita Chamberlin, 1917: 27, est. 1, figs 1-4. Localidade-tipo: Rio de Janeiro, RJ, Brasil. Registro: Canoas.

432. Stenoterommata arnolise $i$ IndicAtTi, Lucas, OTt \& Brescovit, 2008b: 537, figs 27-29, 48-51. Localidade-tipo: São Francisco de Paula, RS, Brasil.

Registro: São Francisco de Paula. 
433. Stenoterommata curyi IndicatTi, Lucas, OtT \& Brescovit, 2008b: 43, figs 56-58. Localidade-tipo: São Francisco de Paula, RS, Brasil.

Registro: São Francisco de Paula

434. Stenoterommata grimpa IndicatTi, LuCAS, OtT \& Brescovit, 2008b: 41, figs 52-55. Localidade-tipo: São Francisco de Paula, RS, Brasil

Registro: São Francisco de Paula

435. Stenoterommata palmar GolobofF, 1995: 69, figs 73a, fig. G. Localidade-tipo: Entre Ríos, Argentina. Indicatti et al. (2008b): 536, figs. 40-47.

Registros: Maquiné, Santana do Livramento, São Francisco de Paula

\section{NEPHILIDAE}

436. Nephila clavipes (LinNé, 1767): 1034. Localidade-tipo: Jamaica. LeVI \& EicKsted (1989): 45, figs 1-4.

Registros: Arroio Grande, Cachoeira do Sul, Cachoeirinha, Cambará do Sul, Campo Bom, Canela, Capão do Leão, Cristal, Eldorado do Sul, Estrela Velha, Lajeado, Machadinho, Maquiné, Marcelino Ramos, Montenegro, Mucum, Nova Petrópolis, Osório, Palmares do Sul, Parobé, Pelotas, Porto Alegre, Rio Pardo, Salto do Jacuí, Santa Maria, Santo Antônio da Patrulha, São Borja, São Leopoldo, São Pedro do Sul, Sobradinho, Tapes, Taquara, Terra de Areia, Triunfo, Viamão.

437. Nephilengys cruentata (FABRICIUS, 1775): 439. Localidadetipo: Rio de Janeiro, Brasil. Levi \& Eicksted (1989): 48, figs $16-25$

Registro: Rio Grande.

\section{NESTICIDAE}

438. Eidmannella pallida (Emerton, 1875): 297, est. 1, figs 2227. Localidade-tipo: August County, Virginia, EUA. GerTsCH (1984): 54, figs 249-268 Registros: Pelotas, Porto Alegre.

439. Nesticus brasiliensis Brignoli, 1979: 915, figs 5-8. Localidade-tipo: Nova Teutônia, SC, Brasil. Отт \& Lise, 2002: 60 , figs $1-5,38$.

Registros: Esmeralda, São Francisco de Paula

440. Nesticus brignolii ОтT \& Lise, 2002: 66, figs 20-24, 35-37. Localidade-tipo: Guaíba, RS, Brasil.

Registros: Canela, Derrubadas, Guaíba, Porto Alegre, Santa Cruz do Sul, Santa Maria, São Francisco de Paula, Viamão.

441. Nesticus potreiro OTt \& Lise, 2002: 60, figs 6-10, 30-34, 38. Localidade-tipo: São Francisco de Paula, RS, Brasil. Registros: Cambará do Sul, Canela, Caxias do Sul, Dom Pedro de Alcântara, Gramado, Machadinho, Maquiné, Osório, Passo Fundo, Porto Alegre, São Francisco de Paula, Torres.

442. Nesticus taim Oтт \& Lise, 2002: 65, figs 17-19, 38. Localidade-tipo: Rio Grande, RS, Brasil.

Registros: Rio Grande, Torres.

\section{OECOBIIDAE}

443. Oecobius navus Blackwall, 1859: 266. Localidade-tipo: Ilha da Madeira. SAntos \& GonZaga (2003): 240, figs 1-5, 18, 19. Registros: Cambará do Sul, Capão da Canoa, Imbé, Maquiné, Minas do Leão, Osório, Pelotas, Porto Alegre, Rio Grande, São Francisco de Paula.

\section{OONOPIDAE}

444. Neoxyphinus ogloblini BIRABÉN, 1953: 454, figs 1-9. Localidade-tipo: Misiones, Argentina.

Registros: Canela, Charqueadas, Derrubadas, Eldorado do Sul, Estrela Velha.

445. Oрораеа viamao Отт, 2003: 78, figs 1-4. Localidade-tipo: Viamão, RS, Brasil.

Registro: Viamão.

446. Xiombarg plaumanni Brignoli, 1979: 916, figs 1-4. Localidade-tipo: Nova Teutônia, SC, Brasil

Registros: Eldorado do Sul, Porto Alegre, São Francisco de Assis, Triunfo.

\section{ORSOLOBIDAE}

447. Losdolobus opytapora Brescovit, Bertoncello \& Ott in BRESCOVIT et al. (2004): 250, figs 1-7, 15-19. Localidade-tipo: São Francisco de Paula, RS, Brasil.

Registro: São Francisco de Paula.
448. Losdolobus xaruanus Lise \& Almeida, 2006: 24, figs 1-18. Localidade-tipo: Bagé, RS, Brasil.

Registro: Bagé.

449. Losdolobus ybypora Brescovit, Ott \& Lise in BRESCOVIT et al. (2004): 254, figs 8-4, 20-24. Localidade-tipo: São Francisco de Paula, RS, Brasil.

Registro: São Francisco de Paula.

\section{OXYOPIDAE}

450. Hamataliwa bituberculata (Mello-LeITÃo, 1929a): 511, est 1, fig. 24. Localidade-tipo: São Paulo de Olivença, AM, Brasil. Registros: Canela, Estrela Velha, Garruchos, Sertão Santana, Triunfo, Viamão.

451. Oxyopes constrictus Keyserling, 1891: 268, est. 10, fig. 202. Localidade-tipo: Taquara, RS, Brasil. Registros: Novo Hamburgo, Taquara, Triunfo.

452. Oxyopes rubrosignatus KeyserLing, 1891: 270, est. 10, fig 203. Localidade-tipo: Nova Friburgo, RJ, Brasil. Mello-Leitão (1929a): 16, est. 1 , figs 11,17 Registros: Montenegro, São Leopoldo, Taquara.

453. Oxyopes salticus Hentz, 1845: 196, est 16, fig. 10 Localidade-tipo: Carolina do Norte e Alabama, EUA. BRADY (1964): 478, figs 80-86, 91-96, 104, 105

Registros: Arroio dos Ratos, Bagé, Bom Jesus, Cachoeira do Sul, Cachoeirinha, Canoas, Capivari do Sul, Charqueadas, Derrubadas, Eldorado do Sul, Encantado, Estância Velha, Guaíba, Itaqui, Montenegro, Muçum, Passo Fundo, Palmares do Sul, Pelotas, Porto Alegre, Restinga Seca, Rio Grande, Rio Pardo, Salto do Jacuí, Santa Maria, Santana do Livramento, Santo Ângelo, São Francisco de Paula, Sobradinho, Taquara, Torres, Triunfo, Vacaria, Viamão.

454. Oxyopes stephanurus Mello-Leitão, 1929a: 501, est. 1, fig. 4. Localidade-tipo: MT, Brasil.

Registro: Itaqui.

455. Peucetia flava Keyserling, 1877b: 700, est. 8, figs 65, 66 Localidade-tipo: Nova Friburgo, RJ, Brasil. SANTOS \& BRESCOVIT (2003): 97, figs 1-4, 13, 15-19, 45

Registros: Caçapava do Sul, Estrela Velha, Montenegro, Santa Maria, São Francisco de Paula, São Leopoldo, Pelotas, Porto Alegre, Triunfo.

\section{PALPIMANIDAE}

456. Otiothops birabeni Mello-Leitão, 1945: 225, fig. 4 Localidade-tipo: Corrientes, Argentina. Brescovit \& Bonaldo (1993): 47, figs 1-4.

Registros: Maquiné, Porto Alegre, Rio Grande, São Jerônimo, Tramandaí, Triunfo.

\section{PHILODROMIDAE}

457. Berlandiella magna Mello-Leitão, 1929b: 124, figs. 126 , 127. Localidade-tipo: PE, Brasil.

Registros: Canela, São Francisco de Paula

458. Cleocnemis moschata Mello-Leitão, 1943a: 202, fig. 31 Localidade-tipo: RS, Brasil.

Registro: Só a localidade-tipo.

459. Cleocnemis taquarae (KeyserLING, 1891): 252, est. 10 fig. 191. Localidade tipo: Taquara, RS, Brasil. Mello-Leitão (1929b): 117 .

Registro: Taquara.

460. Fageia meridionalis Mello-Leitão, 1943a: 204, fig. 33 Localidade-tipo: RS, Brasil Registro: Só a localidade-tipo.

461. Petrichus meridionalis (KeYSerLing, 1891): 251, est. 10 fig. 190. Localidade-tipo: Rio Grande, RS, Brasil. Registro: Rio Grande.

\section{PHOLCIDAE}

462. Guaranita munda (GerTsch, 1982): 104, figs 31-33, 42 44. Localidade-tipo: Catamarca, Argentina. Huber (2000): 100 , figs 379,380 Registro: Quaraí.

463. Mesabolivar luteus (Keyserling, 1891): 171, est. 5, fig. 117. Localidade-tipo: Miracema, MG, Brasil. Huber (2000): 230, figs 907-915.

Registros: Barracão, Derrubadas, Estrela Velha, Glorinha, 
Montenegro, Novo Hamburgo, Pinhal Grande, Porto Alegre, Tenente Portela, Torres, Viamão.

464. Metagonia argentinensis Mello-Leitão, 1945: 227, figs 2, 3a. Localidade-tipo: Puerto Iguazú, Misiones, Argentina. HuBER (2000): 59, figs 66, 113, 147, 219-224.

Registros: Arroio dos Ratos, Caxias do Sul, Derrubadas, Garruchos, Novo Hamburgo, Porto Alegre, Santa Cruz do Sul, São Borja, São Francisco de Paula, São Leopoldo, Tenente Portela, Três Coroas, Viamão.

465. Pholcus phalangioides (Fuessuin, 1775): 9. Localidade-tipo: Europa. BеAтTY et al. (2008): 18, figs 26-28, 50.

Registros: Bagé, Cachoeirinha, Camaquã, Canela, Canoas, Caxias do Sul, Cidreira, Dom Pedrito, Estrela Velha, Gramado, Gravataí, Guaíba, Herval, Maquiné, Montenegro, Novo Hamburgo, Osório, Parobé, Pelotas, Piratini, Porto Alegre, Porto Mariante, Rio Grande, Rio Pardo, Salto do Jacuí, Santa Cruz do Sul, Santa Maria, Santa Vitória do Palmar, Santa Rosa, Santo Ângelo, São Francisco de Paula, São Leopoldo, São Lourenço do Sul, São Sepé, Tapes, Taquara, Torres, Triunfo, Uruguaiana, Vacaria, Viamão.

466. Smeringopus pallidus (BLACKWALl, 1858): 433. Localidadetipo: África. BEATTY et al. (2008): 21, figs 20, 55.

Registro: Porto Alegre.

467. Teuia beckeri Huber, 2000: 314, figs 1259-1264. Localidadetipo: São Leopoldo, RS, Brasil. Registro: São Leopoldo.

468. Tupigea paula Huber, 2000: 323, figs 1303, 1308. Localidade-tipo: São Francisco de Paula, RS, Brasil.

Registros: Palmares do Sul, São Francisco de Paula, Triunfo, Viamão.

\section{PISAURIDAE}

469. Architis brasiliensis (Mello-LeITÃo, 1940a): 199. Localidadetipo: Colatina, ES, Brasil. SANTOS (2007a): 33, figs 18a-f, 20a, b. Registro: Derrubadas.

470. Architis spinipes (TaCZanowsKi, 1873): 95. Localidade-tipo: Guiana Francesa. SANTOS (2007b): 498, figs 3a-d, 4a-c.

Registros: Derrubadas, Tenente Portela.

471. Architis tenuis Simon, 1898: 12. Localidade-tipo: Cametá, PA, Brasil. SAntos (2007a): 7, figs 1, 2a-d, 4a, b, 6. Registro: Porto Alegre.

472. Architis turvo Santos, 2007a: 23, est. 10. Localidade-tipo: Derrubadas, RS, Brasil. Registro: Derrubadas.

473. Thaumasia argyrura Mello-Leitão, 1943a: 160, fig. 6. Localidade-tipo: RS, Brasil.

Registro: Só a localidade-tipo.

474. Thaumasia velox Simon, 1898: 18. Localidade-tipo: Amazonas. Sierwald (1989): 8, figs 13-16, 59-60. Sierwald (1990): 25, figs 16, 21.

Registros: Campo Bom, Gravataí, Pelotas, Porto Alegre, Rio Pardo, Santo Antônio da Patrulha, São Borja, São Francisco de Paula, São Lourenço do Sul, Triunfo.

\section{SALTICIDAE}

475. Agelista andina Simon, 1900a: 383. Localidade-tipo: Salta, Argentina. Scopocira obscura Mello-LeITão (1943a): 230, fig. 57, localidade-tipo: RS, Brasil. Galiano (1963a): 283, est. 3, figs 4-6. Registros: Barra do Ribeiro, Caxias do Sul, Dom Feliciano, Quaraí, Rio Grande, Santa Maria, São Leopoldo, Tapes, Triunfo, Viamão.

476. Anokopsis avitoides Vianna \& Soares, 1980: 697, figs 1-6. Localidade-tipo: Porto Alegre, RS, Brasil.

Registro: Porto Alegre.

477. Aphirape misionensis Galiano, 1981b: 100, figs 21-24, 33, 34, 38. Localidade-tipo: Misiones, Argentina. Registro: Derrubadas.

478. Aphirape uncifera Tullgreen, 1905: 71, est. 9, fig. 36. Localidade-tipo: Jujuy, Argentina. Galiano (1981b): 109, figs $2,3,12-16,28,29,40$.

Registros: Barra do Ribeiro, Cachoeirinha, Canela, Derrubadas, Dom Feliciano, Eldorado do Sul, Estrela Velha, Gravataí, Montenegro, Palmares do Sul, Porto Alegre, São Francisco de Paula, São Jerônimo, Triunfo.

479. Arnoliseus calcarifer (Simon, 1902a): 44. Localidade-tipo: Teresópolis, RJ, Brasil. Braul \& LISE (1996): 101, figs 28-35. Registro: Torres.
480. Asaphobelis physonychus Simon, 1902a: 384. Localidadetipo: Brasil. Galiano (1963a): 298, est. 8, figs 1-4. Lise \& Braul (1994): 261, figs 1-8. Registros: Guaíba, Porto Alegre, Viamão.

481. Ashtabula sexguttata Simon, 1902a: 32. Localidade-tipo: São Paulo, Brasil. Galiano (1963a): 302, est. 9, figs 5-7. BraUl et al. (1997): 143, figs 2-4.

Registros: Cambará do Sul, Derrubadas, São Francisco de Paula. 482. Atelurius segmentatus Simon, 1901c: 154. Localidade-tipo: Caracas, Venezuela. Galiano (1987b): 290, figs 1, 16, 17. Registros: Barra do Ribeiro, Palmares do Sul, Tapes, Triunfo.

483. Beata aenea (Mello-Leitão, 1945): 279, fig. 68. Localidadetipo: Corrientes, Argentina. Galiano (1992): 31, figs 1, 2, 8, 9 , $15,17-20$.

Registros: Barra do Ribeiro, Derrubadas, Estrela Velha, Montenegro, Palmares do Sul, Salto do Jacuí, Tapes, Triunfo, Viamão.

484. Breda apicalis Simon, 1901c: 156. Localidade-tipo: Tefé, AM, Brasil. Galiano (1963a): 313, est. 12, figs 8, 9.

Registros: Barra do Ribeiro, Derrubadas, Palmares do Sul, Pelotas, Porto Alegre, Quaraí, Triunfo, Viamão.

485. Breda bicruciata (Mello-Leitão, 1943a): 226, fig. 52. Localidade-tipo: RS, Brasil.

Registro: Só a localidade-tipo.

486. Chira distincta Vianna, 1983: 4, figs 6-11. Localidade-tipo: Botucatu, Rubião Júnior, SP, Brasil. Registro: Derrubadas.

487. Chira lucina Simon, 1902a: 53. Localidade-tipo: Tijuca, RJ, Brasil. Galiano (1968a): 359, figs 4, 5, 10.

Registros: Barra do Ribeiro, Gravataí, Montenegro, Palmares do Sul, Porto Alegre.

488. Chira spinosa (Mello-Leitão, 1939b): 87, figs 77, 78. Localidade-tipo: Paraguai. Anaurus trimaculatus Mello-LeITão, 1943a: 222, fig. 48, localidade-tipo: Porto Alegre, RS, Brasil Galiano (1968a): 361, figs 3, 15, 16.

Registros: Candelária, Derrubadas, Estrela Velha, São Borja.

489. Chira thysbe Simon, 1902a: 53. Localidade-tipo: RJ, Brasil. Mago taeniatus Mello-Leitão, 1943a: 225, fig. 51, localidadetipo: RS, Brasil. Chira reticulata (Mello-Leitão, 1943a): 232, fig. 60, localidade-tipo: RS, Brasil. Galiano (1968a): 358, fig. 9.

Registros: Arroio dos Ratos, Barra do Ribeiro, Campo Bom, Canela, Canoas, Charqueadas, Eldorado do Sul, Estrela Velha, Garruchos, Gravataí, Guaíba, Montenegro, Novo Hamburgo, Palmares do Sul, Pelotas, Porto Alegre, Roca Sales, Santo Antônio da Patrulha, São Francisco de Paula, Tapes, Terra de Areia, Triunfo, Viamão.

490. Chirothecia semiornata Simon, 1901c: 143. Localidadetipo: Serra do Caraça, Catas Altas, MG, Brasil. Galiano (1963a) 326, est. 16, figs 1, 2; Galiano (1972): 32, figs 55, 65, 66. Registros: Canela, Caxias do Sul, Derrubadas, Gravataí, Porto Alegre, São Francisco de Paula, Torres, Triunfo.

491. Coryphasia fasciiventris (SIMON, 1902a): 384 . Localidadetipo: Serra do Caraça, MG, Catas Altas, Brasil. Galiano (1963a): 296, est. 8, figs 5-8.

Registros: Canela, Caxias do Sul, Derrubadas, Gravataí, Porto Alegre, São Francisco de Paula, Torres.

492. Cotinusa trifasciata (Mello-Leitão, 1943a): 227, fig. 54. Localidade-tipo: RS, Brasil.

Registros: Barra do Ribeiro, Derrubadas, Estrela Velha, Montenegro, Palmares do Sul, Porto Alegre, Rio Grande, São Francisco de Paula, Tapes, Torres, Triunfo.

493. Cotinusa vittata Simon, 1900a: 390. Localidade-tipo: RJ, Brasil. Galiano (1963a): 339, figs 1-8.

Registros: Canela, Derrubadas, Porto Alegre, São Borja, São Francisco de Paula, Torres, Triunfo, Vacaria.

494. Encolpius guaraniticus Galiano, 1968b: 313, figs 48-58. Localidade-tipo: Piñalitos, Misiones, Argentina. Registros: Derrubadas, Triunfo.

495. Euophrys saitiformis Simon, 1901b: 22. Localidade-tipo: Molle, Chile. Galiano (1963a): 352, fig. 4. Braul et al. (1997): 146 , figs 7-9.

Registros: Cachoeirinha, Estrela Velha, Viamão.

496. Euophrys sutrix Holmberg, 1875: 296, est. 6, fig. 5. Localidade-tipo: Buenos Aires, Argentina. Galiano (1963c) 23-28, est. 1, 2.

Registros: Barra do Ribeiro, Capivari, Canela, General Câmara, Osório, Palmares do Sul, Porto Alegre, São Leopoldo, Triunfo. 
497. Frigga kessleri Taczanowski, 1872: 75. Localidade-tipo: Cayenne, Guiana Francesa. Galiano (1979): 125, figs 1, 8, 15, $16,25,35-38$.

Registros: Montenegro, Triunfo.

498. Frigga quitensis (Tullgren, 1905): 76, est. 10, fig. 40 Localidade-tipo: Jujuy, Argentina. Galiano (1979): 128, figs 9, $10,24,32,41,42$.

Registro: Montenegro

499. Gastromicans albopilosa (SIMON, 1903a): 831. Localidadetipo: Paraguai. Galiano (1963a): 306, est. 12, figs 1, 2. Registros: Dom Feliciano, Palmares do Sul, Pelotas, Quaraí, São Pedro do Sul, Triunfo.

500. Gypogyna forceps Simon, 1900b: 44. Localidade-tipo: Paraguai. Galiano (1963a): 360, est. 21, figs 1-3.

Registros: Canoas, Derrubadas, Eldorado do Sul, Gravataí, Guaíba, Montenegro, Novo Hamburgo, Palmares do Sul, Porto Alegre, Santa Maria, São Borja, São Leopoldo, Triunfo, Viamão.

501. Hasarius adansoni (Audouin, 1826): 404, est. 7, figs 8, 13. Localidade-tipo: Egito. Kaston (1948): 493, fig. 1816; est C, figs 1851-1853. Registros: Pelotas, Porto Alegre.

502. Hasarius lisei Vianna \& Soares, 1982: 87, figs 1-7. Localidade-tipo: Montenegro, RS, Brasil.

Registros: Arroio dos Ratos, Barra do Ribeiro, Bom Jesus, Capivari do Sul, Guaíba, Montenegro, Novo Hamburgo, Palmares do Sul, Pelotas, São Leopoldo, Tapes, Triunfo.

503. Helvetia cancrimana (TACZANOWSKI, 1872): 68. Localidadetipo: Uaça, AP, Brasil. RuIz \& Brescovit (2008): 140, figs 1-5. Registros: Barra do Ribeiro, Capivari do Sul, Palmares do Sul.

504. Helvetia labiata Ruiz \& Brescovit, 2008: 141, figs 6, 7. Localidade-tipo: Estrela Velha, RS, Brasil. Registro: Estrela Velha.

505. Hisukattus transversalis Galiano, 1987a: 139, figs 8-10, 13, 19, 28, 29. Localidade-tipo: Buenos Aires, Argentina. Registros: Charqueadas, Palmares do Sul.

506. Hisukattus tristis (Mello-LeItão, 1944): 385, fig. 81. Localidade-tipo: Buenos Aires, Argentina. Galiano (1987a): 141, figs 4-7, 14, 15, 20, 26, 27.

Registros: Piratini, Santana do Livramento, Terra de Areia.

507. Ilargus coccineus Simon, 1901d: 66. Localidade-tipo: Serra do Caraça, Catas Altas, MG, Brasil. Braul et al. (1997): 144, figs 5,6 .

Registros: Cambará do Sul, Derrubadas, São Francisco de Paula

508. Lyssomanes miniaceus Peckham \& Wheeler, 1889: 227. Localidade-tipo: Tijuca, RJ, Brasil. Galiano (1962): 68, est. 5, figs 6-9.

Registros: Campo Bom, Derrubadas, Triunfo.

509. Lyssomanes nigrofimbriatus Mello-Leitão, 1940b: 254 Localidade-tipo: Rio Negro, PR, Brasil. Galiano (1980): 16, figs $15,16$.

Registros: Canela, Derrubadas, Estrela Velha, Putinga, Salto do Jacuí, São Francisco de Paula, Taquara.

510. Lyssomanes pauper Mello-Leitão, 1945: 272, fig. 59 Localidade-tipo: Corrientes, Argentina. Galiano (1962): 80, est. 5, figs 1-5.

Registros: Canela, Derrubadas, Eldorado do Sul, Estrela Velha, Palmares do Sul, Porto Alegre, Putinga, Triunfo, Viamão.

511. Lyssomanes tristis Peckham \& Wheeler, 1889: 232, est. 11, fig. 12. Localidade-tipo: Brasil. Galiano (1980): 40, figs 65$68,80,81$.

Registros: Derrubadas, Porto Alegre, Viamão.

512. Mburuvicha galianoae Scioscia, 1993: 123, figs 1-15. Localidade-tipo: Entre Ríos, Argentina.

Registros: Porto Alegre, Tapes.

513. Mopiopia comatula Simon, 1902a: 375. Localidade-tipo: SP, Brasil. Galiano (1963a): 397, est. 28, figs 3-6. Registro: Derrubadas.

514. Mopiopia labirinthea (Mello-Leitão, 1947b): 301, est. 42, figs 49, 51. Localidade-tipo: Curitiba, PR, Brasil. EDwARDS et al. (2005): 25, figs $31-34,56,57$.

Registro: São Francisco de Paula.

515. Noegus australis (Mello-LeITÃo, 1940b): 254. Localidadetipo: Curitiba, PR, Brasil. Galiano (1968b): 347, figs 89-92. Registros: Canela, Carazinho, Carlos Barbosa, Caxias do Sul, Estrela Velha, Montenegro, Novo Hamburgo, Passo Fundo, São Francisco de Paula, São Leopoldo, Terra de Areia.
516. Pensacola castanea Simon, 1902a: 39. Localidade-tipo: Tijuca, RJ, Brasil. Galiano (1963a): 416, est. 32, figs 3-5. Registros: Palmares do Sul, Triunfo.

517. Phiale gratiosa C. L. Косн, 1846: 193, figs 1240, 1241 Localidade-tipo: Brasil. Galiano (1978): 162, figs 1-4, 8-9. Registro: Guaíba.

518. Phiale tristis Mello-Leitão, 1945: 293. Localidade-tipo Misiones, Argentina. Galiano (1981c): 76, figs 15, 16, 25-27. Registros: Canela, Derrubadas.

519. Plexippus paykulli (Audouin, 1826): 409, est. 7, fig. 22. Localidade-tipo: Egito. Petrunkevitch (1930): 156, figs 140143.

Registros: Lajeado, Porto Alegre, Santa Maria.

520. Psecas chapoda (Рeckham \& Peckham, 1894): 95, est. 9. fig.1. Localidade-tipo: Brasil.

Registros: Derrubadas, São Francisco de Assis.

521. Psecas chrysogrammus (Simon, 1901a): 460. Localidadetipo: PA, Brasil. Galiano (1963a): 424, est. 32, figs 14-18. Registro: Maquiné.

522. Rudra dagostinae Braul \& Lise, 1999: 11, figs 1-3, 11, 12. Localidade-tipo: Guaíba, RS, Brasil. Registro: Guaíba.

523. Rudra humilis Mello-Leitão, 1945: 294, fig. 86. Localidadetipo: Misiones, Argentina. Galiano (1984a): 66, figs 6-8, 11, 17, 18, 21, 27.

Registros: Montenegro, Palmares do Sul, Porto Alegre, Santa Maria, São Leopoldo, Triunfo.

524. Sarinda exilis (Mello-Leitão, 1943a): 232, fig. 59 Localidade-tipo, RS, Brasil. Galiano, 1981a: 15.

Registro: Só a localidade-tipo.

525. Sarinda marcosi Toledo-PIzA, 1937: 309, figs 1, 2. Localidade-tipo: Piracicaba, SP, Brasil. Galiano (1965): 292, est. 5 , fig. 6 , est. 6 , fig. 3 .

Registros: Barra do Ribeiro, Palmares do Sul.

526. Sarinda nigra Рескнaм \& Peckham, 1892: 40, est. 3, fig. 5. Localidade-tipo: Chapada, AM, Brasil. Galiano (1965): 296 , est, 6, fig. 4, est. 7, fig. 103 .

Registros: Palmares do Sul, Porto Alegre, Triunfo.

527. Sassacus helenicus (Mello-Leitão, 1943a): 230, fig. 56 Localidade-tipo: RS, Brasil. Vianna \& SOARES (1982): 89, figs 8-11. Vianna \& Soares (1978): 27, figs 1-7.

Registros: Cambará do Sul, Canela, Derrubadas, Maquiné, Montenegro, Porto Alegre, Triunfo.

528. Scopocira histrio Simon, 1900a: 386. Localidade-tipo: PA, Brasil. Galiano (1963a): 439, est. 36, figs 7-9. Registro: Derrubadas.

529. Semiopyla viperina Galiano, 1985: 284 , figs 6-8, 10, 11 , 14-16, 21-23. Localidade-tipo: Concepción, Paraguai. Registro: Porto Alegre.

530. Sitticus leucoproctus (Mello-Leitão, 1944): 380, fig. 74 Localidade-tipo: Buenos Aires, Argentina. Galiano (1989): 259, figs $1,2,8,9,12-14,19,22$. Registro: Estrela Velha.

531. Synemosyna aurantiaca (Mello-Leitão, 1917c): 138 Localidade-tipo: Pinheiral, RJ, Brasil. Galiano (1966): 348, figs 8-11, 44-46, 49, 61.

Registros: Cachoeirinha, Charqueadas, Derrubadas, Gravataí, Pelotas, Porto Alegre, Rio Grande, São Francisco de Paula, Triunfo.

532. Synemosyna lauretta Рескнам \& Рескнам, 1892: 79 Localidade-tipo: Chapada, AM, Brasil. Galiano (1966): 123, figs $24,42,43,47,58$.

Registro: Derrubadas.

533. Synemosyna scutata (Mello-LeItão, 1943a): 231, fig. 58 Localidade-tipo: RS, Brasil. Galiano (1966): 371, fig. 59. Registro: Rio Grande.

534. Tacuna delecta Peckham \& Pecкham, 1901: 228, fig. 4. Localidade-tipo: RJ, Brasil. Partona modesta Mello-LeITão, 1943a: 228, fig. 55, localidade-tipo: RS, Brasil. Galiano (1995): 114, figs 1-4, 9-13, 26, 28.

Registros: Bagé, Cambará do Sul, Estrela Velha, Montenegro, Porto Alegre, Triunfo, Viamão.

535. Tariona bruneti Simon, 1903a: 782. Localidade-tipo: Teresópolis, RJ, Brasil. Galiano (1963a): 452, est. 39, figs 4-6. Registro: Triunfo. 
536. Theriella bertoncelloi Braul \& Lise, 2003: 123, figs 1-13. Localidade-tipo: São Francisco de Paula, RS, Brasil.

Registro: São Francisco de Paula.

537. Theriella galianoae Braul \& LISE, 1996: 173, figs 1-7. Localidade-tipo: Caxias do Sul, RS, Brasil.

Registros: Caxias do Sul, Triunfo.

538. Thiodina melanogaster Mello-Leitão, 1917c: 132, fig. 4. Localidade-tipo: Pinheiral, RJ, Brasil.

Registros: Barra do Ribeiro, Canoas, Dom Feliciano, Eldorado do Sul, Gravataí, Montenegro, Palmares do Sul, Porto Alegre, Santa Rosa, São Borja, São Sepé, Triunfo.

539. Thiodina robusta Mello-Leitão, 1945: 299, fig. 92. Localidade-tipo: Misiones, Argentina.

Registros: Barra do Ribeiro, Canela, Canoas, Derrubadas, General Câmara, Montenegro, São Borja, Triunfo, Viamão.

540. Tittanatus notabilis (Mello-Leitão, 1943a): 221, fig. 47. Localidade-tipo: Porto Alegre, RS, Brasil. Galiano (1963b): 32 , est. 1, fig. 11 ; est. 2 , figs $1-3$.

Registros: Porto Alegre, Triunfo.

541. Tulpius gauchus Vianna \& Soares, 1983: 48, figs 1-9. Localidade-tipo: Montenegro, RS, Brasil.

Registros: Barra do Ribeiro, Farroupilha, Montenegro, Palmares do Sul, Tapes, Triunfo.

542. Tullgrenella serrana Galiano, 1970: 350, figs 37-42, 55, 64. Localidade-tipo: Buenos Aires, Argentina.

Registro: Santana do Livramento.

543. Vinnius uncatus Simon, 1902a: 45. Localidade-tipo: Bahia, Brasil. Mago proximus Mello-Leitão, 1943a: 224, fig. 50, localidade-tipo: RS, Brasil; Galiano (1963a): 467, est. 42, figs 8-11. Braul \& Lise (2002): 93, figs 9-15.

Registros: Campo Bom, Canela, Derrubadas, Machadinho, Novo Hamburgo, Porto Alegre, Porto Mauá, Roca Sales, São Borja, São Leopoldo, Torres, Três Cachoeiras.

544. Wedoquella denticulata Galiano, 1984b: 345, figs 4-6, 10, 11, 16, 17. Localidade-tipo: Misiones, Argentina. Registros: Derrubadas, Montenegro.

545. Wedoquella macrotheca Galiano, 1984b: 347, figs 1-3, 12 , 13, 20, 21. Localidade-tipo: Misiones, Argentina. Registro: Derrubadas.

546. Wedoquella punctata (Tullgren, 1905): 74, est. 10, fig. 39. Localidade-tipo: Tatarenda, Bolívia. Galiano (1984b): 349, figs 7-9, 14, 15, 18, 10 .

Registros: Derrubadas, Triunfo.

\section{SCYTODIDAE}

547. Scytodes chapeco RHEIMs \& Brescovit, 2009: 40, figs 141-146. Localidade-tipo: Chapecó, SC, Brasil.

Registros: Canela, Encantado, Guaíba, Igrejinha, São Valentim.

548. Scytodes fusca WALCKenAer, 1837: 272. Localidade-tipo: Guiana Francesa. Brescovit \& Rheims (2000): 323, figs 5-8. Registro: Rio Grande do Sul.

549. Scytodes globula Nicolet, 1849: 347, est. 11, figs 1, 2. Localidade-tipo: Chile. Brescovit \& Rheims (2000): 325, figs 21-27, 30-34.

Registros: Arroio do Tigre, Canela, Capão da Canoa, Charqueadas, Estância Velha, Garibaldi, Gravataí, Guaíba, Montenegro, Novo Hamburgo, Pelotas, Porto Alegre, Quaraí, Rio Grande, Santa Maria, São Jerônimo, São Leopoldo, Sapiranga, Torres, Triunfo, Viamão.

550. Scytodes maquine RHEIMs \& Brescovit, 2009: 39, figs 136-140. Localidade-tipo: Maquiné, RS, Brasil.

Registros: Cambará do Sul, Canela, Maquiné, São Francisco de Paula.

551. Scytodes tabuleiro RheIMs \& BREscovit, 2009: 37, figs 130-135. Localidade-tipo: Paulo Lopes, SC, Brasil. Registros: Canela, Machadinho, São Francisco de Paula.

552. Scytodes turvo Rheims \& BREscovit, 2009: 43, figs 157-159. Localidade-tipo: Derrubadas, RS, Brasil. Registro: Derrubadas.

553. Scytodes univittata Simon, 1882: 242. Localidade-tipo: Ta'izz, Yemen. Brescovit \& Rheims (2000): 323, figs 11-20. Registros: Nonoai, Pinhal, Porto Alegre, Rio Grande, São Francisco de Paula, Viamão.

554. Scytodes ytu Rheims \& Brescovit, 2009: 34, figs 124-129. Localidade-tipo: Foz do Iguaçu, PR, Brasil.

Registro: Derrubadas.

\section{SEGESTRIIDAE}

555. Ariadna boesenbergii Keyserling, 1877c: 223, est. 7, fig. 7. Localidade-tipo: Montevideo, Uruguai. Beatty (1970): 476, figs 3, 46-48.

Registros: Porto Alegre, Rio Grande.

556. Segestria ruficeps GuÉrIN, 1832: 8, est. 1. Localidade-tipo: Buenos Aires, Argentina. CAPocasale (1998): 2, figs 1-11. Registro: Pelotas.

\section{SELENOPIDAE}

557. Selenops cocheleti Simon, 1880: 235. Localidade-tipo: Paraguai. Corronca (1998): 131, figs 4-7.

Registro: Porto Alegre.

558. Selenops occultus Mello-Leitão, 1918: 34, fig. 10 Localidade-tipo: MG, Brasil. Corronca (1998): 141, figs 47-50. Registros: Derrubadas, Iraí, Porto Alegre.

559. Selenops rapax Mello-Leitão, 1929d: 96. Localidade-tipo: Niterói, RJ, Brasil. CoRronca (1998): 143, figs 55-58. Registros: Arroio dos Ratos, Canela, Derrubadas, Encantado, Montenegro, Novo Hamburgo, Porto Alegre, Quaraí, Rio Pardo, Santo Antônio da Patrulha, São Borja, São Leopoldo, Três Coroas, Triunfo.

560. Selenops spixi Perty, 1833: 195, est. 38, fig. 12. Localidadetipo: "Província Bahiensis", Brasil. Corronca (1998): 143, figs 59-62.

Registros: Arroio do Tigre, Barra do Ribeiro, Butiá, Campo Bom, Canela, Canoas, Caxias do Sul, Eldorado do Sul, Garibaldi, General Câmara, Gravataí, Guaíba, Herval, Iraí, Itaúba, Lajeado, Machadinho, Minas do Leão, Montenegro, Nova Petrópolis, Novo Hamburgo, Pelotas, Portão, Porto Alegre, Rio Grande, Salto do Jacuí, Santa Maria, Santa Rosa, Santo Antônio da Patrulha, São Francisco de Paula, São Jerônimo, São Leopoldo, São Lourenço do Sul, Sapiranga, Sertão Santana, Tapes, Taquara, Triunfo, Vacaria, Viamão.

\section{SENOCULIDAE}

561. Senoculus darwini (Holmberg, 1883): 42. Localidade-tipo: Argentina. Schiapelli \& Pikelin (1958): 189, figs 1-3. Registros: Guaíba, Marcelino Ramos, Porto Alegre, São Borja, Triunfo.

\section{SICARIIDAE}

562. Loxosceles hirsuta Mello-Leitão, 1931: 13. Localidadetipo: Pinheiro Machado, RS, Brasil. Mello-Leitão (1934): 71, figs 1e, 2c. Gertsch (1967): 141, est. 5, figs 3-5, 12, 13. Registro: Pinheiro Machado.

563. Loxosceles intermedia Mello-Leitão, 1934: 73, figs 1d, 2d, $3 \mathrm{~d}$. Localidade-tipo: Petrópolis, RJ, Brasil. Gertsch (1967): 141, est. 5, figs 1, 2, 14 .

Registros: Arroio Grande, Barra do Ribeiro, Bom Jesus, Campo Bom, Canela, Caxias do Sul, Charqueadas, Dom Feliciano, Esteio, Formigueiro, Gravataí, Guaíba, Ivoti, Lajeado, Machadinho, Maquiné, Minas do Leão, Montenegro, Novo Hamburgo, Osório, Palmares do Sul, Pelotas, Porto Alegre, Porto Mariante, Rio Grande, Rio Pardo, Salto do Jacuí, Santa Maria, Santa Rosa, São Francisco de Paula, São Jerônimo, São José do Hortêncio, São Leopoldo, Sapiranga, Tapes, Tenente Portela, Torres, Três Coroas, Triunfo, Viamão.

564. Loxosceles laeta Nicolet, 1849: 348; est. 1, fig. 11. Localidade-tipo: Chile. Gertsch (1967): 147, est. 6, figs 1-9; est. 7, figs $1-5,8,9$.

Registros: Bagé, Canela, Esteio, Guaíba, Pelotas, Porto Alegre, Santa Maria, Santa Rosa, Santo Ângelo, São Leopoldo, Torres.

\section{SPARASSIDAE}

565. Caayguara albus (Mello-Leitão, 1918): 44, figs 13-15. Localidade-tipo: Pinheiral, RJ, Brasil. RheIms (2010): 4, figs 14-18, 71, 83.

Registro: Iraí.

566. Caayguara cupepemassu Rheims, 2010: 14, figs 39-43, 76. Localidade-tipo: Jundiaí, SP. Brasil. Registro: Derrubadas.

567. Olios caprinus Mello-Leitão, 1918: 45, figs 18, 19. Localidade-tipo: Pinheiral, RJ, Brasil.

Registros: Derrubadas, Iraí. 
568. Olios fasciatus (Keyserling, 1880): 259. Localidade-tipo: sul do Brasil.

Registros: Pelotas, Rio Grande, São Borja.

569. Olios fuscovariatus Mello-Leitão, 1943a: 198, fig. 28. Localidade-tipo: RS, Brasil.

Registro: Só a localidade-tipo.

570. Olios hyeroglyphicus (Mello-LeITão, 1918): 48, figs 25, 26. Localidade-tipo: Pinheiral, RJ, Brasil.

Registros: Canela, Caxias do Sul, Guaíba, Montenegro, Novo Hamburgo, Porto Alegre.

571. Polybetes germaini Simon, 1897b: 486. Localidade-tipo: Paraguai. Pikelin \& Schiapelli (1965): 321, est. 1, figs 3, 4; est. 6, fig. 23; est. 7, figs 31,32 .

Registros: Bom Jesus, Garibaldi, General Câmara, Júlio de Castilhos, Manuel Viana, Montenegro, Novo Hamburgo, Osório, Pelotas, Porto Alegre, Santa Maria, Santana do Livramento, São Jerônimo, São Leopoldo, Torres, Triunfo, Viamão.

572. Polybetes obnuptus Simon, 1897b: 487. Localidade-tipo: Bolívia. Pikelin \& SChiapelli (1965): 324, figs 13, 14, 40-42. Registros: Guaíba, Montenegro, Osório, Porto Alegre, São Leopoldo, São Vicente do Sul, Triunfo.

573. Polybetes punctulatus Mello-Leitão, 1944: 361, fig. 54 Localidade-tipo: Tigre, Buenos Aires, Argentina. Pikelin \& SCHIAPELLI (1965): 328, figs 19-22, 38. Registro: Pelotas.

574. Polybetes pythagoricus (Holmberg, 1875): 287. Localidadetipo: Buenos Aires, Argentina. Pikelin \& Schiapelli (1965): 329, est. 3, figs 11, 12; est. 6, figs 6-28.

Registros: Arroio dos Ratos, Bagé, Camaquã, Canela, Canoas, Erechim, Esmeralda, Gravataí, Guaíba, Osório, Pelotas, Pinheiro Machado, Porto Alegre, Quaraí, Rio Grande, Santana do Livramento, São Francisco de Paula, São Jerônimo, São Marcos, Tapejara, Três Coroas, Triunfo, Vacaria, Viamão.

575. Polybetes rapidus (Keyserling, 1880): 257, est. 7, fig. 141. Localidade-tipo: Taquara, RS, Brasil. Pikelin \& SChiapelli (1965): 333, est. 1, figs 1, 2; est. 6, fig. 24; est. 7, figs 29, 30. Registros: Butiá, Canela, Carazinho, Cruz Alta, Porto Alegre, Quaraí, Rio Pardo, Santa Maria, São Borja, São Jerônimo, Taquara, Tenente Portela, Triunfo.

576. Polybetes rubrosignatus Mello-Leitão, 1943a: 200, figs 29a-b. Localidade-tipo: RS, Brasil.

Registros: Arroio dos Ratos, Campo Bom, Encantado, Montenegro, Nova Petrópolis, Novo Hamburgo, Osório, Pelotas, Porto Alegre, São Leopoldo, Triunfo, Viamão.

\section{SYMPHYTOGNATHIDAE}

577. Anapistula ybyquyra Rheims \& BRescovit, 2003: 329, figs 4-6, 20, 21. Localidade-tipo: Viamão, RS, Brasil.

Registros: Triunfo, Viamão.

\section{SYNOTAXIDAE}

578. Synotaxus longicaudatus (Keyserling, 1891): 209, est. 8, fig. 150. Localidade-tipo: RJ, Brasil. ExLine \& Levi (1965): 181, figs 16-21.

Registros: Maquiné, Terra de Areia, Torres.

\section{TETRAGNATHIDAE}

579. Chrysometa aramba Levi, 1986: 144, figs 231-233. Localidade-tipo: Cambará do Sul, RS, Brasil.

Registros: Cambará do Sul, São Francisco de Paula, Triunfo.

580. Chrysometa boraceia Levi, 1986: 186, figs 14, 15, 568575. Localidade-tipo: Salesópolis, SP, Brasil.

Registros: Bom Jesus, Cambará do Sul, Canela, Charqueadas, Derrubadas, Dom Feliciano, Montenegro, Pelotas, Porto Alegre, São Francisco de Paula, Triunfo, Viamão.

581. Chrysometa cambara Levi, 1986: 192, figs 618-623. Localidade-tipo: Cambará do Sul, RS, Brasil.

Registros: Cambará do Sul, Porto Alegre, São Francisco de Paula, Triunfo, Viamão.

582. Chrysometa itaimba Levi, 1986: 178, figs 519-522. Localidade-tipo: Itaimbézinho, Cambará do Sul, RS, Brasil. Registros: Cambará do Sul, Tavares, Torres, Triunfo, Viamão.

583. Chrysometa ludibunda (Keyserling, 1893): 352, est. 18, fig. 260. Localidade-tipo: RJ, Brasil. Levi (1986): 175, figs 491-496. Registro: Derrubadas.
584. Dolichognatha pinheiral Brescovit \& Cunha, 2001: 103 , figs 39-48. Localidade-tipo: Pinheiral, RJ, Brasil.

Registros: Rio Grande, Triunfo, Viamão.

585. Dolichognatha proserpina (Mello-Leitão, 1943a): 181 Localidade-tipo: Rio Pardo, RS, Brasil.

Registro: Rio Pardo.

586. Glenognatha lacteovittata (Mello-LeITÃo, 1944): 327, fig. 9. Localidade-tipo: La Plata, Buenos Aires, Argentina. Ramírez (2006): 35 , figs $1-10$.

Registros: Derrubadas, Eldorado do Sul, Triunfo.

587. Leucauge argyra (WALCKENAER, 1841): 219, est. 19, fig. 1 Localidade-tipo: Guadalupe. Levi (1980b): 28, figs 60-71. Registros: Butiá, Cachoeirinha, Capivari do Sul, Eldorado do Sul, Gravataí, Guaíba, Nova Santa Rita, Palmares do Sul, Porto Alegre, Restinga Seca, Rio Grande, Santa Vitória do Palmar, São Leopoldo, Tapes, Terra de Areia, Torres, Triunfo, Viamão.

588. Leucauge roseosignata Mello-Leitão, 1943a: 183, fig. 20 Localidade-tipo: RS, Brasil.

Registros: Barra do Ribeiro, Canoas, Charqueadas, Derrubadas, Passo Fundo, Porto Alegre, Tapes, Torres, Triunfo.

589. Leucauge volupis (KeYSERLING, 1893): 356, est. 18, fig. 264 Localidade-tipo: Taquara, RS, Brasil.

Registros: Alegrete, Arroio dos Ratos, Barra do Ribeiro, Butiá, Cachoeirinha, Canoas, Capivari do Sul, Derrubadas, Estrela Velha, Guaíba, Novo Hamburgo, Palmares do Sul, Pelotas, Porto Alegre, Rio Grande, Salto do Jacuí, Santa Vitória do Palmar, Tapes, Taquara, Triunfo.

590. Opas paranensis (Mello-LeITão, 1937): 7, fig. 7. Localidadetipo: Curitiba, PR, Brasil. Levi (2008): 169. Registros: Derrubadas, Triunfo.

591. Tetragnatha exilima (Mello-Leitão, 1943a): 176 Localidade-tipo: RS, Brasil. Dimitrov \& Hormiga (2009): 100, figs 65 a-e. Registro: Só a localidade-tipo.

592. Tetragnatha filigastra Mello-Leitão, 1943a: 192, fig. 23 Localidade-tipo: RS, Brasil Registro: Só a localidade-tipo.

593. Tetragnatha jaculator Tullgren, 1910: 150, est. 3, fig. 73 Localidade-tipo: África. Окима (1992): 230, figs 10a-i Registros: Cachoeira do Sul, Cachoeirinha, Capivari do Sul, Eldorado do Sul.

594. Tetragnatha longidens Mello-Leitão, 1945: 244, fig. 22, 23. Localidade-tipo: Misiones, Argentina.

Registros: Canela, Capivari do Sul, Palmares do Sul, Tapes, Triunfo.

595. Tetragnatha nitens (Audoin, 1826): 323, est. 2, fig. 2 . Localidade-tipo: Egito. Levi (1981): 291, est. 5a-b, figs 23, 24. Окима (1983): 75, figs 4a-1.

Registros: Cachoeira do Sul, Cachoeirinha, Canela, Capivari do Sul, Derrubadas, Eldorado do Sul, Restinga Seca.

596. Tetragnatha ramboi Mello-Leitão, 1943a: 193, figs 24a, b. Localidade-tipo: RS, Brasil.

Registro: Só a localidade-tipo.

\section{THERAPHOSIDAE}

597. Acanthoscurria paulensis Mello-Leitão, 1923: 304, figs 86-88, 178, 179. Localidade-tipo: Pirassununga, SP, Brasil. LuCAs et al. (2010): 564, figs 1-10. Registro: Santa Cruz do Sul.

598. Acanthoscurria suina Рососк, 1903: 87. Localidade-tipo: Uruguai. Schiapelli \& Pikelin (1964): 407, est. 1, figs 20-25. Registros: Bom Jesus, Canoas, Cruz Alta, Nova Petrópolis, Porto Alegre, Santa Maria, Triunfo, Vacaria, Viamão.

599. Catumiri uruguaiense GuadanuccI, 2004: 7, figs 10-15. Localidade-tipo: Lavalleja, Uruguai. Registros: Bossoroca, Rio Grande.

600. Cyrthopholis meridionalis (KEYSERLING, 1891): 6. Localidadetipo: Taquara, RS, Brasil.

Registro: Taquara

601. Eupalestrus campestratus (SIMon, 1891b): 311. Localidadetipo: Paraguai. Bertani (2001): 282, figs 49, 52-53, 55. Registros: Alvorada, Bagé, Barracão, Bento Gonçalves, Bossoroca, Cachoeira do Sul, Camaquã, Canela, Cruz Alta, Dom Pedrito, Gravataí, Guaíba, Ijuí, Nova Prata, Passo Fundo, Pelotas, Porto Alegre, Quaraí, Salto do Jacuí, São Leopoldo, Triunfo, Tupanciretã, Tuparendí, Uruguaiana, Vacaria, Viamão. 
602. Eupalestrus weijenberghi (THORELL, 1894): 31. Localidade-tipo: Córdoba, Argentina. BERTANI (2001): 282, figs 49, 52-53, 55. Registro: Uruguaiana.

603. Grammostola actaeon (Pocock, 1903): 99. Localidade-tipo: Brasil. Mello-Leitão (1923): 204, figs 69-71. BüChERl (1951): figs 3-III, 4, 12, 13, 17-19, 28-III, 31, est. V.

Registros: Arroio dos Ratos, Pinheiro Machado, Porto Alegre, Viamão.

604. Grammostola iheringi (Keyserling, 1891): 19, est. 1, fig. 4. Localidade-tipo: Taquara, RS, Brasil. BüChERL (1951): figs 3IV, 28-IV, 32, est. V.

Registros: São Francisco de Paula, Taquara.

605. Grammostola mollicoma (AuSSERER, 1875): 185. Localidadetipo: RS, Brasil. BücheRL (1951): figs 3-II, 28-II, 29, ests I, II. Registros: Barracão, Lajeado, Maximiliano de Almeida, Porto Alegre, São Sebastião do Caí.

606. Grammostola pulchra Mello-Leitão, 1921: 298. Localidadetipo: Uruguaiana, RS, Brasil. Registro: Uruguaiana.

607. Grammostola pulchripes (Simon, 1891b): 311. Localidadetipo: Paraguai. BücherL (1951): figs 3-I, 28-I, 30, ests III, IV. Registro: Rio Grande do Sul.

608. Homoeomma villosum (Keyserling, 1891): 7, est. 1, fig. 2. Localidade-tipo: Taquara, RS, Brasil. Registro: Taquara.

609. Lasiodora pantherina (KEYSERLING, 1891): 18. Localidadetipo: Taquara, RS, Brasil.

Registro: Taquara.

610. Magulla brescoviti IndicatTI, LuCAS, Guadanucci \& Y AMAMoto, 2008a: 27, figs 2f-j, 3a-f, 4d-e, 7a-i. Localidade-tipo: São Francisco de Paula, RS, Brasil.

Registro: São Francisco de Paula.

611. Plesiopelma rectimanum (Mello-Leitão, 1923): 161. Localidade-tipo: Uruguaiana, RS, Brasil. Registro: Uruguaiana.

612. Vitalius dubius (Mello-Leitão, 1923): 188. Localidadetipo: Ipiranga, SP, Brasil. BERTANI (2001): 298, figs 10-11, 23, 91-100, 182, 183.

Registro: Rio Grande.

613. Vitalius roseus (Mello-Leitão, 1923): 232. Localidade-tipo: Itaqui, RS, Brasil. Bertani (2001): 305, figs 112-116, 185.

Registros: Arroio do Tigre, Bossoroca, Caxias do Sul, Ijuí, Itaqui, Santa Maria, São Gabriel, São Vicente do Sul, Tenente Portela, Tuparendí.

614. Vitalius sorocabae (Mello-Leitão, 1923): 233. Localidadetipo: Sorocaba, SP, Brasil. BERTANi (2001): 292, figs 17, 74-82, 178. Registro: Santa Cruz do Sul.

\section{THERIDIIDAE}

615. Achaearanea tingo LeVI, 1963b: 202, figs 4-6. Localidadetipo: Tingo María, Huánuco, Peru.

Registro: Derrubadas.

616. Achaearanea trapezoidalis (TACZANOWSKI, 1873): 115, est. 5, fig 10. Localidade-tipo: Rio Uaçá, AP, Brasil. Levi (1955): 9, figs 7-13.

Registros: Derrubadas, Garruchos.

617. Ameridion unanimum (KeyserLing, 1891): 181, est. 6, fig. 126. Localidade-tipo: Nova Friburgo, RJ, Brasil. Levi (1963d): 555, figs 131-134. Registros: Cambará do Sul, Terra de Areia.

618. Anelosimus dubiosus (Keyserling, 1891): 187, est. 6, fig. 133. Localidade-tipo: Nova Friburgo, RJ, Brasil. Levi \& SMith (1983): 277, fig. 4. Gonzaga \& Santos (1999): 432, figs 1-3. Agnarsson (2006): 485, figs 7k-p, 13a-f, 14a-g, 15a-g. Registros: Canela, Santa Maria, São Francisco de Paula, Torres.

619. Anelosimus ethicus (Keyserling, 1884a): 44, est. 2, fig. 24. Localidade- tipo: RJ, Brasil. Agnarsson (2005): 391, figs 1a-g, 2a-f, 3a-g.

Registros: Arroio dos Ratos, Arroio Grande, Barra do Ribeiro, Cachoeira do Sul, Cambará do Sul, Caxias do Sul, Gravataí, Guaíba, Maquiné, Montenegro, Pelotas, Porto Alegre, Rio Grande, Santa Maria, São Francisco de Paula, Torres, Triunfo.

620. Anelosimus inhandava Agnarsson, 2005: 401, figs 7e, 8a-f. Localidade-tipo: Rio Inhandava, RS, Brasil.

Registro: Machadinho.
621. Anelosimus jabaquara LeVI, 1956: 414, fig. 18. Localidadetipo: Jabaquara, SP, Brasil. GonZAGA \& SANTos (1999): 434, figs 4, 5. Agnarsson (2006): 484, figs 7e-j, 11a-g, $12 \mathrm{ag}$. Registros: Santa Maria, Triunfo.

622. Anelosimus nigrescens (Keyserling, 1884a): 42, est. 2, fig. 22. Localidade-tipo: MG, Brasil. Agnarsson (2005): 395, figs 1hn, 4a-f, 5a-f, 6a-f.

Registros: Guaíba, Montenegro, Porto Alegre, Rio Grande, Triunfo.

623. Anelosimus studiosus (Hentz, 1850): 274, est. 16, fig. 5. Localidade-tipo: Alabama, EUA. Levi (1956): 418, figs 21 23, 37-39. Agnarsson (2006): 505, figs 49a-f, 50a-h, 51a-f. Registros: Bagé, Bom Jesus, Cambará do Sul, Derrubadas, Nova Petrópolis, Pelotas, Porto Alegre, Rio Grande, Santa Maria, Santa Vitória do Palmar, São Francisco de Paula.

624. Argyrodes elevatus TACZANowski, 1873: 120, est. 5, fig. 12. Localidade-tipo: Uaça, AP, Brasil. ExLine \& Levi (1962): 134 figs 128-132, 154.

Registros: Cachoeirinha, Canela, Canoas, Capivari do Sul, Derrubadas, Eldorado do Sul, Estrela Velha, Júlio de Castilhos, Marcelino Ramos, Montenegro, Palmares do Sul, Pelotas, Porto Alegre, Rio Grande, Salto do Jacuí, Santa Maria, Santa Vitória do Palmar, São Francisco de Paula, São Leopoldo, São Pedro do Sul, Torres, Triunfo, Vacaria, Viamão.

625. Ariamnes attenuatus O. P.-CAMbridge, 1881: 770, est. 66, fig. 3. Localidade-tipo: AM, Brasil. ExLINE \& LeVI (1962): 131, figs 118-127. Registros: Derrubadas.

626. Ariamnes longissimus Keyserling, 1891: 202, est 7, fig. 145. Localidade-tipo: Nova Friburgo, RJ, Brasil. ExLine \& LeVI (1962): 127, figs 100-109.

Registros: Arroio do Meio, Arroio Grande, Barra do Ribeiro, Barracão, Campo Bom, Canela, Eldorado do Sul, Estrela Velha, General Câmara, Gravataí, Guaíba, Iraí, Maquiné, Montenegro, Novo Hamburgo, Pelotas, Porto Alegre, São Borja, São Francisco de Paula, São Leopoldo, Tapes, Triunfo, Viamão.

627. Chrosiothes niteroi Levi, 1964e: 86, figs 31-33. Localidadetipo, Niterói, RJ, Brasil. Marques \& Buckup (1997): 185, fig. 8. Registros: Capão do Leão, Derrubadas, Espumoso, Estrela Velha, Guaíba, Iraí, Júlio de Castilhos, Machadinho, Marcelino Ramos, Montenegro, Porto Alegre, Salto do Jacuí, Santa Cruz do Sul, Santa Maria, São Francisco de Paula, São Valentim, Triunfo, Vacaria, Viamão.

628. Chrosiothes perfidus Marques \& Buckup, 1997: 182, figs 1-5. Localidade-tipo: Montenegro, RS, Brasil.

Registros: Arroio do Tigre, Barra do Ribeiro, Canela, Derrubadas, Estrela Velha, Farroupilha, Gravataí, Iraí, Machadinho, Maquiné, Montenegro, Palmares do Sul, Porto Alegre, Santa Maria, Triunfo, Vacaria, Viamão.

629. Chrysso arops Levi, 1962b: 228, figs 29, 30. Localidadetipo: Teresópolis, RJ, Brasil. Levi (1962b): 229, 230, figs $52-$ $54,61,62$.

Registros: Canela, Gramado, São Francisco de Paula.

630. Chrysso compressa (Keyserling, 1884a): 107, est. 5, fig. 69. Localidade-tipo: Amable María, Peru. Levi (1962b): 226, figs 63-70.

Registros: Derrubadas, Guaíba, Maquiné, Marcelino Ramos, Montenegro, Porto Alegre, São Francisco de Paula, Tapes, Terra de Areia, Triunfo, Viamão.

631. Chrysso gounellei Levi, 1962b: 217, figs 6-8. Localidadetipo: Serra do Caraça, Catas Altas, MG, Brasil. Registros: Maquiné, Torres.

632. Chrysso nigrosterna Keyserling, 1891: 206, est. 7, fig. 148. Localidade-tipo: Taquara, RS, Brasil. Levi (1962b): 217, figs 9-13.

Registros: Barra do Ribeiro, Butiá, Canela, Charqueadas, Derrubadas, Encantado, Farroupilha, General Câmara, Glorinha, Gravataí, Guaíba, Maquiné, Montenegro, Novo Hamburgo, Osório, Passo Fundo, Porto Alegre, Santa Cruz do Sul, Santa Maria, Santo Antônio da Patrulha, Tapes, Taquara, Terra de Areia, Triunfo, Viamão.

633. Chrysso pulcherrima (Mello-Leitão, 1917a): 86, figs 7, 8. Localidade-tipo: RJ, Brasil. Levi (1967a): 182, figs 28-31.

Registros: Antônio Prado, Canoas, Encantado, Gravataí, Guaíba, Montenegro, Muçum, Tenente Portela, Triunfo.

634. Chrysso rubrovittata (Keyserling, 1884a): 159, est. 7, fig. 
98. Localidade-tipo: Provavelmente América do Sul. Levi (1962b): 218, 220, figs 14-17, 18.

Registros: Barra do Ribeiro, Bom Jesus, Campo Bom, Caxias do Sul, Charqueadas, Derrubadas, Estrela Velha, Faxinal do Soturno, Gravataí, Guaíba, Júlio de Castilhos, Maquiné, Montenegro, Nonoai, Pelotas, Porto Alegre, Rio Grande, Salto do Jacuí, Santa Cruz do Sul, Santa Maria, São Francisco de Paula, São Leopoldo, São Valentim, Sertão Santana, Taquari, Tenente Portela, Triunfo, Vacaria, Viamão.

635. Coleosoma acutiventer (Keyserling, 1884a): 113, est. 5, fig. 74. Localidade-tipo: Peru. Levi (1959c): 4, figs 6-11. Registros: Cachoeirinha, Eldorado do Sul, São Francisco de Paula, Triunfo.

636. Coleosoma floridanum Banks, 1900: 98. Localidade-tipo: Punta Gorda, Florida, EUA. Levi (1959c): 6, figs 12-17. Registro: Porto Alegre.

637. Craspedisia cornuta (Keyserling, 1891): 222, est. 8, fig. 163. Localidade-tipo: Nova Friburgo, RJ, Brasil. Levi (1963e): 177, figs 27-31. Registros: Derrubadas, Sapiranga, Triunfo.

638. Cryptachaea altiventer (Keyserling, 1884a): 108, est. 5, fig. 70. Localidade-tipo: América do Sul. Levi (1963b): 204, figs 9-12, 45. Cryptachaea maxima (KeYserLing, 1891): 198, est. 7, fig. 142, localidade-tipo: Rio Grande, RS, Brasil. Levi (1963b): 205, figs 18, 19

Registros: Bagé, Bom Jesus, Butiá, Caçapava do Sul, Cachoeira do Sul, Cambará do Sul, Campo Bom, Candelária, Canela, Canoas, Capão do Leão, Caxias do Sul, Derrubadas, Eldorado do Sul, Encantado, Estrela Velha, General Câmara, Glorinha, Guaíba, Machadinho, Maquiné, Montenegro, Morro Reuter, Nova Petrópolis, Novo Hamburgo, Osório, Pelotas, Porto Alegre, Quaraí, Rio Pardo, Salto do Jacuí, Santa Maria, Santa Vitória do Palmar, São Borja, São Francisco de Paula, São Leopoldo, São Valentim, Sobradinho, Tapes, Torres, Triunfo, Vacaria, Viamão.

639. Cryptachaea analista (Levi, 1963b): 223, figs 72-74. Localidade-tipo: Nova Teutônia, SC, Brasil.

Registros: Cambará do Sul, Canela, Caxias do Sul, Derrubadas, Encantado, Estrela Velha, Iraí, Júlio de Castilhos, Machadinho, Nova Petrópolis, Porto Alegre, Salto do Jacuí, Santa Maria, São Francisco de Paula, Triunfo.

640. Cryptachaea bellula (Keyserling, 1891): 180, est. 6, fig. 125. Localidade-tipo: Nova Friburgo, RJ, Brasil. Levi (1963b): 227, figs 86-90.

Registros: Barra do Ribeiro, Bom Jesus, Cachoeirinha, Cambará do Sul, Campo Bom, Canela, Canoas, Capivari do Sul, Caxias do Sul, Charqueadas, Derrubadas, Eldorado do Sul, Encantado, Estrela Velha, Farroupilha, General Câmara, Glorinha, Gravataí, Guaíba, Machadinho, Montenegro, Novo Hamburgo, Osório, Palmares do Sul, Passo Fundo, Pelotas, Porto Alegre, Rio Pardo, Salto do Jacuí, Santa Cruz do Sul, Santa Maria, Santo Antônio da Patrulha, São Francisco de Paula, São Jerônimo, São Leopoldo, São Sepé, Tapes, Triunfo, Vacaria, Viamão.

641. Cryptachaea cinnabarina (Levi, 1963b): 214, figs 46, 62, 63. Localidade-tipo: Teresópolis, RJ, Brasil.

Registros: Cambará do Sul, Campo Bom, Canela, Derrubadas, Glorinha, Machadinho, Maquiné, Pelotas, São Francisco de Paula, São Leopoldo, Terra de Areia, Torres.

642. Cryptachaea dea (Buckup \& Marques) in BucKup et al. (2006): 62, figs 4-6. Localidade-tipo, Triunfo, RS, Brasil. Registros: Montenegro, Porto Alegre, Triunfo.

643. Cryptachaea digitus (Buckup \& Marques) in BucKup et al. (2006): 61, figs 1-3. Localidade-tipo: Triunfo, RS, Brasil. Registros: Capão do Leão, Maquiné, Santo Antônio da Patrulha, São Francisco de Paula, Triunfo.

644. Cryptachaea hirta (TaCzanowski, 1873): 119. Localidadetipo: Cayena, Guiana Francesa. Theridion bentificum KeyserLing, 1891: 184, est. 6, fig. 129, localidade-tipo: RS, Brasil. Levi (1959b): 70, figs 35-38.

Registros: Alegrete, Arroio Grande, Bagé, Barra do Ribeiro, Bom Jesus, Butiá, Cachoeirinha, Campo Bom, Candelária, Canela, Canoas, Capivari do Sul, Caxias do Sul, Charqueadas, Derrubadas, Dom Feliciano, Dona Francisca, Eldorado do Sul, Encantado, Espumoso, Estrela Velha, Farroupilha, Faxinalzinho, General Câmara, Glorinha, Gravataí, Guaíba, Machadinho, Maquiné, Marcelino Ramos, Montenegro, Muçum, Nova Petrópolis, Novo
Hamburgo, Osório, Palmares do Sul, Pelotas, Porto Alegre, Quaraí, Rio Grande, Rio Pardo, Salto do Jacuí, Santa Cruz do Sul, Santa Rosa, Santa Vitória do Palmar, Santo Antônio da Patrulha, São Francisco de Paula, São Jerônimo, São Leopoldo, São Pedro do Sul, São Sepé, São Valentim, Tapes, Tenente Portela, Terra de Areia, Torres, Tramandaí, Três Coroas, Triunfo, Vacaria, Viamão.

645. Cryptachaea isana (LEvI, 1963b): 229, figs 100-102, 113, 114. Localidade-tipo: Nova Teutônia, SC, Brasil.

Registros: Derrubadas, Glorinha, Maquiné, Novo Hamburgo, Tenente Portela, Viamão.

646. Cryptachaea jequirituba (Levi, 1963b): 226, figs 98, 99. Localidade-tipo: São Paulo, SP, Brasil. GonZÁlEz (1992): 134, figs $1,2$.

Registros: Derrubadas, Garruchos, São Francisco de Paula.

647. Cryptachaea lisei Buckup, Marques \& Rodrigues, 2011: 349, figs 10, 11. Localidade-tipo: Rio Grande, RS, Brasil. Registro: Rio Grande.

648. Cryptachaea passiva (Keyserling, 1891): 195, est. 7, fig. 141. Localidade-tipo: RJ, Brasil. Levi (1963b): 207, figs 26-28. Registros: Agudo, Arroio Grande, Barra do Ribeiro, Barracão, Bom Jesus, Butiá, Cambará do Sul, Campo Bom, Candelária, Canela, Canoas, Capão do Leão, Carazinho, Caxias do Sul, Charqueadas, Derrubadas, Dom Feliciano, Eldorado do Sul, Encantado, Esmeralda, Estrela Velha, Garruchos, General Câmara, Glorinha, Gravataí, Guaíba, Iraí, Júlio de Castilhos, Machadinho, Maquiné, Montenegro, Nonoai, Novo Hamburgo, Osório, Palmares do Sul, Passo Fundo, Pelotas, Porto Alegre, Quaraí, Rio Pardo, Santa Maria, Santa Rosa, Santo Antônio da Patrulha, Santo Antônio das Missões, São Borja, São Francisco de Paula, São Jerônimo, São Leopoldo, São Pedro do Sul, Tapes, Terra de Areia, Torres, Triunfo, Vacaria, Viamão.

649. Cryptachaea pinguis (Keyserling, 1886): 235, est. 20, fig. 290. Localidade-tipo: Blumenau, SC, Brasil. Levi (1963b): 228, figs 93,94

Registros: Alegrete, Bom Jesus, Canela, Capão do Leão, Eldorado do Sul, Esmeralda, Guaíba, Pelotas, Porto Alegre, Quaraí, Santa Maria, São Francisco de Paula, Torres.

650. Cryptachaea rioensis (Levi, 1963b): 209, figs 36-38. Localidade-tipo: Teresópolis, RJ, Brasil.

Registros: Maquiné, Porto Alegre, São Borja, Triunfo.

651. Cryptachaea sicki (Levi, 1963b): 218, figs 48, 70, 71. Localidade-tipo: Teresópolis, RJ, Brasil. Registro: Maquiné.

652. Cryptachaea taim (Buckup \& Marques) in BUCKUP et al. (2006): 63, figs 7-10. Localidade-tipo: Rio Grande, RS, Brasil. Registros: Capão do Leão, Eldorado do Sul, Rio Grande, São Francisco de Paula.

653. Cryptachaea triguttata (Keyserling, 1891): 190, est. 6, fig. 136. Localidade-tipo: Nova Friburgo, RJ, Brasil. Levi (1963d): 542, figs 76, 77. Buckup \& Marques (1996): 46, figs 1, $2,9$. Registros: Campo Bom, Canela, Derrubadas, Glorinha, Iraí, Júlio de Castinhos, Maquiné, Montenegro, Novo Hamburgo, Osório, Porto Alegre, Santa Maria, Santo Antônio das Missões, São Francisco de Paula, São Leopoldo, Viamão.

654. Dipoena atlantica Chickering, 1943: 330, figs 1-4. Localidade-tipo: Barro Colorado Island, Panamá. Levi (1963a): 163 , figs $150-154$.

Registros: Cachoeira do Sul, Canela, Derrubadas, Maquiné, Santo Antônio da Patrulha, São Jerônimo, Torres.

655. Dipoena cordiformis KeYserLING, 1886: 259, est. 21, fig. 307. Localidade-tipo: Blumenau, SC, Brasil. Levi (1963a): 175, figs 245-247. BuCKuP \& MARques (1996): 50, fig. 13.

Registros: Canela, Derrubadas, Triunfo.

656. Dipoena foliata Keyserling, 1886: 260, est. 21, fig. 308 Localidade-tipo: Blumenau, SC, Brasil.

Registros: Cambará do Sul, Viamão.

657. Dipoena granulata (Keyserling, 1886): 257, est. 20, fig. 305. Localidade-tipo: Blumenau, SC, Brasil. Levi (1963a): 182 figs $302,303$.

Registros: Cambará do Sul, Derrubadas, Santana do Livramento, São José dos Ausentes.

658. Dipoena ira Levi, 1963a: 173, figs 235-237. Localidadetipo: Nova Teutônia, SC, Brasil. Buckup \& Marques (1996): 52, fig. 14

Registros: Arroio Grande, Barra do Ribeiro, Canoas, Caxias do Sul, Derrubadas, Estrela Velha, Farroupilha, Glorinha, Gravataí, 
Guaíba, Montenegro, Pelotas, Porto Alegre, São Borja, São Francisco de Paula, Sertão Santana, Tapes, Triunfo, Vacaria, Viamão.

659. Dipoena isthmia Chickering, 1943: 357, figs 40, 41. Localidade-tipo: Chilibre, Canal do Panamá. Levi (1963a): 179, figs 281-284.

Registros: Derrubadas, Santa Maria.

660. Dipoena mendonza Levi, 1967b: 34, figs 38-40. Localidadetipo: Mendoza, Argentina.

Registro: Palmares do Sul.

661. Dipoena niteroi Levi, 1963a: 166, figs 181, 182. Localidadetipo: Niterói, RJ, Brasil. Registro: Derrubadas.

662. Dipoena pallisteri Levi, 1963a: 180, figs 288-291. Localidade-tipo: Cuzco, Peru.

Registros: Barra do Ribeiro, Canoas, Derrubadas, Montenegro, Palmares do Sul, Tapes, Triunfo, Viamão.

663. Dipoena pumicata (Keyserling, 1886): 264, est. 21, fig. 312. Localidade-tipo: Blumenau, SC, Brasil. Levi (1963a): 170, figs 209-218.

Registros: Barra do Ribeiro, Cambará do Sul, Capão do Leão, Charqueadas, Derrubadas, Dom Feliciano, Eldorado do Sul, Encantado, Estrela Velha, Maquiné, Montenegro, Palmares do Sul, Pelotas, Porto Alegre, Santo Antônio da Patrulha, São Francisco de Paula, Tapes, Terra de Areia, Triunfo, Viamão.

664. Dipoena pusilla (Keyserling, 1886): 263, est. 21, fig. 311. Localidade-tipo: Blumenau, SC, Brasil. LeVI (1963a): 165, figs 160-162.

Registros: Cambará do Sul, Derrubadas, General Câmara, Maquiné.

665. Dipoena santacatarinae Levi, 1963a: 168, figs 194-198. Localidade-tipo: Nova Teutônia, SC, Brasil.

Registros: Cambará do Sul, Campo Bom, Derrubadas, Estrela Velha, Glorinha, Maquiné, Montenegro, Santa Maria, Santo Antônio da Patrulha, Terra de Areia, Três Coroas.

666. Dipoena taeniatipes Keyserling, 1891: 224, est. 9, figs 165. Localidade-tipo: RS, Brasil. LEVI (1963a): 154, 181, figs 87-89, 297, 298. Buckup \& Marques (1996): 52, figs 15, 16.

Registros: Barra do Ribeiro, Candelária, Canela, Derrubadas, Estrela Velha, General Câmara, Glorinha, Gravataí, Guaíba, Maquiné, Montenegro, Porto Alegre, Santa Maria, Santo Antônio da Patrulha, São Francisco de Paula, Tapes, Torres, Triunfo, Viamão.

667. Dipoena variabilis (KEYSERLING, 1886): 262, est. 21, fig. 310. Localidade-tipo: Blumenau, SC, Brasil. Levi (1963a): 167, figs 185,186 . LeVi (1963a): 176, figs. 248, 249. BuCKuP \& Marques (1996): 54, fig. 18.

Registros: Canela, Derrubadas, Estrela Velha, Farroupilha, General Câmara, Gravataí, Guaíba, Maquiné, Montenegro, Nonoai, Porto Alegre, Santa Maria, São Francisco de Paula, Tapes, Terra de Areia, Torres, Triunfo, Vacaria, Viamão.

668. Dipoenata morosa (BRyAnt, 1948): 376, figs 50, 52, 53. Localidade-tipo: San José de las Matas, República Dominicana. LeVI (1963a): 153, figs 84-86.

Registros: Barra do Ribeiro, Eldorado do Sul, Glorinha, Tapes, Triunfo, Vacaria, Viamão.

669. Echinotheridion cartum LEVI, 1963b: 236, figs 117-121. Localidade-tipo: Paraguai. Levi (1980a): 177. Ramírez \& GoNZÁLEZ (1999): 195, figs 1-7.

Registro: Triunfo.

670. Emertonella taczanowskii (KEYSERLING, 1886): 47, est. 12, fig. 160. Localidade-tipo: Tumbes, Peru. Levi (1963a): 132, fig. 10. Registros: Arroio do Meio, Barra do Ribeiro, Bom Jesus, Cambará do Sul, Canela, Canoas, Capivari do Sul, Caxias do Sul, Charqueadas, Derrubadas, Dom Feliciano, Eldorado do Sul, Encantado, Esmeralda, Estrela Velha, Farroupilha, General Câmara, Glorinha, Gravataí, Guaíba, Machadinho, Maquiné, Montenegro, Muçum, Nova Petrópolis, Novo Hamburgo, Osório, Palmares do Sul, Pelotas, Porto Alegre, Rio Grande, Roca Sales, Ronda Alta, Salto do Jacuí, Santa Maria, Santo Antônio da Patrulha, São Francisco de Paula, São Jerônimo, Tapes, Terra de Areia, Torres, Três Coroas, Triunfo, Vacaria, Viamão.

671. Episinus teresopolis LEVI, 1964b: 15, figs 24-26. Localidadetipo: Teresópolis, RJ, Brasil.

Registros: Canela, Maquiné, São Francisco de Paula.
672. Euryopis camis Levi, 1963a:132, figs 17-19. Localidadetipo: Nova Teutônia, SC, Brasil.

Registros: Barra do Ribeiro, Bom Jesus, Cachoeirinha, Cambará do Sul, Charqueadas, Derrubadas, Estrela Velha, Porto Alegre, Salto do Jacuí, Santa Maria, São Francisco de Paula, Tapes, Triunfo, Viamão.

673. Euryopis spinifera (Mello-Leitão, 1944): 324, fig. 4. Localidade-tipo: La Plata, Argentina. Levi (1963a): 133, fig. 20. GonZÁLEZ (1990): 47, figs 1-9.

Registros: Cachoeirinha, Derrubadas, Eldorado do Sul, São Francisco de Paula, Tramandaí.

674. Faiditus acuminatus (KeYSERLING, 1891): 207, est. 7, fig. 149. Localidade-tipo: Nova Friburgo, RJ, Brasil. ExLine \& Levi (1962): 157, figs 225-230. Registro: Derrubadas.

675. Faiditus affinis (O. P.-CAMBridge, 1880): 337, est. 30, fig. 16, Localidade-tipo: PR, Brasil. ExLINE \& Levi (1962): 199, figs 400-405

Registros: Machadinho, Maquiné, Triunfo.

676. Faiditus caudatus (TACZANowsKI, 1874): 62. Localidadetipo: Uaça, AP, Brasil. Exline \& Levi (1962): 176, figs 300-322. Registros: Porto Alegre, Triunfo.

677. Faiditus cristinae (GonzÁlez \& Castro, 1996): 132, figs 42, 43. Localidae-tipo: Torres, RS, Brasil. Registro: Torres.

678. Faiditus plaumanni (Exline \& LeVI, 1962): 159, figs 168, 169. Localidade-tipo: Nova Teutônia, SC, Brasil.

Registros: Charqueadas, Eldorado do Sul, General Câmara, Montenegro, Porto Alegre, Santo Antônio da Patrulha, Triunfo, Vacaria, Viamão.

679. Faiditus sicki (ExLINE \& Levi, 1962): 174, figs 295-299. Localidade-tipo: RJ, Brasil.

Registro: São Francisco de Paula.

680. Faiditus striatus (Keyserling, 1891): 213, est. 8, fig. 154. Localidade-tipo: ES, Brasil. ExLINE \& LeVI (1962): 201, figs 408, 409.

Registros: Salto do Jacuí, São Francisco de Paula, Triunfo.

681. Guaraniella bracata BAERT, 1984: 614, figs 28-37. Localidade-tipo: Itapua, San Benito, Paraguai. Registro: Santa Maria.

682. Guaraniella mahnerti BAERT, 1984: 610, figs 17-27. Localidade-tipo: Nova Teutônia, SC, Brasil.

Registros: Cachoeirinha, Derrubadas, Piratini, Porto Alegre, Santa Cruz do Sul, Santana do Livramento, Triunfo, Viamão.

683. Henziectypus rafaeli (Buckup \& MARQUES, 1991): 86, figs 15, 16. Localidade-tipo: Ilha de Maracá, RR, Brasil. Registro: Derrubadas.

684. Hetschkia gracilis Keyserling, 1886: 247, est. 20, fig. 299. Localidade-tipo: Blumenau, SC, Brasil. LEVI (1963e): 172, figs 7-13. Registros: Arroio do Meio, Arroio dos Ratos, Barra do Ribeiro, Barracão, Bom Jesus, Cambará do Sul, Campo Bom, Canela, Caxias do Sul, Derrubadas, Encantado, Estrela Velha, Farroupilha, Glorinha, Gravataí, Guaíba, Machadinho, Maquiné, Muçum, Osório, Passo Fundo, Pelotas, Porto Alegre, Santa Cruz do Sul, Santa Maria, Santo Antônio da Patrulha, São Francisco de Paula, São Leopoldo, Tapes, Tenente Portela, Terra de Areia, Torres, Três Coroas, Viamão.

685. Kochiura decolorata (KeySERLING, 1886): 234, est. 20, fig. 289. Localidade-tipo: Blumenau, SC, Brasil. Buckup \& MARQuEs (1996): 47, figs 3, 4, 10 .

Registros: Bom Jesus, Cambará do Sul, Canela, Caxias do Sul, Rio Pardo, São Francisco de Paula, São Valentim.

686. Kochiura olaup (Levi, 1963d): 580, fig. 236. Localidadetipo: SP, Brasil. BucKup et al. (2011): 351, figs 12, 13. Registros: Cambará do Sul, Rio Grande, Triunfo, Viamão.

687. Latrodectus geometricus C. L. Косн, 1841: 117, est. 284, fig. 684. Localidade-tipo: Colômbia. Levi (1959a): 21, figs 810, 25-28, 37, 39-50, 80-83.

Registros: Canela, Porto Alegre, Santa Maria, Santa Rosa, Santo Ângelo, Taquara, Terra de Areia, Torres.

688. Neospintharus rioensis (ExLINE \& LEVI, 1962): 125, figs 61-65. Localidade-tipo: Teresópolis, RJ, Brasil.

Registros: Barra do Ribeiro, Cambará do Sul, Eldorado do Sul, Montenegro, Passo Fundo, Porto Alegre, Rio Grande, São Francisco de Paula, Triunfo. 
689. Nesticodes rufipes (Lucas, 1846): 263, est. 16, fig. 5. Localidade-tipo: Oran, Algéria. Levi (1967a): 179, figs 24-27. Registros: Butiá, Cidreira, Guaíba, Imbé, Lajeado, Maquiné, Minas do Leão, Nova Tramandaí, Pelotas, Porto Alegre, Rio Grande, Santa Maria, São João do Polêsine, São Pedro do Sul, Tramandaí, Viamão, Xangri-lá.

690. Parasteatoda tepidariorum (C. L. Косн, 1841): 75, figs 646-648. Localidade-tipo: Bavaria, Alemanha. Levi (1955): 32 , figs $69,70,83,84$.

Registros: Bagé, Butiá, Cambará do Sul, Canela, Capão da Canoa, Caxias do Sul, Cidreira, Cruz Alta, Derrubadas, Dois Irmãos, Encruzilhada do Sul, Esteio, Garibaldi, Gramado, Guaíba, Lajeado, Machadinho, Minas do Leão, Montenegro, Novo Hamburgo, Pelotas, Porto Alegre, Rio Grande, Rio Pardo, Salto do Jacuí, Santa Maria, Santa Vitória do Palmar, Santo Ângelo, São Francisco de Paula, Tapes, Triunfo, Viamão.

691. Parasteatoda tesselata (Keyserling, 1884a): 48, est. 2, fig. 27. Localidade-tipo: Nancho, Peru. Levi (1967a): 179, figs 15-19. Registros: Barra do Ribeiro, Barracão, Butiá, Cachoeira do Sul, Candelária, Canela, Canoas, Capivari do Sul, Derrubadas, Eldorado do Sul, Esmeralda, Estrela Velha, General Câmara, Gravataí, Guaíba, Iraí, Lajeado, Machadinho, Maquiné, Marcelino Ramos, Mata, Montenegro, Nova Petrópolis, Osório, Palmares do Sul, Pelotas, Pinhal Grande, Porto Alegre, Quaraí, Rio Grande, Santa Maria, Santo Antônio da Patrulha, São Borja, São Jerônimo, São Leopoldo, São Pedro do Sul, São Sepé, São Valentim, Tapes, Torres, Triunfo, Viamão.

692. Paratheridula perniciosa (Keyserling, 1886): 233, est. 20, fig. 288. Localidade-tipo: Blumenau, SC, Brasil. Levi (1967a): 176 , figs $1-4$. Registro: Canela.

693. Phoroncidia moyobamba Levi, 1964d: 70, figs 1-5. Localidade-tipo: Moyobamba, San Martín, Peru. Buckup \& Marques (1989): 125, figs 4-11. Registro: Derrubadas.

694. Phoroncidia piratini Rodrigues \& Marques, 2010: 248, figs 1-9. Localidade-tipo: Arroio Grande, RS, Brasil. Registros: Arroio Grande, Barra do Ribeiro, Cambará do Sul, Pelotas, Porto Alegre, Rio Grande, Santa Maria, São Francisco de Paula, Viamão.

695. Phoroncidia reimoseri Levi, 1964d: 83, figs 77-81. Localidade-tipo: RS, Brasil. Rodrigues \& MARQues (2010): 250 , figs 10-15.

Registros: Arroio do Meio, Campo Bom, Canela, Caxias do Sul, Cristal, Derrubadas, Estrela Velha, Iraí, Maquiné, Montenegro, Nonoai, Novo Hamburgo, Parobé, Porto Alegre, Salto do Jacuí, Santa Maria, São Francisco de Paula, São Leopoldo, Tenente Portela, Torres, Triunfo, Viamão.

696. Phycosoma altum (Keyserling, 1886): 45, est. 12, fig. 159. Localidade-tipo: Montaña de Nancho, Peru. Levi (1963a): 159 , figs $138,139$.

Registros: Arroio dos Ratos, Barra do Ribeiro, Butiá, Cambará do Sul, Campo Bom, Candelária, Canela, Canoas, Caxias do Sul, Charqueadas, Derrubadas, Dom Feliciano, Eldorado do Sul, Estrela Velha, General Câmara, Gravataí, Guaíba, Maquiné, Montenegro, Novo Hamburgo, Palmares do Sul, Porto Alegre, Quaraí, Santa Maria, Santo Antônio da Patrulha, São Francisco de Paula, São Leopoldo, Tapes, Terra de Areia, Triunfo, Viamão.

697. Platnickina mneon (Bösemberg \& STrand, 1906): 142, est. 12, fig. 286. Localidade-tipo: Kompira, Saga, Japão. Levi (1967a): 181, figs 20-23.

Registros: Guaíba, Nova Petrópolis, Pelotas, Porto Alegre, Santa Maria, São Sepé, Torres, Triunfo.

698. Rhomphaea altissima Mello-Leitão, 1940b: 249 Localidade-tipo: Rio Negro, PR, Brasil. Levi (1967b): 32, figs 35-37.

Registros: Derrubadas, Santo Antônio da Patrulha.

699. Rhomphaea brasiliensis Mello-LeITão, 1920: 174, fig. nãonumerada. Localidade-tipo: Nova Teutônia, SC, Brasil. ExLINE \& Levi (1962): 110, figs 14, 15, 41-43. Registros: Canela, Derrubadas, Porto Alegre, Terra de Areia, Viamão.

700. Rhomphaea palmarensis (González \& CASTRo, 1996): 134, figs 53-55. Localidade-tipo: Entre Ríos, Argentina. Registro: Triunfo.
701. Rhomphaea projiciens O. P.-CAmbridge, 1896: 186, est. 23, figs 9, 10. Localidade-tipo: Teapa, Tabasco, México. ExLINE \& LeVI (1962): 106, figs 8-10, 29-31

Registros: Farroupilha, Montenegro, Santa Maria, Triunfo.

702. Spintharus gracilis Keyseruing, 1886: 244, est. 20, fig. 298 Localidade-tipo: Blumenau, SC, Brasil. Levi (1963c): 227, figs $10-13$.

Registros: Arroio dos Ratos, Cambará do Sul, Campo Bom, Canela, Encantado, Estrela Velha, Farroupilha, General Câmara, Glorinha, Gravataí, Maquiné, Montenegro, Muçum, Nonoai, Novo Hamburgo, Osório, Passo Fundo, Porto Alegre, Santa Cruz do Sul, Santa Maria, Santa Rosa, São Borja, São Francisco de Paula, São Jerônimo, São Leopoldo, Terra de Areia, Torres, Três Coroas, Triunfo, Vacaria, Viamão.

703. Steatoda ancorata (Holmberg, 1876): 13, fig. 16. Localidadetipo: Argentina. Levi (1962a): 34, figs 40-47.

Registros: Guaíba, Manoel Viana, Porto Alegre, Quaraí, Rio Grande.

704. Steatoda grossa (C. L. Косн, 1838): 112, fig. 321. Localidade-tipo: Grécia. Levi (1957b): 404, figs 74, 83-85. Registros: Canela, Erechim, Pelotas, Porto Alegre, Santa Vitória do Palmar.

705. Steatoda iheringi (Keyserling, 1886): 240, est. 20, fig. 295. Localidade-tipo: RS, Brasil. Levi (1962a): 31, figs 33-36. Registros: Arroio do Meio, Bom Jesus, Caçapava do Sul, Guaíba, Pelotas, Porto Alegre, Santa Vitória do Palmar, Xangri-lá.

706. Steatoda retorta GonZáLEZ, 1987: 179, figs 1-13. Localidadetipo: Buenos Aires, Argentina.

Registros: Arroio do Tigre, Bagé, Cambará do Sul, Canela, Canoas, Caxias do Sul, Esmeralda, Garibaldi, Guaíba, Montenegro, Passo Fundo, Porto Alegre, Santa Maria, Três Coroas, Três Passos, Triunfo, Xangri-lá

707. Steatoda triangulosa (WALCKENAER, 1802): 207. Localidadetipo: França. Levi (1967a): 185, figs 53-56. Registro: Alegrete.

708. Stemmops carius Marques \& Buckup, 1996: 70, figs 1-8. Localidade-tipo: Vacaria, RS, Brasil.

Registros: Cambará do Sul, São Francisco de Paula, Triunfo, Vacaria.

709. Styposis selis Levi, 1964c: 35, figs 4-9. Localidade-tipo: Nova Teutônia, SC, Brasil.

Registros: Barra do Ribeiro, Canela, Derrubadas, Eldorado do Sul, Estrela Velha, Maquiné, Palmares do Sul, Porto Alegre, São Francisco de Paula, Tapes,Triunfo, Viamão.

710. Tekellina guaiba Marques \& Buckup, 1993: 127, figs 5, 6. Localidade-tipo: Guaíba, RS, Brasil. Buckup \& Marques (1996): 61, fig. 26.

Registros: Estrela Velha, Guaíba, Porto Alegre, São Francisco de Paula, São Jerônimo, São Leopoldo, Triunfo,Vacaria.

711. Tekellina minor Marques \& BuCKup, 1993: 128, figs 7, 8 . Localidade-tipo: Rio Grande, RS, Brasil.

Registro: Rio Grande.

712. Theridion bergi Levi, 1963d: 581, figs 86, 87. Localidadetipo: Buenos Aires, Argentina. Xavier et al. (1995): 20, figs 2-8. Registros: Montenegro, Rio Grande, Santa Vitória do Palmar, Triunfo.

713. Theridion biezankoi LevI, 1963d: 573, fig. 213. Localidadetipo: Pelotas, RS, Brasil.

Registros: Barra do Ribeiro, Bom Jesus, Canela, Maquiné, Osório, Pelotas, São Francisco de Paula, Tapes, Torres, Viamão.

714. Theridion bisignatus (Mello-LeItão, 1945): 234, fig. 9. Localidade-tipo: Puerto Vitoria, Misiones, Argentina. BuCKuP et al. (2011): 352, figs 14-16.

Registros: Charqueadas, Porto Alegre, Santa Maria, Triunfo.

715. Theridion calcynatum Holmberg, 1876: 14. Localidadetipo: Argentina. Levi (1963d): 548, figs 100-107.

Registros: Arroio do Meio, Arroio Grande, Barra do Ribeiro, Bom Jesus, Butiá, Cambará do Sul, Candelária, Canela, Carazinho, Caxias do Sul, Charqueadas, Derrubadas, Eldorado do Sul, Esmeralda, Estrela Velha, Glorinha, Guaíba, Júlio de Castilhos, Machadinho, Marcelino Ramos, Montenegro, Morro Reuter, Nonoai, Nova Petrópolis, Palmares do Sul, Pelotas, Porto Alegre, Rio Grande, Rio Pardo, Salto do Jacuí, Santa Maria, Santa Rosa, Santa Vitória do Palmar, São Francisco de Paula, São Leopoldo, São Pedro do Sul, Sobradinho, Tapes, Tavares, Triunfo, Vacaria, Viamão. 
716. Theridion eremum LeVI, 1963d: 548, figs 98, 99. Localidadetipo: Nova Teutônia, SC, Brasil.

Registros: Canela, Derrubadas, Eldorado do Sul, Passo Fundo, São Francisco de Paula.

717. Theridion filum LEVI, 1963d: 525, figs 1, 2. Localidadetipo: Nova Teutônia, SC, Brasil. Levi (1963d): 528, figs 17, 18. Registros: Arroio do Meio, Canela, Derrubadas, Encantado, Estrela Velha, Farroupilha, General Câmara, Iraí, Santa Maria, Santo Antônio da Patrulha, São Borja, São Francisco de Paula, Sertão Santana, Tapes, Triunfo.

718. Theridion opolon Levi, 1963d: 575, figs 225, 258, 259. Localidade-tipo: Teresópolis, RJ, Brasil.

Registros: Barra do Ribeiro, Canela, Derrubadas, Estrela Velha, Maquiné, São Francisco de Paula, Terra de Areia, Triunfo, Viamão.

719. Theridion orgea (LeVI, 1967b): 23, figs 5, 6. Localidadetipo: Serra dos Órgãos, RJ, Brasil. Buckup \& MARques (1996): 56, figs 21, 22, 27, 28 .

Registros: Canoas, Maquiné, Machadinho, Passo Fundo, Torres, Triunfo.

720. Theridion pernambucum Levi, 1963d: 532, figs 30-33. Localidade-tipo: Recife, PE, Brasil.

Registros: Cambará do Sul, Guaíba, Montenegro, Porto Alegre.

721. Theridion plaumanni Levi, 1963d: 583, figs 244-248. Localidade-tipo: Nova Teutônia, SC, Brasil.

Registros: Arroio dos Ratos, Bagé, Barra do Ribeiro, Bom Jesus, Cambará do Sul, Campo Bom, Canela, Canoas, Caxias do Sul, Charqueadas, Derrubadas, Eldorado do Sul, Encantado, Estrela Velha, Farroupilha, General Câmara, Glorinha, Gravataí, Guaíba, Maquiné, Montenegro, Novo Hamburgo, Osório, Palmares do Sul, Passo Fundo, Pelotas, Porto Alegre, Quaraí, Rio Pardo, Santa Cruz do Sul, Santa Maria, Santo Antônio da Patrulha, São Francisco de Paula, São Leopoldo, São Sepé, São Valentim, Tapes, Tenente Portela, Terra de Areia, Torres, Triunfo, Vacaria, Viamão.

722. Theridion positivum Chamberlin, 1924: 636, fig. 75 . Localidade-tipo: Pond Island, Golfo da Califórnia, EUA. Levi (1963d): 565, figs 177, 178 .

Registros: Arroio dos Ratos, Bagé, Barra do Ribeiro, Butiá, Caçapava do Sul, Cachoeira do Sul, Canela, Caxias do Sul, Charqueadas, Derrubadas, Dom Feliciano, Dona Francisca, Eldorado do Sul, Encantado, Estrela Velha, General Câmara, Glorinha, Gravataí, Guaíba, Machadinho, Maquiné, Montenegro, Novo Hamburgo, Palmares do Sul, Pelotas, Porto Alegre, Quaraí, Rio Grande, Rio Pardo, Santa Maria, Santa Vitória do Palmar, Santana da Boa Vista, Santo Antônio da Patrulha, São Francisco de Paula, São Jerônimo, São Pedro do Sul, São Sepé, São Valentim, Sobradinho, Tapes, Terra de Areia, Triunfo, Viamão.

723. Theridion quadripartitum KeYSERLING, 1891: 182, est. 6, fig. 127. Localidade-tipo: Botucatu, SP, Brasil. Levi (1963d): 208, figs. 30-33.

Registros: Cambará do Sul, Canela, Caxias do Sul, Derrubadas, Espumoso, Estrela Velha, Farroupilha, Gravataí, Porto Alegre, Rio Pardo, Salto do Jacuí, Santa Maria, São Francisco de Paula, Tapes, Vacaria.

724. Theridion striatum Keyserling, 1884a: 95, est. 5, fig. 62 . Localidade-tipo: RJ, Brasil. Levi (1963d): 527, figs 6-9. Registros: Barra do Ribeiro, Guaíba, Machadinho, Montenegro, Porto Alegre, Santa Maria, São Pedro do Sul, Sobradinho, Triunfo, Vacaria, Viamão.

725. Theridion teresae Levi, 1963d: 560, figs 147, 148. Localidade-tipo: Santa Teresa, ES, Brasil. Levi (1963d): 572, fig. 210.

Registros: Barra do Ribeiro, Canela, Charqueadas, Glorinha, Gravataí, Guaíba, Maquiné, Montenegro, Novo Hamburgo, Porto Alegre, Santo Antônio da Patrulha, Tapes, Terra de Areia, Torres, Triunfo, Viamão.

726. Theridion tinctorium KeYSERLING, 1891: 185, est. 6, fig. 130. Localidade-tipo: RS, Brasil. Levi (1963d): 531, fig. 24. Theridion querulum KeYSERLING, 1891: 186, est. 6, fig. 131, localidade-tipo: RS, Brasil. Buckup \& Marques (1996): 58, fig. 30.

Registros: Agudo, Arroio do Meio, Bagé, Bom Jesus, Butiá, Cambará do Sul, Canela, Canoas, Caxias do Sul, Charqueadas, Estrela Velha, Gravataí, Guaíba, Machadinho, Montenegro, Pelotas, Porto Alegre, Quaraí, Rio Grande, Rio Pardo, Santa Maria, Santa Vitória do Palmar, Santana da Boa Vista, São
Francisco de Paula, São Jerônimo, São Sepé, Sertão Santana, Tapes, Taquara, Triunfo, Vacaria, Viamão.

727. Theridula gonygaster (Simon, 1873): 108, est. 2, fig. 24. Localidade-tipo: Córsega, Itália. Levi (1954): 340, figs 18-22. Registros: Canoas, Eldorado do Sul, Gravataí, Guaíba, Montenegro, Porto Alegre, Santa Maria, São Sepé, Sapiranga, Triunfo.

728. Theridula puebla Levi, 1954: 338, figs 23-25. Localidadetipo: Puebla, México. Registro: Derrubadas.

729. Thwaitesia affinis O. P.-CAMbridge, 1882: 431, est. 31, fig. 8. Localidade-tipo: AM, Brasil. LEVI (1963c): 231, figs 14-19. Registros: Agudo, Arroio do Tigre, Arroio Grande, Bom Jesus, Cambará do Sul, Campo Bom, Canela, Carazinho, Carlos Barbosa, Caxias do Sul, Derrubadas, Dom Feliciano, Eldorado do Sul, Esmeralda, Estrela Velha, Farroupilha, Glorinha, Gravataí, Guaíba, Iraí, Machadinho, Maquiné, Montenegro, Muçum, Nonoai, Novo Hamburgo, Passo Fundo, Pelotas, Porto Alegre, Rio Grande, Rio Pardo, Ronda Alta, Salto do Jacuí, São Borja, São Francisco de Paula, São Sepé, Sobradinho, Tenente Portela, Torres, Vacaria, Viamão.

730. Thymoites anicus Levi, 1964a: 458, figs 17-21. Localidadetipo: SP, Brasil.

Registros: Derrubadas, São Francisco de Paula.

731. Thymoites ebus LeVI, 1964a: 464, figs 46-49. Localidadetipo: Nova Teutônia, SC, Brasil.

Registro: Sobradinho.

732. Thymoites melloleitaoni (BRISTOWE, 1938): 72, figs 8-13. Localidade-tipo: SC, Brasil. Levi (1964a): 461, figs 35, 36. Registro: São Francisco de Paula.

733. Thymoites promatensis LISE \& SiLva, 2009: 131, figs 2-23. Localidade-tipo: São Francisco de Paula, RS, Brasil.

Registros: Porto Alegre, São Francisco de Paula, Tapes, Viamão.

734. Thymoites villaricaensis LeVI, 1964a: 462, figs 39-42. Localidade-tipo: Villarrica, Guaíra, Paraguai.

Registros: Cambará do Sul, Faxinal do Soturno, Santa Maria.

735. Tidarren haemorrhoidale (BERTKAU, 1880): 78. Localidadetipo: RJ, Brasil. Levi (1957a): 73, figs 49-57, 61-64. Registros: Arroio Grande, Canela, Derrubadas, Maquiné, Marcelino Ramos, Palmares do Sul, Porto Alegre, Santa Maria, Tapes, Torres, Triunfo.

736. Wamba congener O. P.-Cambridge, 1896: 191, est. 24, fig. 1. Localidade-tipo: Chicoyoito, Guatemala. Levi (1963d): 563, figs 161-165.

Registros: Canela, Estrela Velha, Gravataí, Machadinho, Pelotas, Santa Maria, Santo Antônio da Patrulha, São Francisco de Paula, Tapes, Terra de Areia.

737. Wamba crispulus (Simon, 1895b): 142. Localidade-tipo: La Guaíra, Venezuela. Levi (1963d): 564, figs 166-172. Registros: Arroio do Tigre, Arroio Grande, Barra do Ribeiro, Bom Jesus, Butiá, Cambará do Sul, Candelária, Canela, Canoas, Capivari do Sul, Caxias do Sul, Charqueadas, Derrubadas, Dom Feliciano, Eldorado do Sul, Estrela Velha, Farroupilha, Glorinha, Gravataí, Guaíba, Júlio de Castilhos, Maquiné, Montenegro, Novo Hamburgo, Osório, Palmares do Sul, Pelotas, Porto Alegre, Quaraí, Rio Grande, Salto do Jacuí, Santa Cruz do Sul, Santa Maria, Santo Antônio da Patrulha, São Francisco de Paula, São Jerônimo, São Pedro do Sul, São Sepé, Tapes, Terra de Areia, Triunfo, Vacaria, Viamão.

738. Wirada araucaria Lise, Silva \& Bertoncello, 2009: 188, figs 25-42. Localidade-tipo: São Francisco de Paula, RS, Brasil. Registro: São Francisco de Paula.

739. Wirada sigillata Lise, Silva \& Bertoncello, 2009: 183, figs 1-24. Localidade-tipo: São Francisco de Paula, RS, Brasil. Registro: São Francisco de Paula.

\section{THERIDIOSOMATIDAE}

740. Epilineutes globosus (O. P.-CAMbridge, 1896): 192, est. 24, figs 5, 6. Localidade-tipo: Tabasco, México. Coddington (1986): 79, figs 169-178, 188-195. Registros: Canela, Maquiné, São Francisco de Paula.

741. Naatlo serrana Rodrigues \& Lise, 2008: 299, figs 1-27. Localidade-tipo: São Francisco de Paula, RS, Brasil. Registro: São Francisco de Paula.

742. Naatlo splendida (TACZANowsKi, 1879): 60. Localidade-tipo: provável Rio Uaçá, AP, Brasil. Coddington (1986): 47, figs 73, 84-90. Registro: Derrubadas. 
743. Theridiosoma caaguara RodRIGUes \& OTT, 2005b: 441, figs 1-6. Localidade-tipo: São Francisco de Paula, RS, Brasil. Registro: São Francisco de Paula.

744. Theridiosoma chiripa Rodrigues \& OTt, 2005a: 79, figs 1-12. Localidade-tipo: Capão do Leão, RS, Brasil.

Registros: Cambará do Sul, Capão do Leão, Charqueadas, São Francisco de Paula, Triunfo.

745. Theridiosoma obscurum (KeYSERLING, 1886): 133, est. 15, fig. 211. Localidade-tipo: Rio Grande, RS, Brasil.

Registro: Rio Grande.

\section{THOMISIDAE}

746. Acentroscelus ramboi Mello-Leitão, 1943a: 201, fig. 30. Localidade-tipo: RS, Brasil.

Registros: Bom Jesus, Campo Bom, General Câmara, Guaíba, Novo Hamburgo, São Leopoldo.

747. Aphantochilus inermipes Simon in Mello-Leitão, 1929b: 13. Localidade-tipo: Santarém, PA, Brasil.

Registro: Derrubadas.

748. Aphantochilus rogersi O. P.-Cambridge, 1870: 744, est. 44, fig. 10. Localidade-tipo: Brasil. Registro: Tenente Portela.

749. Deltoclita rubra Mello-Leitão, 1943a: 203, fig. 32. Localidade-tipo: RS, Brasil. Registro: Só a localidade-tipo.

750. Epicadus heterogaster (GuérIn, 1829): 6, est. 1, fig. 4. Localidade-tipo: América Tropical. Registro: Maquiné.

751. Misumenoides corticatus Mello-Leitão, 1929b: 217, fig. 110. Localidade-tipo: SP, Brasil.

Registros: Cachoeirinha, Cambará do Sul, Derrubadas, Restinga Seca, Rio Grande, Santa Vitória do Palmar.

752. Misumenoides nigripes Mello-Leitão, 1929b: 216. Localidade-tipo: PA, Brasil. Registro: Alvorada.

753. Misumenoides nigromaculatus (KEYSERLING, 1880): 119 est. 2, fig. 66. Localidade-tipo: Porto Alegre, RS, Brasil Registro: Porto Alegre.

754. Misumenops bivittatus (KeYSERLING, 1880): 99, est. 2, fig. 54. Localidade-tipo: Uruguai Registro: Viamão.

755. Misumenops maculissparsus KeyserLing, 1891: 245, est. 10, fig. 180. Localidade-tipo: Taquara, RS, Brasil. LeHTINEN \& MARUSIK (2008): 177, figs 1-4, 18-21, 29, 32 Registros: Rio Grande, Taquara.

756. Misumenops pallens (KeyserLing, 1880): 96, est. 2, fig. 52. Localidade-tipo: Taquara, RS, Brasil.

Registros: Bagé, Butiá, Cachoeirinha, Cambará do Sul, Campo Bom, Canela, Canoas, Capão da Canoa, Caxias do Sul, Derrubadas, Encantado, General Câmara, Gravataí, Guaíba, Montenegro, Muçum, Novo Hamburgo, Palmares do Sul, Pelotas, Porto Alegre, Restinga Seca, Rio Grande, Rio Pardo, Santa Cruz do Sul, Santa Maria, São Borja, São Francisco de Paula, São Leopoldo, São Lourenço do Sul, São Sepé, Sapiranga, Tapes, Taquara, Torres, Três Coroas, Triunfo, Vacaria, Viamão.

757. Misumenops pallidus (KeYSERLING, 1880): 117, est. 2, fig. 65. Localidade-tipo: Taquara, RS, Brasil. LeHTINEN \& MARUSIK (2008): 178, figs 5-13, 22-25, 30, 33 .

Registros: Alvorada, Arroio do Tigre, Bagé, Butiá, Cachoeira do Sul, Cachoeirinha, Cambará do Sul, Campo Bom, Canela, Canoas, Caxias do Sul, Charqueadas, Derrubadas, Eldorado do Sul, Encantado, General Câmara, Gravataí, Guaíba, Maquiné, Marau, Montenegro, Muçum, Novo Hamburgo, Palmares do Sul, Passo Fundo, Pedro Osório, Pelotas, Porto Alegre, Restinga Seca, Rio Grande, Rio Pardo, Santa Cruz do Sul, Santa Maria, Santo Antônio da Patrulha, São Francisco de Paula, São Jerônimo, Tapes, Taquara, Tavares, Torres, Três Coroas, Triunfo, Vacaria, Viamão.

758. Onocolus echinatus (TaCZanowski, 1872): 97. Localidadetipo: Guiana Francesa. Lise (1981a): 20, figs 27-41. Registro: Taquara.

759. Onocolus echinicaudus MeLlo-LeItão, 1929b: 7. Localidadetipo: Paraguai. Lise (1981a): 28, figs 42-57. Registros: Cerro Largo, Santa Rosa, São Borja.

760. Onocolus garruchus Lise, 1979: 67, figs 1-15. Localidadetipo: Garruchos, RS, Brasil.

Registro: Garruchos.
761. Onocolus infelix Mello-Leitão, 1940b: 250. Localidadetipo: Rio Negro, PR, Brasil. Lise (1981a): 49, figs 85-99. Registros: Arroio do Tigre, Barra do Ribeiro, Campo Bom, Canela, Glorinha, Gravataí, Novo Hamburgo, Porto Alegre, São Pedro do Sul, Tapes, Terra de Areia, Triunfo, Viamão.

762. Onocolus intermedius (Mello-LeItão, 1929b): 79, fig. 41 Localidade-tipo: RJ, Brasil. Lise (1981a): 39, figs 64-78. Registros: Butiá, Campo Bom, Derrubadas, Farroupilha, Guaíba, Iraí, Itaúba, Montenegro, Novo Hamburgo, São Leopoldo, Terra de Areia, Triunfo, Viamão.

763. Runcinioides argenteus (Mello-Leitão, 1929b): 211, figs 23a-b. Localidade-tipo: Petrópolis, RJ, Brasil. Lehtinen \& Marusik (2008): 190, figs 50-53, 66, 67.

Registros: Barra do Ribeiro, Canela, Canoas, Caxias do Sul, Derrubadas, General Câmara, Iraí, Montenegro, Morro Reuter, Novo Hamburgo, Porto Alegre, Rio Grande, Santa Maria, São Francisco de Paula, Torres, Triunfo, Viamão.

764. Sidymella kolpogaster (Lise, 1973): 5, figs 5-9. Localidadetipo: Rio Negro, PR, Brasil. Lise (1981b): 134, figs 1-12. Registros: Arroio do Tigre, Farroupilha, Glorinha, Guaíba, Montenegro, Porto Alegre, Triunfo, Viamão.

765. Sidymella longispina (Mello-Leitão, 1943a): 208, fig. 35. Localidade-tipo: RS, Brasil. Lise (1973): 10, figs 19-23. Registros: Canela, Caxias do Sul, Derrubadas, Gravataí, Iraí, Muçum, São Borja, São Francisco de Paula.

766. Sidymella lucida (Keyserling, 1880): 190, est. 4, fig. 105. Localidade-tipo: Nova Granada, Colômbia. Sidyma cancellata Mello-Leitão (1943a): 208, fig. 34, localidade-tipo: RS, Brasil. Lise (1973): 6, figs 15-18.

Registros: Agudo, Cambará do Sul, Canela, Caxias do Sul, Derrubadas, Esmeralda, Gravataí, Montenegro, Muçum, Porto Alegre, Quaraí, Santa Cruz do Sul, Santa Maria, Santa Rosa, São Francisco de Paula, São Valentim, Três Coroas, Triunfo, Vacaria, Viamão.

767. Sidymella multispinulosa (Mello-Leitão, 1944): 4, nomen novum para Sidyma spinifera Mello-Leitão, 1943a, non S. spinifera Mello-LeItão, 1929b. Localidade-tipo: RS, Brasil. Lise (1973): 13, figs 24-33.

Registros: Arroio do Meio, Campo Bom, Canoas, Derrubadas, Estrela Velha, Farroupilha, Iraí, Maquiné, Montenegro, Nonoai, Porto Alegre, Santo Antônio da Patrulha, São Francisco de Paula, São Leopoldo, Tenente Portela, Triunfo, Viamão.

768. Strophius albofasciatus Mello-Leitão, 1929b: 34 Localidade-tipo: PE, Brasil.

Registros: Arroio do Tigre, Bagé, Barra do Ribeiro, Derrubadas, Dois Irmãos, Esmeralda, Farroupilha, Morro Reuter, Palmares do Sul, Passo Fundo, Quaraí, São Borja, São Francisco de Paula, Vacaria, Viamão

769. Synaemops notabilis Mello-LeITão, 1940b: 251. Localidadetipo: PR, Brasil. Registro: São Francisco de Paula.

770. Synaemops rubropunctatus Mello-Leitão, 1929b: 209, fig. 18 Localidade-tipo: RJ, Brasil.

Registros: Guaíba, Santa Rosa

771. Synema fasciatum Mello-Leitão, 1929b: 203. Localidadetipo: Bahia, Brasil. Registro: Passo Fundo.

772. Synema luteovittatum Keyserling, 1891: 247, est. 10, fig. 187 Localidade-tipo: Rio Grande, RS, Brasil Registro: Rio Grande.

773. Synstrophius blanci (Mello-LeITão, 1917b): 11. Localidadetipo: Nova Iguaçu, RJ, Brasil. Registros: Derrubadas, Santo Antônio da Patrulha

774. Titidius albifrons Mello-Leitão, 1929b: 187, figs 93, 94 Localidade-tipo: Teresópolis, RJ, Brasil. Registro: Cambará do Sul.

775. Titidius longicaudatus Mello-LeITão, 1943a: 210, figs 37, 38 Localidade-tipo: RS, Brasil Registro: Só a localidade-tipo

776. Tmarus albolineatus Keyserling, 1880: 159, est. 3, fig. 87. Localidade-tipo: Brasil Registros: Canela, Derrubadas, Torres.

777. Tmarus bifidipalpus Mello-Leitão, 1943a: 211. Localidadetipo: RS, Brasil.

Registro: Só a localidade-tipo. 
778. Tmarus borgmeyeri Mello-Leitão, 1929a: 146, fig. 8. Localidade-tipo: Teresópolis, RJ, Brasil.

Registro: Canela.

779. Tmarus caeruleus Keyserling, 1880: 148, est. 3, fig. 80. Localidade-tipo: PA, Brasil.

Registros: Arroio do Tigre, Montenegro, Porto Alegre, Rio Pardo, Tenente Portela, Triunfo.

780. Tmarus clavipes Keyserling, 1891: 250, est. 10, fig. 189. Localidade-tipo: Taquara, RS, Brasil.

Registros: Taquara, Vacaria.

781. Tmarus elongatus Mello-Leitão, 1929b: 157, figs 67-69. Localidade-tipo: Tijuca, RJ, Brasil. Registro: Torres.

782. Tmarus formosus Mello-Leitão, 1917b: 120, fig. 1. Localidade-tipo: Pinheiral, RJ, Brasil. Registro: Canela.

783. Tmarus planifrons Mello-Leitão, 1943a: 212, fig. 39. Localidade-tipo: RS, Brasil.

Registro: Montenegro.

784. Tmarus polyandrus Mello-Leitão, 1929b: 155, figs 10 , 11. Localidade-tipo: Petrópolis, RJ, Brasil.

Registros: Cachoeira do Sul, Canela, São Valentim, Triunfo, Vacaria, Viamão.

785. Tmarus prognathus Simon in Mello-Leitão (1929b): 156, fig. 66. Localidade-tipo: AM, Brasil.

Registros: Canela, Charqueadas, Derrubadas, Montenegro, Porto Alegre, São Borja, Tenente Portela, Torres, Triunfo.

786. Tmarus pugnax Mello-Leitão, 1929b: 171, fig. 15. Localidade-tipo: RS, Brasil.

Registros: Caxias do Sul, Montenegro, São Borja, Vacaria.

787. Tmarus striolatus Mello-Leitão, 1943a: 214, fig. 40. Localidade-tipo: RS, Brasil.

Registros: Montenegro, Osório, Rio Grande, Triunfo, Viamão.

788. Tmarus variatus Keyserling, 1891: 248, est. 10, fig. 188 Localidade-tipo: Taquara, RS, Brasil. Registros: Porto Alegre, Taquara, Viamão.

789. Uraarachne longa KeyserLing, 1880: 130, est. 22, fig. 71. Localidade-tipo: Porto Alegre, RS, Brasil. RinAldi (1988): 27, figs 11-13.

Registros: Passo Fundo, Porto Alegre, Taquara.

\section{TITANOECIDAE}

790. Goeldia luteipes (Keyserling, 1891): 156, est. 4, fig. 108. Localidade-tipo: Rio Grande, RS, Brasil.

Registros: Porto Alegre, Rio Grande.

\section{TRECHALEIDAE}

791. Dossenus marginatus Simon, 1898: 19. Localidade-tipo: São Paulo de Olivença, AM, Brasil. Silva et al. (2007): 141, figs 1-18, 21-30. Registro: São Francisco de Paula.

792. Paradossenus longipes (TACZANOWski, 1874): 88. Localidadetipo: Cayena, Guiana Francesa. Brescovit et al. (2000): 14, figs 9, 10, 18-22.

Registros: Eldorado do Sul, Estrela Velha, Júlio de Castilhos, Pinhal Grande, Porto Alegre, São Leopoldo, Sapiranga, Terra de Areia, Triunfo.

793. Paratrechalea azul CARICo, 2005: 809, figs 28, 29. Localidade-tipo: Caxias do Sul, RS, Brasil. Silva et al. (2006): 72, figs 7-9, 13-18, 21, 25-36.

Registros: Bossoroca, Cambará do Sul, Canela, Caxias do Sul, Derrubadas, Maquiné, Riozinho, Santa Maria, São Francisco de Paula, Terra de Areia.

794. Paratrechalea galianoae CARICo, 2005: 808, figs 16, 26, 27. Localidade-tipo: General Belgrano, Misiones, Argentina. Silva et al. (2006): 73, figs 10-12, 14, 23, 24.

Registros: Arroio dos Ratos, Cambará do Sul, Campestre da Serra, Canela, Maquiné, São Francisco de Paula, Vacaria.

795. Paratrechalea longigaster CARICO, 2005: 808, figs 15, 24, 25. Localidade-tipo: Santa Maria, Misiones, Argentina. Registro: Bom Jesus.

796. Paratrechalea ornata (Mello-Leitão, 1943b): 107, fig. 7. Localidade-tipo: Bosque Alegre, Córdoba, Argentina. Silva et al. (2006): 75 .

Registros: Arroio dos Ratos, Barracão, Campo Bom, Canela, Caxias do Sul, Dois Irmãos, Jacutinga, Maquiné, Mata, Muçum,
Rolante, São Francisco de Paula, Sapiranga, Terra de Areia, Três Forquilhas, Vacaria.

797. Trechalea boliviensis CARICO, 1993: 252, figs 23, 33, 40 , 65-68. Localidade-tipo: Beni, Bolivia.

Registro: Derrubadas.

798. Trechalea bucculenta (Simon, 1898): 20. Localidade-tipo: Teresópolis, RJ, Brasil. Trechalea cezariana Mello-Leitão, 1931: 12, fig. 2, localidade-tipo: Taquara, RS, Brasil. CARICO (1993): 240, figs 16, 26, 35-38.

Registros: Arroio do Tigre, Estrela Velha, Pinhal Grande, Porto Alegre, Salto do Jacuí, Santa Maria, Taquara, Terra de Areia.

799. Trechaleoides biocellata (Mello-Leitão, 1926): 3. Localidade-tipo: SC e RJ, Brasil. CARICO (2005): 802, figs 3, 8-12. Registros: Arroio do Meio, Arroio do Tigre, Garruchos, Marcelino Ramos, Viamão.

800. Trechaleoides keyserlingi (F. O. P.-CAMBridge, 1903): 163, est. 15, figs 1, 2. Localidade-tipo: RS, Brasil. CARICO (2005): 800 , figs $3-7$.

Registros: São Jerônimo, São Leopoldo.

\section{TROCANTHERIIDAE}

801. Trochantheria ranuncula KARSCH, 1878: 817. Localidade-tipo: Santa Cruz do Sul, RS, Brasil. Platnick (1986): 30, figs 10-11.

Registro: Só a localidade-tipo.

\section{ULOBORIDAE}

802. Miagrammopes brasiliensis RoEwER, 1951: 454, nomen novum para M. albomaculatus Mello-LeITÃo, 1943a: 156, fig. 2. Localidade-tipo: RS, Brasil.

Registro: Só a localidade-tipo.

803. Philoponella fasciata (Mello-Leitão, 1917b): 4. Localidadetipo: Nova Iguaçu, RJ, Brasil. Opell (1979): 542, figs 272-281. Registro: Derrubadas.

804. Uloborus trilineatus Keyserling, 1882: 214, est. 15, fig. 13 Localidade-tipo: Lechugal, Peru. Uloborus bucki Mello-Leitão, 1943a: 157, fig. 3, localidade-tipo: Porto Alegre, RS, Brasil. Registros: Porto Alegre, Triunfo.

\section{ZODARIIDAE}

805. Cybaeodamus meridionalis LiSe, OTT \& RoDRIgUeS, 2009: 260, figs 1-20. Localidade-tipo: Xangri-lá, RS, Brasil. Registros: Canoas, Porto Alegre, Viamão, Xangri-lá.

806. Cybaeodamus taim Lise, OTt \& Rodrigues, 2009: 261, figs 21-36. Localidade-tipo: Rio Grande, RS, Brasil. Registros: Barra do Ribeiro, Rio Grande, Viamão.

807. Tenedos procreator JocQué \& BAERT, 2002: 114, figs 32a-e. Localidade-tipo: Pinhão, PR, Brasil.

Registro: São Francisco de Paula.

\section{ZORIDAE}

808. Odo serrimanus Mello-Leitão, 1936: 29, fig. 57. Localidadetipo: RS, Brasil. Mello-Leitão (1943a): 197, fig. 26. Localidadetipo: Porto Alegre, RS, Brasil.

Registro: Porto Alegre.

Agradecimentos. Para Arno A. Lise (PUCRS), Antônio D Brescovit (IBSP) e Adalberto J. Santos (UFMG) pela leitura crítica do manuscrito. Aos ex-bolsistas, ex-estágiários, ex-estudantes de pós-graduação e todos aqueles que de alguma maneira contribuíram na ampliação do acervo de aranhas do MCN. A Rafael Araújo pelo processamento dos dados dessa coleção em Programa Excel.

\section{REFERÊNCIAS BIBLIOGRÁFICAS}

Agnarsson, I. 2005. Revision and phylogenetic analysis of American ethicus and rupununi groups of Anelosimus (Araneae, Theridiidae). Zoologica Scripta 34:389-413.

2006. A revision of the New World eximius lineage of Anelosimus (Araneae, Theridiidae) and a phylogenetic analysis using worldwide exemplars. Zoological Journal of the Linnean Society 146:453-593.

Archer, A. F. 1958. Studies in the orbweaving spiders (Argiopidae) 4. American Museum Novitates 1922:1-21.

Audouin, J. V. 1826. Explication sommaire des planches d'arachnides de l'Egypte et de la Syrie, publiées par Jules- 
Cesar Savigny. In: Description de l'Égypte. Paris, Histoire Naturelle, Zoologie. v.22, p.291-430.

Ausserer, A. 1875. Zweiter Beitrag zur Kenntniss der Arachniden-Familie der Territelariae Thorell (Mygalidae Autor). Verhandlungen der Kaiserlichen-Königlichen Zoologisch-botanischen Gesellschaft in Wien 25:125-206.

BAERT, L. 1984. Mysmenidae and Hadrotarsinae from the Neotropical Guaraní Province (Paraguai and South Brazil) (Araneae). Revue Suisse de Zoologie 91(3):603-616.

1987. The genus Brattia Simon, 1894 in South America (Araneae, Linyphiidae). Bulletin et Annales de la Société Royale Entomologique de Belgique 123:261-265.

BAnks, N. 1900. Some new North American spiders. The Canadian Entomologist 32:96-102.

Beatty, J. A. 1970. The spider genus Ariadna in the Americas (Araneae, Dysderidae). Bulletin of the Museum of Comparative Zoology 139:433-517.

Beatty, J. A.; Berry, J. W. \& Huber, B. A. 2008. The pholcid spiders of Micronesia and Polynesia (Araneae, Pholcidae). The Journal of Arachnology 36:1-25.

Bertani, R. 2001. Revision, cladistic analysis, and zoogeography of Vitalius, Nhandu, and Proshapalopus; with notes on other theraphosine genera (Araneae, Theraphosidae). Arquivos de Zoologia 36:265-356.

BertKau, P. 1880. Verzeichniss der von Prof. Ed. van Beneden auf seiner im Auftrage der belgischen Regierung unternommen wissenschaftlichen reise nach Brasilien und La Plata im Jahren 1872-73 gesammelten Arachniden. Mémoires couronnés et mémoires des savants étrangers, publiés par l'Académie Royale des Sciences, des Lettres et des Beaux-arts de Belgique 43(2):1-120.

Birabén, M. 1953. Neoxyphinus nuevo género de arañas de la familia Oonopidae. Physis 20(5):453-458.

Bishop, S. C. \& Crosby, C. R. 1938. Studies in American spiders: miscellaneous genera of Erigoneae, part II. Journal of New York Entomological Society 46:55-107.

BlackWall, J. 1858. Descriptions of six newly discovered species and characters of new genus of Araneidea. The Annals and Magazine of Natural History 1(3):426-434.

1859. Descriptions of newly discovered spiders captured by James Yate Johnson Esq., in the Island of Madeira. The Annals and Magazine of Natural History 4(3):255-267. 1863. Description of newly discovered spiders captured in Rio de Janeiro by John Gray and the Rev. Hamlet Clark. The Annals and Magazine of Natural History, Series 3, 11:29-45.

Bonaldo, A. B. 1994. A subfamília Eutichurinae na Região Neotropical, com a revisão do gênero Eutichurus Simon, 1896 (Araneae, Miturgidae). Iheringia, Série Zoologia, (76):101-159.

1997. On the new Neotropical spider genus Ianduba (Araneae, Corinnidae). Iheringia, Série Zoologia, (83):165-180.

2000. Taxonomia da subfamília Corinninae (Araneae, Corinnidae) nas regiões Neotropical e Neártica. Iheringia, Série Zoologia, (89):3-148.

Bonaldo, A. B. \& Brescovit, A. D. 1992. As aranhas do gênero Cheiracanthium C. L. Koch, 1839 na Região Neotropical (Araneae, Clubionidae). Revista Brasileira de Entomologia 36(4):731-740.

Bonaldo, A. B. \& Buckup, E. H. 1995. Revisão do gênero Radulphius (Araneae, Miturgidae, Eutichurinae). Iheringia, Série Zoologia, (78):127-156.

Bösenberg, W. \& STrand, E. 1906. Japanische Spinnen. Abhandlungen herausgegeben von der Senckenbergischen naturforschenden Gesellschaft 30:93-422.

Brady, A. 1964. The lynx spiders of North America, north of Mexico (Araneae: Oxyopidae). Bulletin of the Museum of Comparative Zoology 131(13):431-518.

Braul, A.; Bertoncello, L. A. \& Lise, A. A. 2000. Descrição do macho de Araneus horizonte Levi, 1991 (Araneae, Araneidae). Biociências 8(1):123-126.

Braul, A. \& Lise, A. A. 1996. Theriella, um novo gênero de Salticidae para a Região Neotropical (Araneae). Biociências 4(2):171-177.

1999. Description of Rudra dagostinae sp. n. and Rudra brescoviti sp. n., from Brazil (Araneae, Salticidae). Studies on Neotropical Fauna and Environment 34:10-15.
2002. Revisão taxonômica das espécies de Vinnius e a proposição de dois gêneros novos (Araneae, Salticidae). Biociências 10(2):87-125.

2003. Description of Theriella bertoncelloi sp. n. from southern Brazil (Araneae, Salticidae). Revista Ibérica de Aracnología 7:123-126

Braul, A.; Silveira, M. R. \& Lise, A. A. 1997. Descrição das fêmeas de Ashtabula sexguttata e Illargus coccineus e do macho de Euophrys saitiformis (Araneae, Salticidae). Biociências 5:141-150.

Brescovit, A. D. 1992a. Revisão das aranhas neotropicais do gênero Anyphaenoides Berland, 1913 (Araneae, Anyphaenidae). Revista Brasileira de Entomologia 36(4):741-757.

1992b. Revisão do grupo prospera do gênero Aysha Keyserling, 1891 na Região Neotropical (Araneae, Anyphaenidae). Iheringia, Série Zoologia, (72):23-104.

1993. Novas espécies do gênero Macrophyes O. P.-Cambridge da Região Neotropical (Araneae, Anyphaenidae). Iheringia, Série Zoologia, (75):113-116

1997a. Revisão de Anyphaeninae Bertkau a nível de gêneros na região Neotropical. Revista Brasileira de Zoologia, Suplemento, 13:(1):1-187.

. 1997b. Revisão das aranhas neotropicais do gênero Wulfilopsis Soares \& Camargo, 1955 (Araneae, Anyphaenidae) Arachnologia 25-26:1-15.

1998. Sobre o gênero Osoriella: descrição de duas espécies novas e da fêmea de $O$. rubella (Araneae, Anyphaenidae, Anyphaeninae). Iheringia, Série Zoologia, (84):109-120.

1999. Revisão das aranhas do gênero Jessica Brescovit (Araneae, Anyphaenidae). Revista Brasileira de Entomologia 43(3/4):249-269.

Brescovit, A. D.; Bertoncello, L. A.; Ott, R. \& Lise, A. A. 2004. Description and ecology of two new species of the Brazilian spider genus Losdolobus Platnick \& Brescovit (Araneae, Dysderoidea, Orsolobidae). Revista Ibérica de Aracnología 9:249-257.

Brescovit, A. D. \& Bonaldo, A. B. 1992. Gênero Clubionoides Edwards (Araneae, Clubionidae): combinações novas e redescrição de quatro espécies neotropicais. Revista Brasileira de Entomologia 36(3):685-692.

1993. On the genus Otiothops in Brazil. Bulletin de L' Institute Royal des Sciences Naturelles de Belgique 63:47-50.

Brescovit, A. D. \& Cunha, F. DE S. 2001. Four new species of Dolichognatha Pickard-Cambridge, 1869 from Brazil and description of the female of D. maturaca Lise, 1993 (Araneae: Tetragnathidae). Bulletin of the British Arachnological Society 12:97-104.

Brescovit, A. D. \& Lise, A. A. 1993. Novas espécies e ocorrências de aranhas dos gêneros Apodrassodes e Apopylus (Araneae, Gnaphosidae). Biociências 1(1):101-110.

Brescovit, A. D. \& Lopardo, L. 2008. The first record of the spider genus Trogloneta Simon in the Southern Hemisphere (Araneae, Mysmenidae) with description of three new species from Brazil and remarks on the morphology. Acta Zoologica 89:93-106.

Brescovit, A. D.; Raizer, J. \& Amaral, M. E. 2000. Descriptions and notes on the genus Paradossenus in the Neotropical region (Araneae, Trechaleidae). The Journal of Arachnology 28:7-15.

Brescovit, A. D. \& Rheims, C. A. 2000. On the synantropics species of the genus Scytodes Latreille (Araneae, Scytodidae) of Brazil, with synonymies and records of these species in other neotropics countries. Bulletin of the British Aracnological Society 11:320-330.

Brescovit, A. D. \& Simó, M. 1998. On a new species of Asthenoctenus Simon from Brazil, with notes on the systematics of the genus (Araneae, Ctenidae). Arachnologia 27:1-8.

2007. On the Brazilian Atlantic Forest species of the spider genus Ctenus Walckenaer, with the description of a neotype for $C$. dubius Walckenaer (Araneae, Ctenidae, Cteninae). Bulletin of the British Arachnological Society 14:1-17.

Brignoli, P. M. 1979. Ragni del Brasile V. Due nuovi generi e quattro nuove specie dello stato di Santa Catarina (Araneae). Revue Suisse de Zoologie 86(4):913-924. 
Bristowe, W. S. 1938. Some new termitophilous spiders from Brazil. The Annals and Magazine of Natural Hisstory 2(11):67-73.

Bryant, E. B. 1948. The spiders of Hispaniola. Bulletin of the Museum of Comparative Zoology 100:331-459.

Bücherl, W. 1950. Revisão do gênero Enoploctenus Simon, 1897. Memórias do Instituto Butantan 23:1-40.

1951. Estudos sobre a biologia e a sistemática do gênero Grammostola Simon, 1892. Monografias do Instituto Butantan 1:1-203.

1952. Aranhas do Rio Grande do Sul. Memórias Instituto Butantan 24:127-155.

Buckup, E. H. \& Brescovit, A. D. 1993. Aranhas do gênero Zimiromus, seis novas espécies do Brasil (Araneae, Gnaphosidae). Revista Brasileira de Entomologia 37(1):181-187

Buckup, E. H. \& Marques, M. A. L. 1989. Aranhas Theridiidae da Ilha de Maracá, Roraima, Brasil. I. Nova espécie de Echinotheridion e descrição da fêmea de Phoroncidia moyobamba (Araneae). Iheringia, Série Zoologia, (69):123-129.

1991. Aranhas Theridiidae da Ilha de Maracá, Roraima, Brasil. II. Gênero Achaearanea (Araneae). Iheringia, Série Zoologia, (71):81-89.

1996. Descrições, transferências e novas sinonímias em Theridiidae (Araneae). Iheringia, Série Zoologia, (81):45-62.

Buckup, E. H.; Marques, M. A. L. \& Otт, R. 2006. Três espécies novas de Achaearanea (Araneae, Theridiidae) do Brasil ocorrentes em serapilheira. Iheringia, Série Zoologia, 96(1):61-64.

Buckup, E. H.; Marques, M. A. L. \& Rodrigues, E. N. L. 2011. Três espécies novas do gênero Cryptachaea (Araneae) e notas taxonômicas em Theridiidae. Iheringia, Série Zoologia, 100(4):341-355.

Buckup, E. H. \& Meyer, A. C. 1993. Sobre o macho de Alpaida scriba (Araneae, Araneidae). Revista Brasileira de Entomologia 37(2):353, 354.

Camargo, H. F. DE A. 1950. Contribuição ao estudo das aramhas brasileiras (Arachnida, Araneae). Três espécies novas e uma pouco conhecida. Papéis Avulsos do Departamento de Zoologia 9(15):223-248.

1953. Sobre algumas aranhas que ocorrem no Brasil, com descrição de um alótipo (Arachnida-Araneae). Papéis Avulsos do Departamento de Zoologia, São Paulo 11(19):301-340.

Cambridge, F. O. P.-. 1899. Arachnida-Araneida. In: Godman, F. D. \& SAvin, O. Biologia Centrali-Americana. v.2, p.41-88

1902. New species of spiders belonging to the genus Ctenus with supplementary notes. The Annals and Magazine of Natural History 9(7):401-415.

1903. On some new species of spiders belonging to the families Pisauridae and Senoculidae; with characters of a new genus. Proceedings of the Zoological Society of London 1903(1): $151-168$.

1904. Arachnida - Araneidea and Opiliones. In: Biologia Centrali-Americana, Zoologia. London. v.2, p.465-560.

Cambridge, O. P.-. 1870. On some new genera and species of Araneida. Proceedings of the Zoological Society of London 1870:728-741.

1879. On some new and rare spiders from New Zeland, with characters of four genera. Proceedings of the Zoological Société of London 1879:681-703.

1880. On some new and little known spiders of the genus Argyrodes. Proceedings of the Zoological Society of London 1880:320-344.

1881. On some new genera and species of Araneidea. Proceedings of the Zoological Society of London 1881:765-775.

1882. On new genera and species of Araneidea. Proceedings of the Zoological Society of London 1882:423-442.

1896. Arachnida. Araneida. In: Biologia CentraliAmericana, Zoology. London. v.1, p.161-224.

1889. Arachnida - Araneida. In: Biologia CentraliAmericana, Zoology. London. v.1, p.1-56.

1890. Arachnida - Araneida. In: Biologia Centrali-

Americana, Zoology. London. v.1, p.57-72.

. 1894. Arachnida - Araneida. In: Biologia Centrali-

Americana, Zoology. London. v.1, p.121-144.
1898. Arachnida - Araneida. In: Biologia CentraliAmericana, Zoology. London. v.1, p.233-288.

CanAls, J. 1931. Las arañas del genero Mastophora Holmberg en La Argentina. Anales del Museu Buenos Aires 37:17-27.

Capocasale, R. M. 1998. Arañas del Uruguai, VIII. Contribución al conocimiento de Segestria ruficeps Guérin (Araneae, Segestriidae). Comunicaciones Zoologicas del Museo de Historia Natural del Montevideo 12(190):1-12.

2001. Redescripción de Lycosa poliostoma (C. L. Koch) (Araneae, Lycosidae). Revista Ibérica de Aracnología 3:79-86.

Caporiacco, L. DI. 1947. Diagnosi preliminari di specie nuove di Aracnidi della Guiana Brittanica. Monitores Zoológico Italiano 56:20-34.

CARICO, J. E. 1993. Revision of the genus Trechalea Thorell (Araneae, Techaleidae) with a review of the taxonomy of the Trechaleidae and Pisauridae of the Western Hemisphere. The Journal of Arachnology 21:226-257.

2005. Descriptions of two new spider genera of Trechaleidae (Araneae, Lycosoidea) from South America. The Journal of Arachnology 33(3):797-812.

Chamberlin, R. V. 1916. Results of the Yale Peruvian Expedition of 1911. The Arachnida. Bulletin of the Museum of Comparative Zoology 60(6):177-299.

1917. New spiders of the family Aviculariidae. Bulletin of the Museum of Comparative Zoology 61:25-75.

. 1924. The spider fauna of the shores and islands of the Gulf of California. Proceedings of the California Academy of Sciences 12:561-694.

Chamberlin, R. V. \& Ivie, W. 1942. A hundred new species of American spiders. Bulletin of the University of Utah 32(13):3-117

Chickering, A. M. 1943. Twenty-one new species of Dipoena (Theridiidae) from Panama. Transactions of the American microscopical Society 62:329-378.

. 1960. Three new species of Micrathena from South America Breviora 121:1-11.

. 1961. The genus Micrathena (Araneae, Araneidae) in Central America. Bulletin of the Museum of Comparative Zoology 125(13):392-470.

CLERCK, C. 1758. Svenska spindlar, uti sina hufvud-slågter indelte samt under några och sextio särskildte arter beskrefne och med illuminerade figurer uplyste. Stockholmiae. 154p.

Codpington, J. 1986. The genera of the spider family Theridiosomatidae. Smithsonian Contributions to Zoology 422:1-96.

Corronca, J. A. 1998. The South American spiders of the genus Selenops (Araneae, Selenopidae) with a description of three new species. Studies on Neotropical Fauna and Environment 33:124-148.

DAHL, F. 1906. Symbiose, kommensalismmus, parasitismus. Naturwissenschaftliche Wochenshrift, Neue Folge, 5(46): 734,735 .

Dimitrov, D. \& Hormiga, G. 2009. Revision and cladistic analysis of the orbweaving spider genus Cyrtognatha Keyserling, 1881 (Araneae, Tetragnathidae). Bulletin of the American Museum of Natural History 317:1-140.

Edwards, G. B.; Rinaldi, I. M. P. \& Ruiz, G. R. S. 2005. A review of some South American species of jumping spiders (Araneae: Salticidae) described by Mello-Leitão from Brasil, with resolution of the genus Asaphobelis. Biota Neotropica 5(2):1-31.

Eickstedt, V. T. D. von. 1978. Estudo sistemático de Phoneutria nigriventer (Keyserling, 1891) e Phoneutria keyserlingi (Pickard-Cambridge, 1897) (Araneae, Labidognatha, Ctenidae). Memórias do Instituto Butantan 42/43:95-126.

Emerton, J. 1875. Notes on spiders from caves in Kentucky, Virginia and Indiana. American Naturalist 9:278-281.

Exline, H. \& Levi, H. W. 1962. American spiders of the genus Argyrodes (Araneae, Theridiidae). Bulletin of the Museum of Comparative Zoology 127(2):75-202.

1965. The spider genus Synotaxus (Araneae: Theridiidae). Transactions of the American Microscopical Society 84(2): $177-184$.

FABricius, J. V. 1775. Systema Entomologiae, sistens Insectorum classes, ordines, genera, species, adiectis, synonymis, locis 
descriptionibus observationibus. Flensburg and Lipsiae 1775: $1-832$.

1793. Entomologia Systematica emendata et aucta, secundum classes, ordines, genera, species adjectis synonimis, locis observationibus descriptionibus. Haefniae 2:407-428.

ForsKål, P. 1775. Descriptiones Animalium, Avium, Amphibiorum, Piscium, Insectorum, Vermium; quae in itinere orientali observavit Petrus Forskål. Hauniae 1775:85, 86.

Framenau, V. W.; Scharff, N. \& Levi, H. W. 2009. Not from "Down Under": new synonymies and combinations for orbweaving spiders (Araneae: Araneidae) erroneously reported from Australia. Zootaxa 2073:22-30.

Fuesslin, J. C. 1775. Verzeichniss der ihm bekannten schweizerischen Insekten, mit einer ausgemahlten kupfertafel nebst der Ankündigung eines neuen Insekten werkes. Zurich und Winterthur 1775:1-62.

Galiano, M. E. 1962. Redescripciones de especies del genero Lyssomanes Hentz, 1845, basadas en los ejemplares tipicos; descripción de una especie nueva (Araneae, Salticidae). Acta Zoologica Lilloana 18:45-97.

1963a. Las espécies americanas de arañas de la família Salticidae descriptas por Eugène Simon. Redescripciones basadas en los exemplares típicos. Physis 23(66):273-470.

1963b. Revisión del genero Agelista Simon, 1900, con nota sobre Titanattus notabilis (Mello-Leitão) comb. n. Physis 24(67):29-34.

1963c. Las variaciones individuales en Evophrys sutrix Holmberg, 1874 (Araneae, Salticidae). Revista de la Sociedad Entomológica Argentina 24:23-28.

1965. Salticidae (Araneae) formiciformes IV. Revisíón del género Sarinda Peckham, 1892. Revista del Museo Argentino de Ciencias Naturales "Bernardino Rivadavia” 1(4):267-312.

1966. Salticidae (Araneae) formiciformes. V. Revisión del género Synemosyna Hentz, 1848. Revista del Museo Argentino de Ciencias Naturales "Bernardino Rivadavia" 1(6):339-380.

1968a. Adiciones a la revision del genero Chira Peckham, 1896 (Araneae, Salticidae). Physis 27(75):349-396

1968b. Revision de los generos "Acragas, Amycus, Encolpius, Hypaeus y Noegus" (Salticidae, Araneae). Revista del Museo Argentino de Ciencias Naturales "Bernardino Rivadavia" 2(3):267-360.

1970. Revision del genero Tullgrenella Mello-Leitão, 1941

(Araneae, Salticidae). Physis 29(79):323-355.

1972. Revision del genero "Chirothecia" Taczanowsky, 1878

(Araneae, Salticidae). Revista del Museo Argentino de Ciencias Naturales "Bernardino Rivadavia" 4(1):1-42.

. 1978. Revisión del género Phiale Koch, C. L., 1846 (Araneae,

Salticidae). I. Redescripción de Phiale gratiosa, P. mimica y P. rufoguttata. Physis 37:161-167.

1979. Revision del genero Frigga C. L. Koch, 1851. (Araneae, Salticidae). Acta Zoologica Lilloana 33(2):113-135.

1980. Revisión del género Lyssomanes Hentz, 1845 (Araneae, Salticidae). Opera Lilloana 30:1-104.

1981a. Catalogo de los especimenes tipicos de Salticidae

(Araneae) descriptos por Candido F. de Mello-Leitão. Segunda parte. Physis (Secc. C) 39:11-17.

1981b. Revision del genero "Aphirape" C. L. Koch, 1851

(Araneae, Salticidae). Comunicaciones del Museo Argentino de Ciencias Naturales "Bernardino Rivadavia" 1(7):93-111.

1981c. Revisión del género Phiale C. L. Koch, 1846. (Araneae, Salticidae) III. Las especies polimorficas del grupo Mimica. The Journal of Arachnology 9:61-85.

1984a. Revision del genero Rudra Peckham y Peckham, 1885 (Araneae, Salticidae). Physis 42(103):63-72.

1984b. Descripcion de Wedoquella nuevo genero (Araneae,

Salticidae). The Journal of Arachnology 11:343-352.

1985. Two new species of Semiopyla with notes on $S$. cataphracta (Araneae, Salticidae). Revue Suisse de Zoologie 92(2):281-290

1987a. Descripcion de Hisukattus nuevo genero (Araneae, Salticidae). Revista de la Sociedad Entomológica Argentina 44(2):137-148. 1987b. Revision de los generos del grupo Hurieae (Araneae, Salticidae). The Journal of Arachnology 15(3):285-301.

1989. Las espécies de Sitticus del grupo Leucoproctus (Araneae, Salticidae). Revista de la Sociedad Entomológica Argentina 45 (1-4):257-269.

1992. Notas sobre dos espécies de Dryphias Simon (Araneae, Salticidae). Revista de la Sociedad Entomológica Argentina 50(1-4):29-41.

1995. El genero Tacuna (Araneae, Salticidae). Physis 50:111-120.

Gertsch, W. J. 1967. The spider genus Loxosceles in South America (Araneae, Scytodidae). Bulletin of the American Museum of Natural History 136(3):117-173.

1982. The spider genera Pholcophora and Anopsicus (Araneae, Pholcidae) in North America, Central America and the West Indies. Bulletin of the Association for Mexican Cave Studies 8:95-144

1984. The spider family Nesticidae (Araneae) in North America, Central America and the West Indies. Texas Memorial Museum Bulletin 31:1-91.

Glueck, S. 1994. A taxonomic revision of the orb weaver genus Acacesia (Araneae: Araneidae). Psyche 101(1-2):59-84

Goloboff, P. A. 1988. Xenonemesia, un nuevo género de Nemesiidae (Araneae, Mygalomorphae). The Journal of Arachnology 16:357-363.

1995. A revision of the South American spiders of the family Nemesiidae (Araneae, Mygalomorphae). Part I: Species from Peru, Chile, Argentina, and Uruguay. Bulletin of the American Museum of Natural History 224:1-189.

Gonzaga, M. de O. \& Santos, A. J. 1999. The females of Anelosimus dubiosus and Anelosimus jabaquara (Araneae, Theridiidae). The Journal of Arachnology 27:432-434.

GonZÁlez, A. 1987. Una nueva especie del genero Steatoda Sundevall (Araneae, Theridiidae). Revista de la Sociedad Entomológica Argentina 44:179-183.

1990. Nota sobre Euryopis spinifera (Mello-Leitão, 1944) (Araneae, Theridiidae). Revista de la Sociedad Entomológica Argentina 48:47-52.

1992. Descripción del macho de Achaearanea jequirituba (Araneae, Theridiidae). The Journal of Arachnology 20:134-136.

GonzÁlez, A. \& CAstro, D. Del C. 1996. Neotropical spiders of the genus Argyrodes Simon (Araneae, Theridiidae). Bulletin of the British Arachnological Society 10(4):127-137

Guadanucci, J. P. L. 2004. Description of Catumiri n. gen. and three new species (Theraphosidae: Ischnocolinae). Zootaxa 671:1-14.

Guérin-Méneville, F. E. 1829. Iconographie du régne animal de Cuvier, ou représentation d'après nature de l'une des espèces les plus remarquables et souvent non encore figurées de chaque genre d'animaux. Paris. v. 2.

1832. Description of Segestria ruficeps. Magasin de Zoologie, de Guérin-Méneville. v.2.

Hahn, C. W. 1822. Monographie der Spinnen. Nürnberg. v.3. p. $1,2$.

Harrod, J. C; Levi, H. W. \& Leibensperger, L. 1991. The Neotropical orbweavers of the genus Larinia (Araneae, Araneidae). Psyche 97(3-4):241-265.

Hensel, R. 1872. Beiträge zur Kenntniss der Säugethiere SüdBrasiliens. Abhandlungen der Königlichen. Akademie der Wissenschaften zu Berlin 1872:1-130

Hentz, N. M. 1842. Descriptions and figures of the araneides of the United States. Boston Journal of Natural History 4:54-57; 223-231.

1845. Descriptions and figures of the Araneides of the United States. Boston Journal of Natural History 5:15-202. 1847. Descriptions and figures of the araneides of the United States. Boston Journal of Natural History 5:443-418.

1850. Descriptions and figures of the araneides of the United States. Boston Journal of Natural History 6:18-35. 271-295.

Hingston, R. W. G. 1932. A Naturalist in the Guiana Forest London, Arnold \& Co. 348p.

Höfer, H. \& BRESCOvit, A. D. 2000. A Revision of the Neotropical spider genus Ancylometes Bertkau (Araneae: Pisauridae). Insect Systematics \& Evolution 31:323-360.

Holmberg, E. L. 1875. Descriptions et notices d'arachnides de la 
République Argentine. Periódico zoológico de Sociedad Entomológica Argentina 1:283-302.

1876. Los Arácnidos Argentinos. Anales de Agricultura 4:1-30.

1883. Neothereutes darwini Holmb., representante de una nueva familia de Citigradas. Boletín de la Academia nacional de ciencias de la Republica Argentina 5:35-48.

Huber, B. A. 2000. New world pholcid spiders (Araneae: Pholcidae): a revision at generic level. Bulletin of the American Museum of Natural History (254):1-348

Indicatti, R. P.; Lucas, S. M. \& Brescovit, A. D. 2007. A new species of the spider genus Xenonemesia Goloboff and first record of $X$. platensis Goloboff from Brazil (Araneae, Mygalomorphae, Microstimatidae). Zootaxa 1485:43-49.

Indicatti, R. P.; Lucas, S. M.; Guadanucci, J. P. L. \& Yamamoto, F. U. 2008a. Revalidation and revision of the genus Magulla Simon 1892 (Araneae, Mygalomorphae, Theraphosidae). Zootaxa 1814:21-36.

Indicatti, R. P.; Lucas, S. M.; Ott, R. \& Brescovit, A. D. 2008 b. Litter dwelling mygalomorph spiders (Araneae: Microstigmatidae, Nemesiidae) from Araucaria forests in southern Brazil, with the description of five new species. Revista Brasileira de Zoologia 25:529-546.

JoCQUÉ, R. \& BAERT, L. 2002. A revision of the Neotropical spider genera Tenedos O.P.-Cambridge and Ishania Chamberlin (Araneae, Zodariidae). Bulletin de l'Institut Royal des Sciences Naturelles de Belgique (Entomologie) 72:67-173.

Karsch, F. 1878. Exotisch-araneologisches. Zeitschrift für Naturwissenschaften 51:332-333, 771-826.

1880. Arachnologische Blätter. Zeitschrift für Naturwissenschaften 53:373-409.

Kaston, B. J. 1948. Spiders of Connecticut. Connecticut State Geological Natural History Survey Bulletin 70:1-874.

Keyserling, E. 1864. Beschreibungen neuer und wenig bekannter Arten aus der Familie Orbitelae Latr. oder Epeiridae Sund. Sitzungsberichte und Abhandlungen der naturwissenschaftlichen Gesellschaft Isis in Dresden 1863:63-98, 119-154.

1865. Beiträge zur kenntniss der Orbitelae Latrl. Verhandlungen der Kaiserlichen-Königlichen Zoologischbotanischen Gesellschaft in Wien 15:799-856.

1877a. Einige spinnen von Madagascar. Verhandlungen der Kaiserlichen-Königlichen Zoologisch-botanischen Gesellschaft in Wien 27:85-96.

1877b. Ueber Amerikanische Spinnen-arten der unterordnung Citigradae. Verhandlungen der Kaiserlichen-Königlichen Zoologisch-botanischen Gesellschaft in Wien 26:609-708. 1877c. Amerikanische spinnen aus deu Familien der Pholcoidae, Scytodoidae und Dysderoidea. Verhandlungen der Kaiserlichen-Königlichen Zoologisch-botanischen Gesellschaft in Wien 27:205-234.

1878. Spinnen aus Uruguai und einigen anderen gegenden Amerikas. Verhandlungen der Kaiserlichen-Königlichen Zoologisch-botanischen Gesellschaft in Wien 27:571-624. 1879. Neue Spinnen aus Amerika. Verhandlungen der Kaiserlichen-Königlichen Zoologisch-botanischen Gesellschaft in Wien 29:293-349.

1880. Die Spinnen Amerikas. Laterigradae. Nürnberg, Bauer \& Raspe. v.1, 283p.

1882. Neue Spinnen aus Amerika. IV. Verhandlungen der Kaiserlichen-Königlichen Zoologischen und Botanischen Gesellschaft in Wien 32:195-226.

1884a. Die Spinnen Amerikas. Theridiidae. Nürnberg, Bauer \& Raspe. v.2, part 1, 222p.

1884b. Neue Spinnen aus Amerika. Verhandlungen der Kaiserlichen-Königlichen Zoologischen und Botanischen Gesellschaft in Wien 33:649-684.

1886. Die Spinnen Amerikas. Theridiidae. Nürnberg, Bauer \& Raspe. v.2, part 2, 295p.

1891. Die Spinnen Amerikas. Brasilianische Spinnen. Nürnberg, Bauer \& Raspe. v.3, 278p.

1892. Die Spinnen Amerikas. Epeiridae. Nürnberg,

Bauer \& Raspe. v.4, part 1, p.1-208p.

1893. Die Spinnen Amerikas. Epeiridae. Nürnberg, Bauer \& Raspe. v.4, part 2, p.209-377.

KoсH, C. L. 1836. Die Arachniden. Nürnberg. v.3, p.1-120.
1838. Die Arachniden. Nürnberg. v.4, p.1-144.

1839a. Die Arachniden. Nürnberg. v.5, p.1-158.

1839b. Die Arachniden. Nürnberg. v.6, p.1-156.

1840. Die Arachniden. Nürnberg. v.8, p.1-40.

1841. Die Arachniden. Nürnberg. v.8, p.41-131.

1845. Die Arachniden. Nürnberg. v.12, p.1-166.

1846. Die Arachniden. Nürnberg. v.13, p.1-234.

1847. Die Arachniden. Nürnberg. v.14, p.89-210.

Koch, L. 1871. Die Arachniden Australiens, nach der Natur beschrieben und abgebildet. Nürnberg. v.1, 104p.

1872. Beitrag zur kenntniss der Arachniden-faunaTirols. Zweite Abhandlung. Zeitschrift Ferdinandeums Tirol Vorarlberg, Serie 3, 17:239-328

1875. Aegyptische und abyssinische Arachniden, Nürnberg. 96p.

LEECH, R. 1972. A revision of the Neartic Amaurobiidae (Arachnida: Araneida). Memoirs of the Entomological Society of Canada 84:1-182

Lehtinen, P. T. \& Marusik, Y. M. 2008. A redefinition of Misumenops F. O. Pickard-Cambridge, 1900 (Araneae, Thomisidae) and review of the New World species. Bulletin of the British Arachnological Society 14(4):173-198.

Levi, H. W. 1954. The spider genus Theridula in North and Central America and the West Indies (Araneae, Theridiidae) Transactions of the American Microscopical Society 73:31-343

1955. The spider genera Coressa and Achaearanea in America north of Mexico. American Museum Novitates 1718: $1-33$

1956. The spider genera Neottiura and Anelosimus in America (Araneae: Theridiidae). Transactions of the American Microscopical Society 75(4):407-422.

1957a. The spider genera Chrysso and Tidarren in America (Araneae, Theridiidae). Journal of the New York Entomological Society 63:59-81

1957b. The spider genera Crustulina and Steatoda in North America, Central America, and the West Indies (Araneae, Theridiidae). Bulletin of the Museum of Comparative Zoology 117(3):367-424.

1959a. The spider genus Latrodectus (Araneae, Theridiidae) Transactions of the American Microscopical Society 78(1):7-43.

1959b. The spider genera Achaearanea, Theridion, and Sphyrotinus from Mexico, Central America, and the West Indies (Araneae, Theridiidae). Bulletin of the Museum of Comparative Zoology 121(3):56-163.

1959c. The spider genus Coleosoma (Araneae, Theridiidae). Breviora 100:1-8.

1962a. The spider genera Steatoda and Enoplognatha (Araneae, Theridiidae). Psyche 69(1):11-36.

1962b. More American spiders of the genus Chrysso (Araneae, Theridiidae). Psyche 69(4):209-237.

1963a. American spiders of the genera Audifia, Euryopis and Dipoena (Araneae: Theridiidae). Bulletin of the Museum of Comparative Zoology 129(2):123-183.

1963b. American spiders of the genus Achaearanea and the new genus Echinotheridion (Araneae, Theridiidae). Bulletin of the Museum of Comparative Zoology 129(3):189-240.

1963c. The American spiders genera Spintharus and Thwaitesia (Araneae: Theridiidae). Psyche 70(4):223-234. 1963d. American spiders of the genus Theridion (Araneae, Theridiidae). Bulletin of the Museum of Comparative Zoology 129(10): 483-592.

1963e. The spider genera Cerocida, Hetschkia, Wirada and Craspedisia. (Araneae: Theridiidae). Psyche 70(3):170-179. 1964a. The spider genus Thymoites in America (Araneae: Theridiidae). Bulletin of the Museum of Comparative Zoology 130(7):447-471 1964b. American spiders of the genus Episinus (Araneae, Theridiidae). Bulletin of the Museum of Comparative Zoology 131(1):1-25.

1964c. The American spiders of the genera Styposis and Pholcoma (Araneae, Theridiidae). Psyche 71(1):32-39.

1964d. American spiders of the genus Phoroncidia (Araneae, Theridiidae). Bulletin of the Museum of Comparative Zoology 131(3):65-86. 
1964e. The spider genera Stemmops, Chrosiothes, and the new genus Cabello from America. Psyche 71(2):73-92 1967a. Cosmopolitan and pantropical species of theridiid spiders (Araneae: Theridiidae). Pacific Insects 9:175-186.

1967b. Habitat observations, records, and new South American theridiid spiders (Araneae, Theridiidae). Bulletin of the Museum Comparative Zoology 136(2):21-37.

1980a. The male of Echinotheridion (Araneae: Theridiidae). Psyche 87(3,4):177-179.

1980b. The orb-weaver genus Mecynogea, the subfamily Metinae and the genera Pachygnatha, Glenognatha and Azilia of the subfamily Tetragnathidae north of Mexico (Araneae: Araneidae). Bulletin of the Museum of Comparative Zoology 149:1-74.

1981. The American orb-weaver genera Dolichognatha and Tetragnatha north of Mexico (Araneae: Araneidae, Tetragnathidae). Bulletin of the Museum of Comparative Zoology 149:271-318.

1985. The spiny orb-weaver genera Micrathena and Chaetacis (Araneae: Araneidae). Bulletin of the Museum of Comparative Zoology 150(8):429-618.

1986. The Neotropical orb-weaver genera Chrysometa and Homalometa (Araneae: Tetragnathidae). Bulletin of the Museum of Comparative Zoology 151(3):91-215.

1988. The Neotropical orb-weaving spiders of the genus Alpaida (Araneae: Araneidae). Bulletin of the Museum of Comparative Zoology 151(7):365-487.

1989. The Neotropical orb-weaver genera Eperoides, Bertrana and Amazonepeira (Araneae, Araneidae). Psyche 96(1,2):75-99.

1991a. The Neotropical and Mexican species of the orbweaver genera Araneus, Dubiepeira, and Aculepeira (Araneae: Araneidae). Bulletin of the Museum of Comparative Zoology 152(4):167-315.

1991b. The Neotropical orb-weaver genera Edricus and Wagneriana (Araneae: Araneidae). Bulletin of the Museum of Comparative Zoology 152(6):363-415.

1992. Spiders of the orb-weaver genus Parawixia in America (Araneae: Araneidae). Bulletin of the Museum of Comparative Zoology 153(1):1-46.

1993a. The orb-weaver genus Kaira (Araneae: Araneidae). The Journal of Arachnology 21(3):209-225.

1993b. The Neotropical orb-weaving spiders of the genera Wixia, Pozonia, and Ocrepeira (Araneae: Araneidae). Bulletin of the Museum of Comparative Zoology 153(2): $47-141$

1993c. American Neoscona and corrections to previous revisions of Neotropical orb-weavers (Araneae: Araneidae). Psyche 99(2-3):221-239.

1995a. Orb-weaving spiders Actinosoma, Spilasma, Micrepeira, Pronous, and four new genera (Araneae: Araneidae). Bulletin of the Museum of Comparative Zoology 154(3):153-213.

1995b. The Neotropical orb-weaver genus Metazygia

(Araneae: Araneidae). Bulletin of the Museum of Comparative Zoology 154(2):63-151.

1996a. The American orb weavers Hypognatha, Encyosacus, Xylethrus, Gasteracantha, and Enacrosoma (Araneae, Araneidae). Bulletin of the Museum of Comparative Zoology 155 (3):89-157.

1996b. The genus Taczanowskia of the orb-weaver spider family Araneidae (Araneae). Anales del Instituto de Biologia, Universidad Nacional Autóctone de México, Série Zoologia, 67(2):183-195.

1997. The American orb weavers of the genera Mecynogea Manogea, Kapogea and Cyrtophora (Araneae: Araneidae). Bulletin of the Museum of Comparative Zoology 155(5):215-255.

1999. The Neotropical and Mexican orb weavers of the genera Cyclosa and Allocyclosa (Araneae: Araneidae). Bulletin of the Museum of Comparative Zoology 155(7):299-379

2003. The bolas spiders of the genus Mastophora (Araneae:

Araneidae). Bulletin of the Museum of Comparative

Zoology 157(5):309-382.

2004. Comments and new records for the American genera
Gea and Argiope with description of new species. Bulletin of the Museum of Comparative Zoology 158(2):47-65.

2005. The spider genera Heterognatha, Testudinaria and Ursa in South America (Araneae: Araneoidea). Bulletin of the British Arachnological Society 13(6):185-198.

2007a. The orb-weaver genus Mangora in South America (Araneae, Araneidae). Bulletin of the Museum of Comparative Zoology 159(1):1-144.

$2007 \mathrm{~b}$. Type species of araneid and tetragnathid genera. Harvard University. Disponível em: <http:// www.oeb.harvard.edu/faculty/levi>. Acesso em: 15.10.2010. 2008. On the tetragnathid genera Alcimosphenus, Leucauge, Mecynometa and Opas (Araneae, Tetragnathidae). The Journal of Arachnology 36:167-170.

Levi, H. W. \& Eicksted, V. R. D. von. 1989. The Nephilinae spiders of the neotropics (Araneae: Tetragnathidae). Memórias do Instituto Butantan 51(2):43-60.

Levi, H. W. \& Sмith, D. R. R. 1983. A new colonial Anelosimus spider from Suriname (Araneae: Theridiidae). Psyche 89:275-278.

LinNÉ, C. DE. 1767. Systema Naturae per regna tria natures, secundum classes, ordines, genera, species, cum characteribus differentiis, synonymis, locis, 13th ed. Stockolm. v.1, p.1030-1037.

Lise, A. A. 1973. Contribuição ao conhecimento do gênero Sidyma no Brasil, com a descrição de uma nova espécie (Araneae - Thomisidae). Iheringia, Série Zoologia, (43):3-47. 1979. Tomisideos neotropicais I: Onocolus garruchus sp. n. (Araneae - Thomisidae - Stephanopsinae). Iheringia Série Zoologia, (54):67-76.

1981a. Tomisídeos neotropicais V: revisão do gênero Onocolus Simon, 1895 (Araneae, Thomisidae, Stephanopsinae). Iheringia, Série Zoologia, (57):3-97.

1981b. Thomisideos neotropicais VI. Sidyma kolpogaster Lise, 1973 descrição do macho e nova ocorrência (Araneae, Thomisidae, Stephanopsinae). Iheringia, Série Zoologia, (57):129-135.

Lise, A. A. \& AlmeidA, L. 2006. A new species of Losdolobus Platnick \& Brescovit, 1994 (Araneae: Dysderoidea: Orsolobidae) from southern Brazil. Zootaxa 1277:23-27.

Lise, A. A. \& Braul JR, A. 1994. Asaphobelis physonychus Simon: descrição da fêmea, e novas contribuições para o conhecimento do macho (Araneae, Salticidae). Revista Brasileira de Zoologia 11(2):261-264

1995. Acacesia graciosa, a new species from the Neotropica region (Araneae, Araneidae). Biociências 3(2):179-184.

Lise, A. A.; Ferreira, A. C. K. \& Silva, E. L. C. DA. 2010 Description of a new species of Pikelinia (Araneae: Filistatidae) from Brazil, with notes on its ecology. Zootaxa 2604:61-68.

Lise, A. A.; Ott, R. \& Rodrigues, E. N. L. 2009. On the Neotropica genus Cybaeodamus (Araneae, Zodariidae, Storeniinae). Iheringia, Série Zoologia, 99(3):259-272.

Lise, A. A. \& Silva, E. L. C. DA. 2009. A new species of Thymoites Keyserling, 1884 (Araneae, Theridiidae). Studies on Neotropical Fauna and Environment 44(2):131-136.

Lise, A. A.; Silva, E. L. C. DA \& Bertoncello, L. A. 2009. Two new species of the Neotropical spider genus Wirada Keyserling, 1886 (Araneae: Theridiidae) from southern Brazil. Studies on Neotropical Fauna and Environment 44(3):183-194.

LuCAS, H. 1836. Notice sur une nouvelle espèce d'A appartenant au genre Lycose. Annales de la Societé entomologique de France 5:521-526.

1846. Histoire naturelle des animaux articules. In Exploration scientifique de l'Algerie pendant les annees $1840,1841,1842$ publiee par ordre du Gouvernement et avec le concours d'une commission academique. Paris, Sciences physiques, Zoologie. v.1, p.89-271.

1857. Arachnides. In: SAGRA, R. de. Histoire physique, politique et naturelle de l'Isle de Cuba. Animaux articulés. Paris. v.4-5, p. 69-84.

Lucas, S. M.; Paula, F. dos S.; Gonzalez Filho, H. M. \& Brescovit, A. D. 2010. Redescription and new records of Acanthoscurria paulensis (Araneae: Mygalomorphae: Theraphosidae). Zootaxa 27(4):563-568.

Magalhães, I. L. F. DE \& Santos, A. J. 2011. Description of the male of Pozonia bacillifera (Araneae: Araneidae). Zoologia 28(1):112-114. 
Marques, M. A. L. \& Buckup, E. H. 1993. Novas espécies de Tekellina do Brasil (Araneae, Theridiidae). Iheringia, Série Zoologia, (74):125-132.

1996. Novas espécies sulamericanas do gênero Stemmops (Araneae; Theridiidae). Biociências 4(2):69-74.

1997. Duas novas espécies de Chrosiothes e descrição do macho de $C$. niteroi (Araneae, Theridiidae). Iheringia, Série Zoologia, (83):181-186.

Martins, R. \& Bertani, R. 2007. The non-Amazonian species of the Brazilian wandering spiders of the genus Phoneutria Perty, 1833 (Araneae, Ctenidae), with the description of a new species. Zootaxa 1526:1-36.

Medam, V. 2001. On the genus Eilica (Araneae, Gnaphosidae) from Argentina. The Journal of Arachnology 29:423-426.

Mello-Leitão, C. F. 1917a. Notas Arachnológicas; V - Espécies novas ou pouco conhecidas do Brasil. Brotéria, Série Zoologia, 15:74-102.

1917b. Generos e espécies novas de araneidos. Archivos da Escola Superior de Agricultura e Medicina Veterinária 1(1):3-19.

1917c. Aranhas novas ou pouco conhecidas de thomisidas e salticidas brasileiras. Archivos da Escola Superior de Agricultura e Medicina Veterinária 1(2):117-151.

1918. Drassoideas do Brasil. Archivos da Escola Superior de Agricultura e Medicina Veterinária 2:17-74.

1920. Algumas aranhas novas. Revista Sociedade Brasileira de Sciencias (3):169-176.

1921. On the genus Grammostola, Simon. The Annals and Magazine of Natural History 7(9):293-305.

1922. Novas clubionidas do Brasil. Archivos da Escola Superior de Agricultura e Medicina Veterinária 6:17-56. 1923. Theraphosideas do Brasil. Revista do Museu Paulista 13:1-438.

1925. Pequenas notas aracnológicas. Boletim do Museu Nacional do Rio de Janeiro 1(6):460.

1926. Algumas aranhas novas do Brasil meridional. Boletim do Museu Nacional Rio de Janeiro 2:1-18.

1929a. Oxyopideos do Brasil. Revista do Museu Paulista 16:489-536.

1929b. Aphantochilidas e thomisidas do Brasil. Archivos do Museu Nacional 31:1-359.

1929c. Mimetideos do Brasil. Revista do Museu Paulista 16:537-568.

1929d. Aranhas de Pernambuco, colhidas por D. Bento Pickel. Annaes da Academia Brasileira de Sciencias 1(2):91-112.

1931. Arachnideos do Rio Grande do Sul. Boletim Biológico

2: $10-14$.

1932. Notas sobre as micratheneas do Brasil. Annaes da

Academia Brasileira de Sciencias 4(2):73-97.

1934. Espécies brasileiras do gênero Loxosceles Lowe.

Annaes da Academia Brasileira de Sciencias 6(2):69-73.

1935a. Dois generos raros de aranhas das collecções do Instituto Butantan. Memórias do Instituto Butantan 19:363-366.

1935b. Three interesting new Brasilian spiders. Revista Chilena de Historia Natural 39:94-98.

1936. Contribution à l'etude des cténides du Brésil.

Festschrift zum 60 Geburstage von Professor Dr.

Embrick Strand 1:1-31.

1937. Aranhas novas ou raras. Annaes da Academia

Brasileira de Sciencias 9:1-12.

1938. Um gênero e sete espécies novas de aranhas.

Memórias Instituto Butantan 11:311-317.

1939a. Aracnídeos. Boletim Biológico, Nova Série, 6(2):281-294.

1939b. Araignées américaines du Musée d'histoire naturelle

de Bâle. Revue Suisse de Zoologie 46(2):43-93.

.1939c. Les arachnides et la zoogéographie de l'Argentine. Physis 17:601-630.

1939d. Algunos arachnidos de Sudamerica. Revista Chilena de Historia Natural 43:169-176.

1940a. Aranhas do Espírito Santo coligidas por Mario Rosa, em 1936, 1937. Archivos de Zoologia do Estado de São Paulo 2:199-214. 1940b. Aranhas do Paraná. Arquivos do Instituto Biológico 11(30):235-257.

1940c. Arañas de la província de Buenos Aires y de las gobernaciones de La Pampa, Neuquén, Rio Negro y Chubut Revista del Museu de La Plata, Nueva Serie, 2(9):3-62.

. 1941. Las arañas de Córdoba, La Rioja, Catamarca, Tucumán, Salta y Jujuy colectadas por los professores Birabén. Revista del Museu de La Plata 2(12):99-197.

1942. Arañas del Chaco y Santiago del Estero. Revista del Museo de la Plata, Nueva Serie, 2(16):381-426.

. 1943a. Catálogo das aranhas do Rio Grande do Sul. Arquivos do Museu Nacional 37:149-245.

1943b. Arañas nuevas de Mendoza, La Rioja y Córdoba colectadas por el profesor Max Biraben. Revista del Museo de La Plata, Nueva Serie, Zoología, 3(120):101-121.

1944. Arañas de la provincia de Buenos Aires. Revista del Museu La Plata, Nueva Serie, Zoología, 3:311-393.

1945. Arañas de Misiones, Corrientes y Entre Ríos. Revista del Museu de La Plata, Nueva Serie, Zoología, 4:213-302. 1947a. Algumas aranhas novas de Pedra Açú e Paraná. Papéis avulsos do Departamento de Zoologia 8(11):127-135. 1947b. Aranhas do Paraná e Santa Catarina, das coleções do Museu Paranaense. Arquivos do Museu Paranaense 6(6):231-304

Miller, J. A. 2007. Review of erigonine spider genera in the Neotropics (Araneae: Linyphiidae, Erigoninae). Zoological Journal of the Linnean Society 149 (Suppl. 1):1-263.

Millidge. A. F. 1991. Further linyphiid spiders (Araneae) from South America. Bulletin of the American Museum of Natural History 205:1-199.

MülleR, H. G. 1987. Apodrassodes mono n. sp. from Brazil (Araneida: Gnaphosidae). Bulletin of the British Arachnological Society 7(5):145.

Nicolet, H. 1849. Arácnidos. In: GAY, C. ed. Historia física e política de Chile. Zoologia. Paris, C. Gay. v.3, p.319-543.

Oкuмa, C. 1983. New synonimies and new records of some cosmopolitan species of the genus Tetragnatha (Araneae: Tetragnathidae). Esakia 20:29-80.

1992. Notes on the Neotropical and Mexican species of Tetragnatha (Araneae: Tetragnathidae) with descriptions of three new species. Journal Faculty Agronomic Kyushu University 36:219-243.

Opell, B. D. 1979. Revision of the genera and tropical American species of the spider family Uloboridae. Bulletin of the Museum of Comparative Zoology 148(10):443-549.

Отт, R. 2003. Descrição de duas espécies novas de Opopaea do sul do Brasil (Oonopidae, Araneae). Iheringia, Série Zoologia, 93(2): 177-182.

Otт, R. \& Brescovit, A. D. 2003. Description of the females of Anapis castilla and Anapisona bordeaux (Araneae, Anapidae). The Journal of Arachnology 31:340-343.

Otт, R. \& Lise, A. A. 1997a. Proposição de Acanthocymbium gen. n. e descrição de duas espécies de Antronetes Millidge, da Região Neotropical (Araneae, Linyphiidae). Biociências 5(1):195-205.

1997b. Duas espécies novas de Labicymbium Millidge, 1991, da Região Neotropical (Araneae, Linyphiidae). Biociências 5(2):53-50.

2002. On Nesticus from meridional South America (Araneae, Nestidae). Iheringia, Série Zoologia, 92(4):59-71.

Papavero, N. 1973. Essays on the history of Neotropical dipterology, with special reference to collectors (17501905). São Paulo, Museu de Zoologia, Universidade de São Paulo. v.2. 230p.

Pecкham, G. W. \& Pecкham, E. G. 1892. Ant-like spiders of the family Attidae. Occasional Papers of the Natural History Society of Wisconsin 2(1):1-84.

1894. Spiders of the Marptusa group. Occasional Papers of the Natural History Society of Wisconsin 2:85-156. 1901. Pellenes and some other genera of the family Attidae. Bulletin of the Wisconsin Natural History Society (N.S.) 1:195-233.

Peckham, G. W. \& Wheeler, W. H. 1889. Spiders of the subfamily Lyssomanae. Transactions of the Wisconsin Academy of Science, Arts and Letters 7:222-256.

Perty, M. 1833. Arachnides Brasiliensis. In: SpIX, J. B. DE \& 
Martius, F. P. eds. Delectus Animalium Articulatorum quae in itinere per Braziliam ann. 1817 et 1820 colligerunt. Monachii. p.191-209.

Petrunkevitch, A. 1930. The spiders of Porto Rico. Transactions of the Connencticut Academy of Arts and Sciences 31(3):1-191.

Piel, W. H. 2001. The systematics of Neotropical orb-weaver spiders in the genus Metepeira (Araneae: Araneidae). Bulletin of the Museum of Comparative Zoology 157(1):1-92.

Pikelin, B. S. G. \& Schiapelli, R. D. 1948. Arañas argentinas II. Comunicaciones del Museo Argentino de Ciencias Naturales "Bernardino Rivadavia" (4):1-20.

1965. El genero Polybetes Simon, 1897 en la Argentina.

Revista del Museo Argentino de Ciencias Naturales "Bernardino Rivadavia" 1(5):310-338.

Platnick, N. I. 1975. A revision of the South American spider genus Trachelopachys (Araneae, Clubionidae). American Museum Novitates 2589:1-25.

1985. Notes on the spider genus Eilica (Araneae: Gnaphosidae). Journal of the New York Entomological Society 93(3):1073-1081.

1986. A revision of the spider genus Trochanteria (Araneae: Gnaphosoidea). Bulletin of the British Arachnological Society 7(1):29-33.

1994. A revision of the spider genus Caponina (Araneae, Caponiidae). American Museum Novitates 3100:1-15.

2011. The world spider catalog, version 11.5. American Museum of Natural History. Disponível em: <http:// research.amnh.org/iz/spiders/catalog >. Acesso em: 15.01.2011.

Platnick, N. I. \& Ewing, C. 1995. A revision of the tracheline spiders (Araneae, Corinnidae) of southern America. American Museum Novitates 3128:1-41.

Platnick, N. I. \& Lise, A. A. 2007. On Nyetnops, a new genus of the spider subfamily Nopinae (Araneae, Caponiidae) from Brazil. American Museum Novitates 3595:1-9.

Platnick, N. I. \& Murphy, J. A. 1987. Studies on Malagasy spiders, 3. The Zelotine Gnaphosidae (Araneae, Gnaphosoidea), with a review of the genus Camillina. American Museum Novitates 2874:1-33

Platnick, N. I. \& Rocha, C. F. D. 1995. On a new Brazilian spider of the genus Trachelopachys (Araneae, Corinnidae) with notes on misplaced taxa. American Museum Novitates 3153: $1-8$

Platnick, N. I. \& Shadab, M. U. 1976. A revision of the Neotropical spider genus Zimiromus, with notes on Echemus (Araneae. Gnaphosidae). American Museum Novitates 2609:1-24.

1979. A review of the spider genera Anapisona and Pseudoanapis (Araneae, Anapidae). American Museum Novitates 2672:1-20.

1981. On the spider genus Eilica (Araneae, Gnaphosidae). Bulletin of American Museum of Natural History 170: $183-188$.

1982. A revision of the American spiders of the genus Camillina (Araneae, Gnaphosidae). American Museum Novitates 2748:1-38.

1983. A revision of the Neotropical spider genus Apodrassodes (Araneae, Gnaphosidae). American Museum Novitates 2763:1-14.

1984a. A revision of the Neotropical spiders of the new genus Apopyllus (Araneae, Gnaphosidae). American Museum Novitates 2788:1-9.

1984b. A revision of the spider genera Trachyzelotes and Urozelotes (Araneae, Gnaphosidae). American Museum Novitates 2792:1-30.

1989. A review of the spider genus Teminius (Araneae, Miturgidae). American Museum Novitates 2963:1-11.

Poсоск, R. I. 1903. On some genera and species of South American Aviculariidae. The Annals and Magazine of Natural History 11(7):81-115.

Poeta, M. R. P.; Marques, M. A. L. \& Buckup, E. H. 2010a. O gênero Eustala (Araneae, Araneidae) no sul do Brasil: duas espécies novas, descrições, complementares e novas ocorrências. Iheringia, Série Zoologia, 100(2):151-161.

2010b. Sobre algumas espécies do gênero Eustala (Araneae, Araneidae) do Brasil. Iheringia, Série Zoologia, $100(3): 267-274$.
Polotow, D. \& Brescovit, A. D. 2009. Revision and cladistic analysis of Isoctenus and description of a new Neotropical genus (Araneae, Ctenidae, Cteninae). Zoological Journal of the Linnean Society 155:583-614.

Polotow, D.; Brescovit, A. D. \& Otт, R. 2007. Description and ecological notes on Isoctenus malabaris sp. nov. (Araneae, Ctenidae) from southern Brazil. Iheringia, Série Zoologia, 97(2):215-218.

Polotow, D.; Brescovit, A. D. \& Pellegatti-Franco, F. 2005. A redescription of Isoctenus coxalis (F.O.P.- Cambridge, 1902) comb. nov. and description of I. corymbus, a new species of cave dwelling spider (Araneae, Ctenidae, Cteninae) from the State of Goiás, Brazil. Revista Ibérica de Aracnología 11:37-42.

Ramírez, M. J. 1997. Revisión y filogenia de los generos Ferrieria y Acanthoceto (Araneae, Anyphaenidae, Amaurobioidinae). Iheringia, Série Zoologia, (82):173-203.

2003. The spider subfamily Amaurobioidinae (Araneae, Anyphaenidae): a phylogenetic revision at generic level. Bulletin of the American Museum of Natural History 277:1-262.

2006. Descripción de la hembra de Glenognatha lacteovittata (Mello-Leitão), nueva combinación (Araneae, Tetragnathidae). Physis, Sección C, 52(122-123):35-37.

Ramírez, M. J. \& GonZÁLEZ, A. 1999. New or little-known species of the genus Echinotheridion Levi (Araneae, Theridiidae). Bulletin of the British Arachnological Society 11(5):195-198.

Ramírez, M. J. \& Grismado, C. J. 1997. A review of the spider family Filistatidae in Argentina (Arachnida, Araneae), with a cladistic reanalysis of filistatid genera. Entomologica Scandinavica 28(3):319-349

Ramírez, M. J.; Grismado, C. J. \& Blick, T. 2004. Notes on the spider family Agelenidae in Southern South America (Arachnida: Araneae). Revista Ibérica de Aracnología 9:179-182.

Reimoser, E. 1917. Die Spinnengattung Micrathena Sundevall. Verhandlungen der Kaiserlichen-Königlichen Zoologisch-Botanischen Gesellschaft in Wien 67:73-160.

Rheims, C. A. 2010. Caayguara a new genus of huntsman spiders from the Brazilian Atlantic forest (Araneae: Sparassidae). Zootaxa 2630:1-29.

Rheims, C. A. \& Brescovit, A. D. 2003. Description of six new species of Anapistula Gertsch (Araneae, Symphytognathidae) from Brazil. Bulletin of the British Arachnological Society 12(7):324-330.

2004. Revision and cladistic analysis of the spider family Hersiliidae (Arachnida, Araneae) with emphasis on Neotropical and Nearctic species. Insect Systematics \& Evolution 35(2): 189-239.

2009. New additions to the Brazilian fauna of the genus Scytodes Latreille (Araneae: Scytodidae) with emphasis on the Atlantic Forest species. Zootaxa 2116:1-45.

Rinaldi, I. M. P. 1988. Misumenops Cambridge e Uraarachne Keyserling (Araneae, Thomisidae, Thomisinae): sinonímias, novas combinações e redescrições. Revista Brasileira de Entomologia 32:19-30.

Rodrigues, E. N. L. 2005a. Descrição da fêmea de Sphecozone tincta (Araneae, Linyphiidae) e novas ocorrências no Brasil. Iheringia, Série Zoologia, 95(1):103-105.

2005b. Nova espécie de Scolecura (Araneae, Linyphiidae) do sul do Brasil. Iheringia, Série Zoologia, 95(4):411-413.

2007a. Espécie nova de Pseudotyphistes (Araneae, Linyphiidae) do sul do Brasil. Iheringia, Série Zoologia, 97(2):177-180.

2007b. Espécie nova de Asemostera Simon e primeiro registro de A. latithorax (Keyserling) para o Rio Grande do Sul, Brasil. Revista Brasileira de Zoologia 24(4):883-886. 2008. Duas novas espécies de Labicymbium (Araneae Linyphiidae) do sul do Brasil. Revista Brasileira de Zoologia 25(2):323-327.

Rodrigues, E. N. L. \& Lise, A. A. 2008. Description of two new species of Naatlo (Araneae; Theridiosomatidae) from Brazil. Revista Brasileira de Zoologia 25(2):299-308.

Rodrigues, E. N. L. \& Marques, M. A. L. 2010. Sobre o gênero Phoroncidia: nova espécie, ecologia e descrição do macho de $P$. reimoseri com novas ocorrências para o sul do Brasil (Araneae, Theridiidae). Iheringia, Série Zoologia, 100(3):247-253. 
Rodrigues, E. N. L. \& Mendonç JR., M. S. 2011. Araneid orbweavers (Araneae, Araneidae) associated with riparian forests in southern Brazil: a new species, complementary descriptions and new records. Zootaxa 2759:60-68.

Rodrigues, E. N. L. \& OtT, R. 2005a. Nova espécie de Theridiosoma (Araneae, Theridiosomatidae) do sul do Brasil. Iheringia, Série Zoologia, 95(1):79-81.

2005b. Aranhas da família Theridiosomatidae: espécie nova e novas ocorrências no Brasil. Iheringia, Série Zoologia, 95(4): 441-443.

2006. Sobre o gênero Vesicapalpus (Araneae, Linyphiidae) no sul do Brasil. Iheringia, Série Zoologia, 96(4):407-412. . 2010a. A new species of Psilocymcium with the descriptions of the male and new records of $P$. lineatum at South Brazil (Araneae: Linyphiidae). Zoologia 27(3):445-450

2010b. On the Neotropical spider genus Eurymorion (Araneae: Linyphiidae). Zoologia 27(4):649-659.

Roewer, C. F. 1951. Neue namen einiger Araneen-Arten. Abhandlungen von Naturwissenschaftlichen Verein zu Bremen 32:437-456.

Ruiz, G. R. S. \& Brescovit, A. D. 2008. Revision of Helvetia (Araneae, Salticidae: Heliophaninae). Revista Brasileira de Zoologia 25(1):139-147.

SAntos, A. J. 2007a. A revision of the Neotropical nursery-web spider genus Architis (Araneae: Pisauridae). Zootaxa 1578:1-40. . 2007b. A phylogenetic analysis of the nursery-web spider family Pisauridae, with emphasis on the genera Architis and Staberius (Araneae: Lycosoidea). Zoologica Scripta 36:489-507.

Santos, A. J.; Álvares, E. S. S. \& Brescovit, A. D. 2003. On the third valid species of the genus Aglaoctenus Tullgren (Araneae, Lycosidae). Revista Ibérica de Aracnología 8:89-93.

Santos, A. J. \& Brescovit, A. D. 2001. A revision of the South American spider genus Aglaoctenus Tullgren, 1905 (Araneae, Lycosidae, Sosippinae). Andrias 15:75-90.

2003. A revision of the Neotropical species of the lynx spider genus Peucetia Thorell 1869 (Araneae: Oxyopidae). Insect Systematics \& Evolution 34:95-116.

Santos, A. J. \& Gonzaga, M. O. 2003. On the spider genus Oecobius Lucas, 1846 in South America (Araneae, Oecobiidae). Journal of Natural History 37:239-252.

Schiapelli, R. D. \& Pikelin, B. S. G. 1958. Arañas argentinas III. Arañas de Misiones. Revista del Museo Argentino de Ciencias Naturales "Bernardino Rivadavia" 3:187-231. 1964. El genero Acanthoscurria Ausser, 1871 (Araneae, Theraphosidae) en la Argentina. Physis 24(68):391-417.

Scioscia, C. L. 1993. Description of Mburuvicha galianoae, new genus and species (Araneae, Salticidae). Bulletin of the British Arachnology Society 9(4):123-125.

SiERWALD, P. 1989. Morphology and ontogeny of female copulatory organs in American Pisauridae, with special reference to homologous features (Arachnida: Araneae). Smithsonian Contributions to Zoology 484:1-24.

1990. Morphology and homologous features in the male palpal organ in Pisauridae and other spider families, with notes on the taxonomy of Pisauridae (Arachnida: Araneae). Nemouria 35:1-59.

Silva, E. L. C. DA \& Lise, A. A. 2009. A new species of the wolf spider genus Arctosa (Araneae, Lycosidae) from Southern Brazil. Revista Peruana de Biología 15(2):27-32.

Silva, E. L. C. Da; Lise, A. A.; Buckup, E. H. \& Brescovit, A. D. 2006. Taxonomy and new records in the Neotropical spider genus Paratrechalea (Araneae, Lycosoidea, Trechaleidae). Biociências 14(1):71-72.

Silva, E. L. C. DA; Lise, A. A. \& Carico, J. E. 2007. Revision of the Neotropical spider genus Dossenus (Araneae, Lycosoidea, Trechaleidae). Insect Systematics \& Evolution 38:138-148.

Simó, M. \& Brescovit, A. D. 2001. Revision and cladistic analysis of the Neotropical spider genus Phoneutria Perty, 1833 (Araneae, Ctenidae), with notes on related Ctenidae. Bulletin of the British Arachnology Society 12:67-82.

Simon, E. 1873. Aranéides nouveaux ou peu connus du midi de l'Europe. (2e mémoire). Mémoires de la Societé royale des sciences de Liége 5(2):1-174

1880. Révision de la famille des Sparassidae (Arachnides). Actes de la Societé linnéenne de Bordeaux 34:223-351.
1882. II. Étude sur les arachnides de l'Yemen méridional. In Viaggio ad Assab nel Mar Rosso, dei signori G. Doria ed O Beccari con il R. Aviso "Esploratore" dal 16 Novembre 1879 al 26 Febbraio 1880. Annali del Museu civico di storia naturale di Genova 18:207-260.

1886. Arachnides recueillis em 1882-1883 dans la Patagonie méridionale, de Santa Cruz a Punta-Arena. Bulletin de la Societé Zoologique de France 11:558-577.

1891a. Voyage de M. E. Simon au Venezuela (Décembre 1887-Avril 1888). Observations biologiques sur les Arachnides. 1. Araignées sociales. Annales de La Societé Entomologique de France 1891:5-14

1891b. Etudes arachnologiques. 23e Mémoire. XXXVIII Descriptions d'espèces et de genres nouveaux de la famille des Aviculariidae. Annales de la Societé Entomologique de France 60:300-312.

1893. Descriptions d'espèces et de genres nouveaux de l'ordre des Araneae. Annales de la Societé Entomologique de France 62:299-330.

1894. Histoire Naturelle des Araignées. Paris. v. 1, p. 489-760.

1895a. Histoire naturelle des Araignées. Paris, Librarie Encyclopedique de Roret. v.1, fasc. 4, p.761-1084.

1895b. Etudes arachnologiques. 26e. XLI. Descriptions d'espèces et de genres nouveaux de l'ordre des Araneae. Annales de la Societé Entomologique de France 64:131-160.

1896. Descriptions d’Arachnides nouveaux de la famille des Clubionidae. Annales de La Societé Entomologique de Belgique 40:400-422.

1897a. Liste des arachnides recueillis aux ilês du Cap-Vert dans La République Argentine et Le Paraguay et descriptions d'espèces nouvelles. In: Viaggio del Dott. A. Borelli nella Republica Argentina e nel Paraguay. Bolletino dei Musei di zoologia e di anatomia comparata della Universitá di Torino 12(270): 1-8.

1897b. Etudes arachnologiques. 27e Mémoire. XLII. Descriptions d'espèces nouvelles de l'ordre des Araneae. Annales de la Societé e Etomologique de France 65:465-510. 1898. Descriptions d'arachnides nouveaux des familles der Agelenidae, Pisauridae, Lycosidae et Oxyopidae. Annales de la Societé entomologique de Belgique 42:1-34

1900a. Descriptions d'arachnides nouveaux de la famille des Attidae. Annales de la Societé entomologique de Belgique 44:381-407

1900b. Etudes arachnologiques. 30e Mémoire. XLVII Descriptions d'espèces nouvelles de la famille des Attidae. Annales de la Societé entomologique de France 69:27-61. 1901a. Histoire naturelle des Araignées. Paris, Librarie Encyclopedique de Roret. v.2, fasc. 3, p.381-668.

1901b. Liste des arachnides recueillis par M. Ch. E. Porter en 1899 à Quilpué et à Molle, et par M. B. Wilson en avril 1900 au Rio Aysen (Patagonie occidentale). Revista Chilena de Historia Natural 5:17-22.

1901c. Description d'Arachnides noveaux de de la famille des Salticidae (Attidae) (suite). Annales de la Societé entomologique de Belgique 45:141-161.

1901d. Etudes arachnologiques. 31e Mémoire. L. Descriptions d'espèces nouvelles de la famille des Salticidae (suite). Annales de la Societé entomologique de France 70:66-76.

1902a. Description d'Arachnides noveaux de de la famille des Salticidae (Attidae) (suite). Annales de la Societé entomologique de Belgique 46:24-56, 363-406.

1902b. Arachnoideen. In: Ergebnisse der Hamburger magalhaensische Sammelreise 6(4):1-47.

1903a. Histoire naturelle des Araignées. Paris, Librarie Encyclopedique de Roret. v. 2, fasc. 4, p. 669-1080.

1903b. Descriptions d'arachnides nouveaux. Annales de La Societé Entomologique de Belgique 47:21-39.

1905. Étude sur lês Arachnides recueillis en Patagonie par Le Dr Fillipo Silvestri. Bollettino dei Musei di Zoologia ed Anatomia Comparata della Reale Universitá di Torino 20:1-17.

Soares, B. A. M. \& CAmargo, H. F. DE A. 1948. Aranhas coligidas pela Fundação Brasil-Central (Arachnida-Araneae). Boletim do Museu Paraense Emílio Goeldi 10:355-409. 
Strand, E. 1908a. Diagnosen neuer aussereuropäischer Argiopiden. Zoologischer Anzeiger 33:1-4.

1908b. Exotisch-araneologisches. I. Amerikanische, hauptsächlich in Peru, Bolivien und Josemitetal in Californien gesammelte Spinnen, Jarhrbücher des Nassauischen Vereins für Naturkunde 61:223-260.

1916. Systematische-faunistische studien über Paläarktische, Afrikanische und Amerikanischen Spinnen des Senckenbergishen Museums. Archiv für Naturgeschichte 81(9):1-153.

TACZANOWSKI, L. 1872. Les aranéides de la Guyane française. Horae Societatis Entomologicae Rosicae 9:64-112.

1873. Les Aranéides de la Guyane française. Horae Societatis Entomologicae Rosicae 9:64-150, 261-286. 1874. Les Aranéides de la Guyane Française. Horae Societatis Entomologicae Rosicae 9:56-115. 1878. Les aranéides du Perou central. Horae Societatis Entomologicae Rossicae 14:140-175.

1879. Les aranéides du Perou central. Horae Societatis Entomologicae Rossicae 15:102-136.

Teixeira, R. A. \& Lise, A. A. 2010. Description of the female of the orb-weaver spider Testudinaria gravatai (Araneae: Araneidae). Zoologia 27(1):128-130.

Thorell, T. 1878. Studi sui ragni Malesi e Papuani. Part II. Ragni di Amboina raccolti dal Prof. Beccari. Annali del Museo cívico di Storia Naturale Giacomo Doria 13:1-317.

1894. Förteckning öfver arachnider från Java och närgrändsande öar, insamlade af Carl Aurivillius; jemte beskrifningar å några sydasiatiska och sydamerikanska spindlar. Bihang Svenska till Kongl Svenska Vetens-kapsAkademiens Handllingar 20(4):1-63.

Toledo-PizA, S. DE. 1937. Novas espécies de aranhas myrmecophilas do Brasil e considerações sobre o seu mimetismo. Revista do Museu Paulista 23:307-309.

Traw, M. B. 1996. A revision of the Neotropical orb-weaving spider genus Scoloderus (Araneae: Araneidae). Psyche 102(12):49-72.

Tullgren, A. 1905. Araneida from the Swedish Expedition through the Gran Chaco and the Cordilleras. Arkivev för Zoologi 19(2):1-81.

1910. Araneae. In: Wissenschaftliche Ergebnisse der Schwedischen Zoologischen Expedition nach dem Kilimandjaro, dem Meru und dem Umbegenden Massaisteppen Deutsch-Ostafrikas 1905-1906 unter Leitung von Prof. Dr Yngve Sjöstedt. Stockholm, 20(6): $85-172$

Vellard, J. 1924. Études de Zoologie. Archivos do Museu Nacional 2:121-170.

Vianna, M. J. B. 1983. Descrição do gênero Pensacolops, g. n. e de nova espécie de Chira Peckham, 1896 (Araneae, Salticidae). Boletim de Zoologia Universidade de São Paulo 7:1-6.

Vianna, M. J. B. \& Soares, B. A. M. 1978. Contribuição ao estudo dos Salticidae do Brasill. II. (Araneae). Revista Brasileira de Biologia 38(1):27-30.

1980. Contribuição ao estudo dos Salticidae do Brasil, VIII (Araneae). Revista Brasileira de Biologia 40(4):697-699 1982. Contribuição ao estudo dos Salticidae (Araneae) do Brasil. IX. Revista Brasileira de Entomologia 26(1):87-91. 1983. Contribuição ao estudo dos Salticidae (Araneae) do Brasil. VII. Boletim de Zoologia Universidade de São Paulo 6:47-51.

VInson, A. 1863. Aranéides des ilês de la réunion, Maurice et Madagascar. Paris. 337p.

Walckenaer, C. A. 1802. Faune parisienne. Insectes. ou Histoire abrégée des insectes de environs de Paris. Paris. v. 2, p.187-250.

1837. Histoire naturelle des insectes, Aptères. 1. Paris, Librairie Encyclopédique de Roret. 682p.

1841. Histoire naturelle des insectes, Aptères. 2. Paris, Librairie Encyclopédique de Roret. 548p.

White, A. 1841. Description of new and little known Arachnida. The Annals and Magazine of Natural History 1(7):471-477.

Xavier, E.; Baptista, R. L. C. \& Trajano, E. 1995. Biology and redescription of Theridion bergi Levi, 1963 (Araneae, Theridiidae), a semiaquatic spider from Brazilian caves. Revue Arachnologique 11(2):17-28. 